NBER WORKING PAPER SERIES

\title{
KNOWLEDGE OF FUTURE JOB LOSS AND IMPLICATIONS FOR UNEMPLOYMENT INSURANCE
}

\author{
Nathaniel Hendren \\ Working Paper 21819 \\ http://www.nber.org/papers/w21819 \\ NATIONAL BUREAU OF ECONOMIC RESEARCH \\ 1050 Massachusetts Avenue \\ Cambridge, MA 02138 \\ December 2015
}

I am very grateful to Daron Acemoglu, Raj Chetty, Amy Finkelstein, Jon Gruber, Luigi Pistaferri, Rob Townsend, and a long list of seminar participants for their comments. I also thank Trevor Bakker, Augustin Bergeron, Lizi Chen, Michael Droste, Robert Fluegge, Frina Lin, Jeremy Majerovitz, Jimmy Narang, Nina Roussille, and Priyanka Shende for helpful research assistance. Early versions of Sections 4 and 6 of this paper appeared in the second chapter in my MIT PhD thesis and also circulated under the title "Private Information and Unemployment Insurance". Support from NSF Graduate Research Fellowship and the NBER Health and Aging Fellowship, under the National Institute of Aging Grant Number T32-AG000186 is gratefully acknowledged. The views expressed herein are those of the author and do not necessarily reflect the views of the National Bureau of Economic Research.

NBER working papers are circulated for discussion and comment purposes. They have not been peer-reviewed or been subject to the review by the NBER Board of Directors that accompanies official NBER publications.

(C) 2015 by Nathaniel Hendren. All rights reserved. Short sections of text, not to exceed two paragraphs, may be quoted without explicit permission provided that full credit, including () notice, is given to the source. 
Knowledge of Future Job Loss and Implications for Unemployment Insurance

Nathaniel Hendren

NBER Working Paper No. 21819

December 2015, Revised June 2016

JEL No. H0

\section{ABSTRACT}

This paper studies the implications of individuals' knowledge of future job loss for the existence of an unemployment insurance (UI) market. Learning about job loss leads to consumption decreases and spousal labor supply increases. This suggests existing willingness to pay estimates for UI understate its value. But, it yields new estimation methodologies that account for and exploit responses to learning about future job loss. Although my new willingness to pay estimates exceed previous estimates, I estimate much larger frictions imposed by private information. This suggests privately-traded UI policies would be too adversely selected to be profitable, at any price.

Nathaniel Hendren

Harvard University

Department of Economics

Littauer Center Room 235

Cambridge, MA 02138

and NBER

nhendren@gmail.com

A Online appendix is available at http://www.nber.org/data-appendix/w21819 


\title{
Knowledge of Future Job Loss and Implications for Unemployment Insurance
}

\author{
Nathaniel Hendren*
}

July, 2016

\begin{abstract}
This paper studies the implications of individuals' knowledge of future job loss for the existence of an unemployment insurance (UI) market. Learning about job loss leads to consumption decreases and spousal labor supply increases. This suggests existing willingness to pay estimates for UI understate its value. But, it yields new estimation methodologies that account for and exploit responses to learning about future job loss. Although my new willingness to pay estimates exceed previous estimates, I estimate much larger frictions imposed by private information. This suggests privately-traded UI policies would be too adversely selected to be profitable, at any price.
\end{abstract}

\section{Introduction}

The risk of job loss is one of the most salient risks faced by working-age individuals. Job loss leads to drops in consumption and significant welfare losses. ${ }^{1}$ Millions of people hold life insurance, health insurance, liability insurance, and many other insurance policies. ${ }^{2}$ Why isn't there an analogous thriving market for insurance against losing one's job? ${ }^{3}$

\footnotetext{
*Harvard University, nhendren@fas.harvard.edu. I am very grateful to Daron Acemoglu, Raj Chetty, Amy Finkelstein, Jon Gruber, Luigi Pistaferri, Rob Townsend, and a long list of seminar participants for their comments. I also thank Trevor Bakker, Augustin Bergeron, Lizi Chen, Michael Droste, Robert Fluegge, Frina Lin, Jeremy Majerovitz, Jimmy Narang, Nina Roussille, and Priyanka Shende for helpful research assistance. Early versions of Sections 4 and 6 of this paper appeared in the second chapter in my MIT PhD thesis and also circulated under the title "Private Information and Unemployment Insurance". Support from NSF Graduate Research Fellowship and the NBER Health and Aging Fellowship, under the National Institute of Aging Grant Number T32-AG000186 is gratefully acknowledged.

${ }^{1}$ See Gruber (1997), Browning and Crossley (2001), Aguiar and Hurst (2005), Chetty (2008), and Blundell et al. (2012).

${ }^{2} 60 \%$ of people in the US have insurance against damage to their cell phones and 1.4 million pets have health insurance in North America (see http://www.warrantyweek.com/archive/ww20131114.html and http://www.embracepetinsurance.com/pet-industry/pet-insurance/statistics).

${ }^{3}$ Two companies have attempted to sell such policies in the past 20 years. PayCheck Guardian attempted to sell policies from 2008, but stopped selling in 2009 with industry consultants arguing "The potential set of policyholders are selecting against the insurance company, because they know their situation better than an insurance company might" (http://www.nytimes.com/2009/08/08/your-money/08money.html). More recently, IncomeAssure has partnered with states to offer top-up insurance up to a $50 \%$ replacement rate for workers in some industries and occupations (https://www.incomeassure.com). Back-of-the envelope calculations suggest their markups exceed $500 \%$ over actuarially fair prices, and it has been criticized for shrouding the true price by not saliently noting that the government provides the baseline $30-40 \%$ replacement rate (e.g. http://www.mlive.com/jobs/index.ssf/2011/08/get_out_your_calculator_before_you_buy_p.html \#).
} 
This paper provides empirical evidence that unemployment or job loss insurance would be too adversely selected to deliver a positive profit, at any price. This market failure provides a potential rationale for government intervention that requires workers to pay into a government UI system.

I begin by documenting several pieces of evidence that individuals have knowledge about their future job loss that could be used to adversely select an insurance contract. First, I use data from the Health and Retirement Study (HRS) that asks individuals about their likelihood of losing their job. I show these subjective probability elicitations are predictive of subsequent job loss, even conditional on a wide range of observable characteristics one might expect an insurer to use to mitigate any asymmetric information. Second, spouses are more likely to enter the labor market when individuals learn they might lose their job (as indicated through high subjective probability elicitations). Finally, using data from the Panel Study of Income Dynamics, I explore the consumption patterns around job loss and unemployment spells. While unemployment is associated with significantly lower food expenditure growth of $7-10 \%$ (Gruber (1997)), there is also a 2.7\% drop in year $t-1$ (relative to $t-2$ ) food expenditure growth prior to the onset of unemployment in year $t$. The drop occurs even on a sample who remain employed in these pre-periods and who experience no change in income. This suggests the consumption drop is indicative of forwardlooking savings behavior anticipating potential job loss. Taken together, these patterns suggest individuals have knowledge about their future job loss. ${ }^{4}$ Moreover, the labor supply and ex-ante consumption responses suggest individuals would prefer to have more financial resources in the event of job loss. This implies they would naturally have a demand for unemployment insurance and use their knowledge to (adversely) select insurance contracts.

Given these patterns, the primary task of the paper is to ask: Can this knowledge of future job loss explain why there is not a thriving private market for unemployment insurance? Whether a market can exist depends on whether the markup individuals are willing to pay for insurance exceeds the cost imposed by worse risks adversely selecting their contract - defined as the "pooled price ratio" in Hendren (2013). ${ }^{5}$ Therefore, I analyze the implications of the reduced-form empirical patterns for both the (a) markup individuals are willing to pay for UI and (b) the pooled price

\footnotetext{
${ }^{4}$ As discussed below in the related literature, these patterns are also consistent with findings in previous literature identifying behavior consistent with knowledge of future job loss. Importantly, I show this knowledge is predictive even after controlling for observables insurers might use to try to remove any asymmetric information.

${ }^{5}$ This no trade condition was provided in Hendren (2013). Section 4 provides a simple generalization of that model to an unemployment context that allows for both moral hazard and also dynamic consumption and labor supply responses. I show that the no trade condition in Hendren (2013) generalizes to this setting. In particular, the pooled price ratio depends on the distribution of job loss probabilities but does not depend on the responsiveness of unemployment to UI benefits. The first dollar of insurance provide first-order welfare gains, whereas the behavioral response imposes a second order impact on the cost of insurance, a point recognized by Shavell (1979). So although the moral hazard can affect the optimal level of social insurance, it does not readily provide a singular explanation for the absence of a private UI market.
} 
ratio.

A large literature has attempted to estimate the markup individuals are willing to pay for UI. The most common approach estimates the impact of unemployment on the first difference in consumption and then scales this impact by a coefficient of relative risk aversion (Baily (1976); Gruber (1997)). However, the empirical results above suggest unemployment affects consumption not only at the onset of unemployment but also in the year prior. This suggests the first difference estimate understates the causal effect of unemployment on consumption. To correct for this bias, I develop a two-sample instrumental variables strategy that scales the first difference impact of unemployment on consumption by the amount of information revealed over the time period measuring the difference. This forms a "first stage" of the amount of information revealed over the time frame comprising the length of the first difference. Using the subjective probability elicitations to form this first stage, I show one needs to multiply the $7-10 \%$ consumption drop by around 1.25 to arrive at the causal impact of unemployment on consumption of $8-13 \%$. Scaling by a coefficient of relative risk aversion (e.g. 2) yields the markup individuals are willing to pay for UI (e.g. 16-26\%).

In addition to exploiting the consumption drop upon unemployment, the presence of ex-ante behavioral responses presents an opportunity for a new method for estimating the willingness to pay for UI. Under conditions discussed below, the response of current consumption and spousal labor supply to a change in the likelihood of future unemployment reveals the size of the marginal willingness to pay for UI. ${ }^{6}$ I show that the $2.7 \%$ consumption drop in year $t-1$ versus $t-2$ suggests that individuals are willing to pay a markup for UI of $30 \%$ multiplied by the coefficient of relative risk aversion (i.e. a $60 \%$ markup for a coefficient of relative risk aversion of 2.) Analogously, I show that scaling the ex-ante spousal labor supply responses by the elasticity of labor force participation with respect to a change in wages reveals the markup individuals would be willing to pay for UI. For a semi-elasticity of 0.5 , this again suggests individuals are willing to pay of around a $60 \%$ markup for UI.

Are these willingness to pay estimates sufficient to overcome the hurdles imposed by adverse selection? To answer this question, I build on the strategies developed in Hendren (2013) to estimate the pooled price ratio. I use the information contained in the subjective probability elicitations to provide non-parametric lower bounds and semi-parametric point estimates on the pooled price ratio. This yields lower bounds that are generally in excess of $70 \%$ and point estimates in excess of $300 \%$. The pooled price ratio remains large across varying assumptions about the observables insurers would use to price the UI policies and also is quite persistent across subgroups. Since these estimates generally exceed the estimates for the willingness to pay for UI, the results suggest a

\footnotetext{
${ }^{6}$ As shown in Section 5.2, this approach does not require state independence of the utility function in contrast to the canonical approach in Baily (1976); Gruber (1997) and Chetty (2006).
} 
private UI policies would be too heavily adversely selected to deliver a positive profit, at any price.

Related literature This paper is related to a large literature studying the degree to which individuals are insured against unemployment and income shocks ${ }^{7}$ and their behavioral response to these adverse events. ${ }^{8}$ The methods of this paper are related to a broad literature using subjective expectation data to identify properties of individual beliefs (Pistaferri (2001); Manski (2004)). In particular, this paper is most closely related to the work of Stephens (2004), who illustrates that subjective probability elicitations in the HRS are predictive about future unemployment status, and to Stephens (2001) and Stephens Jr (2002) who find evidence of ex-ante consumption drops and spousal labor supply increases in the U.S. using the PSID.

Relative to previous literature, the primary contribution of this paper is to study the implications of these empirical patterns for the workings of a private UI market. ${ }^{9}$ By using subjective probability elicitations to identify the 'supply side' frictions imposed by private information, the paper utilizes many of the tools developed in Hendren (2013). On the demand side, I develop a new methodology to measure demand for UI when individuals have knowledge of future job loss. Exante behavioral responses suggest previous methodologies under-state the value of UI (e.g. Gruber (1997)). I provide a correction for this method. In addition, these ex-ante behavioral responses open a potentially fruitful new pathway to valuing insurance by exploiting the ex-ante responses to measure the value of insurance. In particular, the fact that people drop current food expenditure and increase in spousal labor supply when they learn they might lose their job suggests job loss is significantly under-insured in the U.S., regardless of whether one believes the utility function is state-dependent or individuals have more time to cook or search for lower prices when unemployed. ${ }^{10}$

Finally, this paper also contributes to the growing literature documenting the impact of private

\footnotetext{
${ }^{7}$ In the UI context, see Baily (1976); Acemoglu and Shimer (1999, 2000); Chetty (2006); Shimer and Werning (2007); Blundell et al. (2008); Chetty (2008); Shimer and Werning (2008); Landais et al. (2010). See also Bach (1998) for one of the only papers documenting adverse selection in a UI context in which mortgage insurance companies provide mortgage payments in the event of job loss.

${ }^{8}$ For example, see Guiso et al. (1992); Dynan (1993); Hubbard et al. (1994); Carroll and Samwick (1997, 1998); Carroll et al. (2003); Lusardi (1997, 1998); Engen and Gruber (2001); Guariglia and Kim (2004); Bloemen and Stancanelli (2005); Barceló and Villanueva (2010); Campos and Reggio (2015); Brown and Matsa (2015). Most closely, Basten et al. (2012) and Gallen (2013) find evidence of ex-ante savings increases in response to future unemployment in Norway and Denmark.

${ }^{9}$ Along the way, the analysis clarifies the empirical estimands required to answer this question. For example, one needs to know whether the elicitations are predictive of job loss conditional on public information insurers would use to price insurance. Further, when studying ex-ante consumption responses, it is important to restrict to a sample that remains employed in these periods to estimate the demand that would be held by potential insurance customers. To the best of my knowledge, this paper is the first to document that food expenditure growth drops on the sub-sample of those who remain employed in the pre-period and experience no drop in consumption.

${ }^{10}$ See Aguiar and Hurst (2005) for a discussion and evidence that expenditure measurements may mis-state the impact of retirement and job loss on consumption.
} 
information on the workings of insurance markets and the micro-foundations for under-insurance. Previous literature often tests for private information by asking whether existing insurance contracts are adversely selected (Chiappori and Salanié (2000); Finkelstein and Poterba (2004)). My results suggest this literature has perhaps suffered from a "lamp-post" problem, as forebode in Einav et al. (2010): If private information prevents the existence of entire markets, it is difficult to identify its impact by looking for the adverse selection of existing contracts. Combining with the evidence in Hendren (2013) that private information prevents the existence of health-related insurance markets for those with pre-existing conditions, the results suggest a broader pattern: the frictions imposed by private information form the boundary to the existence of insurance markets.

The rest of this paper proceeds as follows. Section 2 discusses the data used in the analysis. Section 3 presents a series of motivating statistics establishing the presence of private information that individuals would use to (adversely) select insurance. Section 4 places these patterns in the context of a general model of unemployment risk. A private market will not be profitable if the markup individuals would be willing to pay for UI is less than the pooled price ratio in Hendren (2013). Section 5 considers the implications of the patterns in Section 3 for measuring individual's willingness to pay for UI, and Section 6 considers the implications for measuring the pooled price ratio. Section 7 discusses robustness and alternative theories of market non-existence. Section 8 concludes.

\section{Data}

The data draw upon two panel surveys: the Health and Retirement Survey (HRS) and the Panel Study of Income Dynamics (PSID). The HRS provides measures of subjective probability elicitations about future unemployment and measures of spousal labor supply. The PSID does not contain subjective probability elicitations, but includes a panel of information on food expenditures.

\section{$2.1 \quad$ HRS}

The HRS sample draws from waves of the Health and Retirement Study (HRS) spanning years 1992-2013. The HRS samples individuals over 50 and their spouses (included regardless of age). ${ }^{11}$ The baseline sample includes everyone under 65 in the survey who holds a job in the current survey wave and is not self-employed or in the military.

Subjective Probability Elicitations A main benefit of using the HRS is that it contains a battery of subjective expectation information about future adverse events. In particular, the survey

\footnotetext{
${ }^{11}$ The analysis below will explore how the results vary with age, and the ex-ante consumption responses documented using the younger sample in the PSID will provide complementary evidence of private information in younger samples.
} 
asks respondents: What is the percent chance (0-100) that you will lose your job in the next 12 months? Figure I presents the histogram of these elicitations. As noted in previous literature (Gan et al. (2005)), the responses concentrate on focal point values, especially zero. Taken literally, these responses of zero (or 100\%) imply individuals would be willing to bet an infinite amount of money against the chance of losing (or keeping) ones' job. As a result, at no point will these elicitations be used as true measures of individuals beliefs. Instead, I follow the approach of Hendren (2013) by treating these elicitations as noisy and potentially biased measures of true beliefs about losing one's job. To maintain this distinction, I will let $Z$ denote the responses to these survey questions, and I will let $P$ denote the subjective probability held by the individual that governs their willingness to pay for lotteries and financial contracts, as in Savage (1954). These "true" beliefs, $P$, are related to individual's willingness to pay for an unemployment insurance contract, but will be assumed to be unobserved to the econometrician, $Z \neq P$.

Outcomes Corresponding to the elicitation, the survey allows for the construction of whether or not an individual will involuntarily lose their job in the subsequent 12 months from the survey, denoted $U$. The subsequent wave asks individuals whether they are working at the same job as the previous wave (roughly 2 years prior). If not, respondents are asked when and why they left their job (e.g. left involuntarily, voluntarily/quit, or retired). For the baseline analysis, I define becoming unemployed as involuntarily losing one's job in the subsequent 12 months following the previous survey date, and I exclude voluntary quits and retirement in the baseline specifications. ${ }^{12}$

Public Information Estimating private information requires specifying the set of observable information insurers could use to price insurance policies. Changing the set of observable characteristics simulates how the potential for adverse selection varies with the underwriting strategy of the potential insurer. The data contain a very rich set of observable characteristics that wellapproximate variables used by insurance companies in disability, long-term care, and life insurance (Finkelstein and McGarry (2006); He (2009); Hendren (2013)) and also contain a variety of variables well-suited for controlling for the observable risk of job loss. The baseline specification includes

\footnotetext{
${ }^{12} \mathrm{By}$ focusing on the incidence of unemployment in the subsequent 12 months, the empirical work below will estimate the frictions imposed by private information on a hypothetical insurance market that provides payment in the event the individual involuntarily loses his/her job in the subsequent 12 months. However, the analysis will also consider robustness analyses to other definitions of job loss. For example, I construct a measure of job loss in the 6-12 months following the survey. This removes cases where the individuals knew about an immediately impending job loss that could potentially be circumvented by an insurer imposing a waiting period on the insurance policy. I also construct measures of job loss in the 6-24 month window, and measures of whether the individual is unemployed in the subsequent survey round (roughly 24 months after the previous survey). I also construct an outcome that identifies the set of job losses that lead to a government UI claim by interacting the job loss indicator with an indicator for receiving positive government unemployment insurance benefits in between survey waves.
} 
a set of these job characteristics including job industry categories, job occupation categories, log wage, $\log$ wage squared, job tenure, and job tenure squared, along with a set of demographic characteristics: census division dummies, gender dummies, age, age squared, and year dummies. ${ }^{13}$ I also consider specifications that condition on lagged unemployment incidence, and also to a less comprehensive set of controls such as just age and gender. ${ }^{14}$

Spousal Labor Supply The analysis below will also explore spousal labor supply responses on the sub-sample of married households in the HRS. I define labor market participation as an indicator of the spouse working for pay in the current wave of the survey. Labor market entry is defined as an indicator for the spouse working for pay in the current wave but not in the previous wave of the survey ( 2 years prior). ${ }^{15}$

\subsection{PSID}

I also follow previous literature by exploiting the impact of unemployment on food expenditure in the Panel Study of Income Dynamics (PSID) (Gruber (1997); Chetty and Szeidl (2007)). ${ }^{16}$ I utilize a sample to heads of household between the ages of 25 and 65 who have non-missing food expenditure. I define food expenditure as the sum of food expenditure in and out of the home, plus food stamps. ${ }^{17}$ Following Gruber (1997), I restrict the baseline sample to those with less than a threefold change in food expenditure relative to the previous year and whose household head is in the labor force (i.e. either employed or unemployed and looking for work). For some specifications, I utilize a measure of household expenditure needs, which the PSID constructs to measure the total expenditure needs given the age and composition of the household.

For the unemployment indicator, I use the measure of current unemployment/employment status at the time of the survey. Because the food expenditure questions ask about how much spending is typical in the household, this timing of employment measure will more accurately create a comparison between the employed and unemployed. However, this definition differs from the job loss definition used in the HRS analysis. Therefore, I replicate the results using a measure

\footnotetext{
${ }^{13}$ This set is generally larger than the set of information previously used by insurance companies who have tried to sell unemployment insurance. Income Assure, the latest attempt to provide private unemployment benefits, prices policies using a coarse industry classification, geographical location (state of residence), and wages.

${ }^{14}$ I also assess robustness to additional health status controls that include indicators for a range of doctor-diagnosed medical conditions (diabetes, a doctor-diagnosed psychological condition, heart attack, stroke, lung disease, cancer, high blood pressure, and arthritis) and linear controls for bmi.

${ }^{15}$ The primary analysis will focus on labor market entry by previously non-working spouses, as opposed to total spousal labor supply because of the presence of correlated shocks to labor earning opportunities within the household arising from spouses working in the same labor market, industry, or firm.

${ }^{16}$ Consumption questions are also asked on a $10 \%$ sub-sample in the HRS a follow-up survey (that is not asked at the same time the elicitations are provided).

${ }^{17}$ In addition to analyzing food expenditure, I also explore the robustness of the results to the post 1997 broader consumption expenditure measures that are asked every two years. See Footnote 26.
} 
of job loss defined as an indicator for being laid off or fired from the job held in the previous wave of the survey. ${ }^{18}$ For the primary sample construction, I select those who are employed in the previous two years of the survey, analogous to the sample selection in the HRS requiring that individuals are employed at the time of eliciting their job loss probability.

\subsection{Summary Statistics}

Table I presents the summary statistics of the main samples. For the baseline HRS sample, there are 26,640 observations (individuals $\mathrm{x}$ years) in the sample, which correspond to 3,467 unique households. This drops to 2,214 households when using the married subsample. The PSID sample contains 65,450 observations (individuals x year) from 9,557 individuals who are heads of household.

Individuals in the samples have relatively similar earnings ( $\$ 36 \mathrm{~K}$ in the HRS; $\$ 40 \mathrm{~K}$ in the PSID), although earnings are slightly higher in the PSID sample which restricts to household heads. The household heads in the PSID are also more likely to be male (83\% versus $40 \%) .{ }^{19}$

The most notable distinction between the HRS and PSID samples is the difference in their age distributions. The HRS sample is older, with a mean age of 56 as opposed to 41 . Despite this, the frequency of involuntary job loss and subsequent unemployment is fairly similar, with annualized rates of job loss of $3.1 \%$ in the HRS and $2.8 \%$ in the PSID sample. The PSID sample is more likely to be unemployed (2.4\% versus $1.9 \%$ in the HRS), perhaps because job losses in the HRS sample are more likely to lead to retirement: the retirement hazard in the HRS sample is $5.3 \%$ per year versus just $1.7 \%$ in the PSID sample. ${ }^{20}$ As discussed below, the analysis will assume an insurer can separate involuntary job loss from retirement; if this is not possible, the knowledge of future retirement plans could present an additional source of adverse selection in a private UI market.

For the married HRS sample, $69.3 \%$ of spouses are employed and $3.9 \%$ of spouses enter the labor market (defined as an indicator for being out of the labor force in the previous wave and in the labor force in the current wave of the survey. For the PSID sample, mean household food expenditure is $\$ 7,314$.

Finally, the second-to-last set of rows in Table 1 reports the summary statistics for the subjective probability elicitations. While $3.1 \%$ of the HRS sample loses their job in the subsequent 12 months

\footnotetext{
${ }^{18}$ I only include job losses coded as "fired or laid off", and do not include cases where the individual quit, the job was seasonal/temporary, or the company "folded/changed hands/moved out of town/went out of business". I do not include this latter case because it includes cases where the individual never loses employment (but had a change in job title because, for example, of a change in management).

${ }^{19}$ Although the HRS is a representative sample of individuals over 50 and their spouses, the sample of women exceeds $50 \%$ because women are more likely than men to be married to someone over age 65 (and those over age 65 are not included in the baseline sample).

${ }^{20}$ I construct the yearly retirement hazard in the HRS by computing the fraction of the sample who is retired in the subsequent wave (2 years forward) and dividing by 2 .
} 
from the survey, the mean subjective probability elicitation is $15.7 \% .^{21}$ Such biasedness is common with subjective probability elicitations (see, e.g., Hurd (2009)). In particular, for low probability events there is a natural tendency for measurement error in elicitations to lead to an upward bias. This provides further rationale for treating these elicitations as noisy and potentially biased measures of true beliefs, as is maintained throughout the empirical analyses below. ${ }^{22}$

\section{Knowledge of Future Job Loss}

This section documents three empirical patterns. First, individuals' subjective probabilities are predictive of future job loss conditional on a wide range of observables that insurers could potentially use to price an insurance policy. Second, when individual's learn they might lose their job, spouses are more likely to enter the labor market. Third, consumption growth differs for those who do versus those who do not lose their job in the 1-2 years prior to job loss. These empirical patterns will provide a basis for considering the implications for the workings of a private UI market, discussed in Sections 4-6.

\subsection{Private Information about Future Job Loss Using Subjective Probability Elicitations}

Do people have private information about their likelihood of becoming unemployed? To explore this, Figure II explores whether those with higher subjective probability elicitations, $Z$, are more likely to experience a job loss in the subsequent 12 months, $U$, conditional on year dummies, demographic characteristics, and job characteristics, $X$. The figure presents the coefficients on 5 bins of elicitations from a regression of $U$ on these bin dummies and the observable controls, $X$. To be specific, I partition the unit interval into bins, $G_{j}$, and regress an indicator for job loss in the subsequent 12 months from the survey, $U_{i t}$, on observable controls at time $t, X_{i t}$, and bin indicators,

$$
U_{i t}=\alpha+\sum_{j=1}^{n} \psi_{j} 1\left\{Z_{i t} \in G_{j}\right\}+\Gamma X_{i t}+\epsilon_{i t}
$$

Figure II plots the coefficients, $\psi_{j}$, omitting the lowest bin (corresponding to $Z=0$ ) and adding back the mean job loss probability for those in the lowest bin of $1.9 \%$. Standard errors are clustered by household. The figure reveals an increasing pattern: those with higher subjective probability elicitations are more likely to lose their job, conditional on demographics and job characteristics.

Table II presents the results from a linear parameterization of this relationship. I regress the indicator for job loss in the subsequent 12 months, $U_{i t}$, on observable controls at time $t, X_{i t}$, and

\footnotetext{
${ }^{21}$ This significant divergence between elicitations and job loss means was noted in Stephens (2004).

${ }^{22} \mathrm{An}$ alternative explanation is that individuals hold overly pessimistic beliefs about losing their job. I return to a discussion of the implications of biased beliefs in Section 7 .
} 
the subjective probability elicitation, $Z_{i t}$ :

$$
U_{i t}=\alpha+\beta Z_{i t}+\Gamma X_{i t}+\epsilon_{i t}
$$

Table II reports the coefficient $\beta$ and its standard error, clustering by household. For the baseline specification with demographics and job characteristics, the estimated slope is 0.0836 (s.e. 0.00675). For every $1 \mathrm{pp}$ increase in the elicitation, $Z$, individuals are roughly $0.08 \mathrm{pp}$ more likely to lose their job in the subsequent 12 months. This suggests the elicitations contain information about unemployment beyond what is captured by the observables.

Columns (2)-(4) illustrate the robustness of the estimated coefficient to alternative control variables. Dropping job characteristics leads to a slightly higher coefficient of 0.0956 (s.e. 0.00685); adding additional controls for health characteristics reduces the coefficient to 0.0822 (s.e. 0.00736). Adding individual fixed effects only reduces the coefficient to 0.0738 (s.e. 0.012). Of course, an insurer could never condition on an individuals' fixed effect, as this would require conditioning on information realized in the future in order to construct the individual-specific sample mean. But, the specification suggests that much of individuals' knowledge reflects time-varying knowledge about future unemployment. This underscores the difficulty that would be faced by an insurance company attempting to use observable variables to reduce the asymmetric information problem.

Columns (5)-(10) illustrate the presence of private information across a range of subsamples. Although the HRS primarily focuses on older workers, columns (5)-(6) split the sample into those above and below 55 years old. The coefficients are relatively similar, illustrating the stability of the patterns across the age ranges observed in the data. Columns (7)-(8) split the sample into those with above- and below-median wage earnings to show the stability of the pattern across the income distribution. Finally, columns (9)-(10) split the sample into those with more and less than 5 years of job tenure. Here again, the pattern is similar with the estimated coefficient ranges around 0.07-0.09. In short, the presence of private information about unemployment appears consistent across subsamples of the data.

\subsection{Spousal Labor Supply Response to Knowledge of Future Job Loss}

Individuals have knowledge about their future job loss. Would they use this information to adversely select an insurance contract if it were offered to them? More generally, how do individuals react to learning they might lose their job? If individuals are under-insured against the risk of job loss, learning today that you might lose your job tomorrow should trigger anticipatory responses to earn more income today and cut back on consumption. This subsection explores the first of these two 
responses by studying the spousal labor supply response. ${ }^{23}$

Figure III explores whether those who believe they are more likely to lose their job have spouses that are more likely to enter the labor market. The figure replaces the subsequent job loss variable, $U_{i t}$, in equation (1), with an indicator equal to 1 if the spouse not working for pay last wave and working for pay in the current wave of the survey. The results suggest that spouses of individuals who are likely to lose their job are more likely to enter the labor market. In particular, spouses of individuals with $Z>50$ as opposed to $Z=0$ are 2 percentage points more likely to enter the labor force. On the one hand, this is a small effect: it suggests roughly 1 in 50 extra spouses are induced into the labor market when the elicitation is above $50 \%$. On the other hand, relative to the base entry rate of these spouses of $3.9 \%$, it is quite large. For values $Z<50$, the response is more muted, perhaps consistent with a model in which labor market entry has high fixed cost.

Table III linearly parameterizes the relationship in Figure III, estimating an equation

$$
L F P_{i t}=\beta Z_{i t}+\Gamma X_{i t}+\epsilon
$$

where $\beta=\frac{d L F P}{d Z}$ is the response of spousal labor supply to a 1 pp increase in the subjective probability elicitation, $Z$. Column (1) of Table III presents this coefficient of 0.0258 (s.e. 0.0087). Column (2) restricts the sample to those who do not end up losing their job in the 12 months after the survey, yielding 0.0256 (s.e. 0.009). This suggests households are responding to the risk of unemployment, even if the realization does not occur. Column (3) uses a specification that defines spousal work as an indicator for full-time employment, as opposed to any working for pay. This definition includes shifts from part time to full time work in the definition of labor market entry, and finds a similar slope of 0.0255 (s.e. 0.0099).

One threat to interpreting this coefficient as the impact of learning one might lose their job on spousal labor supply is that it may in part reflect a selection effect. For example, perhaps individuals who are more likely to lose their jobs may be more likely to have spouses that have less labor force attachment and are more likely to come and go into the labor market. To this aim, Column (4) considers a placebo test that uses the lagged value of the elicitation, $Z_{i t-2}$ instead of $Z_{i, t}$ (where year $t-2$ corresponds to the previous wave of the survey conducted 2 years prior). Here, the coefficient is 0.00122 (s.e. 0.008) and is not statistically distinct from zero. Columns (5) and (6) add household and individual fixed effects to the specification in Column (1), yielding similar coefficients. In short, the results suggest that in response to learning about future job loss spouses

\footnotetext{
${ }^{23}$ This analysis extends a large literature on the added worker effect (e.g. Gruber and Cullen (1996)) and builds on Stephens Jr (2002) who shows evidence of an ex-ante response by spouses to unemployment shocks in the PSID. Here, I provide further evidence these responses are related to learning one might lose their job, as captured by subjective probability elicitations.
} 
are more likely to enter the labor market. ${ }^{24}$ This suggests not only that individuals and households have private information about future job loss, but that they would act upon this information if presented with opportunities to mitigate this risk, such as private UI markets.

\subsection{Consumption Response to Knowledge of Future Job Loss}

The previous sections establish using HRS data that individuals have private information and suggests they would take actions to mitigate this risk. This subsection seeks further evidence of this knowledge of future job loss in a broader sample using a widely analyzed variable: food expenditure in the PSID. There is a large literature studying the impact of unemployment on measures of consumption and food expenditure. For example, Gruber (1997) and Chetty and Szeidl (2007) document a 6-10\% average drop in food expenditure upon unemployment. However, if individuals learn ex-ante about their potential future unemployment, one would expect these cuts to occur prior to the actual unemployment incidence. Here, I explore this hypothesis by documenting a drop in household food expenditure in the 1-2 years prior to the job loss or unemployment spell.

Following Gruber (1997), let $g_{i, t}=\log \left(c_{i, t}\right)-\log \left(c_{i, t-1}\right)$ denote yearly food expenditure growth, where $c_{i, t}$ is food expenditure of household $i$ in year $t$. Let $U_{i t}$ denote an indicator for being unemployed in year $t, U_{i t}$. I regress food expenditure growth on leads and lags of unemployment:

$$
g_{i, t}=a_{k}+\Delta_{k}^{F D} U_{i, t-k}+\Gamma_{k} X_{i, t}+\epsilon_{i, t}
$$

I run separate regressions for each lead/lag of unemployment, $k$. The coefficient $\Delta_{k}^{F D}$ measures the average difference in consumption growth in period $t$ between those who are and are not unemployed in period $t-k$. To control for other life-cycle or aggregate trends in consumption that might affect $g_{i, t}$, I include a cubic in the household head's age and a full set of year dummies in the controls, $X_{i, t}$.

Figure IV plots the coefficients $\Delta_{k}^{F D}$ for $k=-4,-3, \ldots, 0, \ldots, 3,4$ for the baseline sample of those who are employed in years $t-1$ and $t-2$. Consistent with previous literature, the figure documents a $7-8 \%$ impact on consumption at the onset of unemployment; but, the figure also reveals a $2-3 \%$

\footnotetext{
${ }^{24}$ In addition to impacts on entry, one may also expect to see fewer spouses leave the labor force in response to learning about future unemployment prospects for the other earner. However, a countervailing force could arise from correlated labor demand shocks (e.g. from spouses working in the same industry). To explore these patterns, Column (7) defines labor market exit as an indicator for a spouse working for pay last wave and not working for pay in the current period. The coefficient of 0.0174 (s.e. 0.0119 ) is positive, although not statistically significant. This suggests spouses are perhaps slightly more likely to exit, consistent with households facing correlated unemployment shocks. To this aim, Column (9) shows that the the elicitation is positively related to spousal unemployment in the subsequent year, with a coefficient of 0.0213 (s.e. 0.0097). Spouses of those who learn they may lose their job may wish to keep their job, but may not always have that choice. In this case, the estimates for the impact of learning about future job loss on spousal labor supply under-state the response that would occur if the opportunity set available to the spouse were held fixed.
} 
impact in the year prior to unemployment. ${ }^{25}$ Note the dependent variable is log food expenditure growth. For example, the difference in 2-year consumption growth for those who do versus do not become unemployment in year $t$ is roughly 10\%. Moreover, the impact of unemployment appears to be a long-run shock to food expenditure that does not recover, as shown in Stephens (2001).

To explore the robustness of this differential food expenditure growth in year $t-1$ relative to $t-2$, Table IV presents the results of a regression of the difference in log food expenditure in year $t-2$ and year $t-1, \log \left(c_{t-1}\right)-\log \left(c_{t-2}\right)$, on an indicator for unemployment in current period and controls for an age cubic and year dummies. Column (1) reports the shows that the pattern in Figure IV corresponds to a $-2.71 \%$ (s.e. $0.975 \%$ ) drop in food expenditure ${ }^{26}$ in the year before unemployment occurs. Column (2) of Table V adds controls for both the change in household size in years $t-2$ versus $t-1$ and the change in expenditure needs, delivering a fairly similar coefficient of $-2.11 \%$ (s.e. $1.05 \%$ ) and suggesting the patterns are not driven by changes in household size or composition around the time of unemployment. ${ }^{27}$ Column (3) restricts the sample to those under age 50 - a group largely not captured by the HRS analysis above. This yields a coefficient of $-2.88 \%$ (s.e. $1.06 \%$ ), which is similar in magnitude but not statistically distinguishable from the baseline estimate. This suggests knowledge of future job loss is present across the age distribution in the U.S, not only the older sample surveyed by the HRS.

The baseline figure studies consumption patterns around unemployment, which may be distinct from a job loss event; Column (4) illustrates the ex-ante food expenditure response to future job loss (regardless of whether it leads to future unemployment). ${ }^{28}$ Individuals who experience a job loss in the future year are likely to have already dropped their consumption by $2.6 \%$ (s.e. $0.824 \%$ ) relative to those who will not experience a future job loss in the subsequent year. ${ }^{29}$ Overall, the results suggest food expenditure drops in the years prior to the job loss or unemployment spell.

\footnotetext{
${ }^{25}$ We do not see a significant drop in consumption in the earlier years (e.g. $t-3$ relative to $t-4$ ). This is consistent with evidence discussed below that a large portion (e.g. 10\%) of knowledge of future job loss in period $t$ is revealed in years $t-2$ relative to $t-1$, but not as much is revealed in the earlier years. See Section 6 and Online Appendix Figure I that regresses $U_{i, t+k}$ on $Z_{i t}$ for $k=1,2, \ldots$.

${ }^{26}$ Online Appendix Figure II replicates the baseline regression in Figure IV using more recent PSID data on total household expenditure on a sample that is surveyed every two years. The broad patterns are similar, although the consumption drop upon unemployment is slightly larger (e.g. 12\%) when using total consumption expenditure as opposed to food expenditure. There is also an ex-ante response of $3.6 \%(p=0.055)$ in $t-2$ relative to $t-4$ in total consumption expenditure.

${ }^{27}$ Restricting to the subsample of 53,327 observations for which the needs variable is available drops the coefficient in column (1) to $2.4 \%$, suggesting roughly half of the drop in the point estimate is driven by differential sample composition; of course, all of these point estimates are well within 1 standard error of the baseline estimate.

${ }^{28}$ Online Appendix Figure III presents the lead and lag estimates as in Figure IV using job loss instead of unemployment and finds similar patterns to Figure IV.

${ }^{29}$ Temporary or seasonal work is coded separately and not included in job loss. Therefore, the ex-ante consumption responses in the PSID suggest the patterns in the HRS are not driven solely by knowledge about fixed term temporary contracts.
} 
Forward looking behavior versus correlated shocks There are two competing mechanisms that could be driving these results. On the one hand, the ex-ante responses are consistent with forward looking behavior in response to a lower future income. Learning one might lose their job should have a tendency to lower expenditure today and an increase in savings for the future. On the other hand, the ex-ante responses could also be consistent with individuals consuming handto-mouth $(c=y)$ if income drops prior to unemployment.

To distinguish between these mechanisms, Column (5) of Table IV adds controls for a cubic polynomial of changes in log household income to the baseline specification. This yields a coefficient of $2.72 \%$ (s.e. $0.969 \%$ ) nearly identical to the baseline specification in Column (1). The results are similar with higher and lower order polynomial controls, or restricting those with small income changes between $t-1$ and $t-2$. Column (6) adds controls for a cubic polynomial of changes in $\log$ income of the household head, yielding a coefficient of $-2.81 \%$ (s.e. $0.983 \%$ ). ${ }^{30}$ To understand why the results are not significantly affected by adding controls for income, Online Appendix Figure IV replicates Figure IV using log household income as the dependent variable as opposed to $\log$ food expenditure. For those employed in both $t-2$ and $t-1$, unemployment in period $t$ is not associated with any significant income change in any of the years prior to unemployment. ${ }^{31}$ Rather, the consumption drop is consistent with an anticipatory response to learning about future unemployment.

\section{Model}

Individuals appear to be taking actions - cutting consumption and increasing spousal labor supply - in response to learning they might lose their job. This suggests the onset of job loss and unemployment imposes a financial burden that generates a desire for additional financial resources something that would be naturally satisfied by an unemployment insurance product. Is this private information the reason one does not see a thriving private market for unemployment insurance?

This section develops a simple model in which individuals face a risk of losing their job to frame and address this question. The framework builds upon a model of Hendren (2013) by incorporating dynamics and precautionary responses, and allows for the possibility of moral hazard

\footnotetext{
${ }^{30}$ The sample sizes are slightly lower for these specifications due to non-response to income questions. The food expenditure patterns are similar when restricting to a sample with non-missing income reports.

${ }^{31}$ Note the levels of the coefficients are around -0.4 in the pre-periods, indicating that on average lower income populations are more likely to experience unemployment. The absence of an ex-ante drop in income differs from the findings of Davis and von Wachter (2011) for plant closings. To be sure, there are sub-samples in the PSID for which income does decline; in particular, if one includes those who are unemployed in $t-1$ or $t-2$, then income does decline prior to the unemployment measurement (as shown in Stephens (2001)). In this sense, the patterns identified here are similar to those found in Stephens (2001) who shows roughly a $2 \%$ drop in the year prior to a job loss; the main empirical distinction is that I illustrate that these patterns hold on the sample who remain employed in periods $t-1$ and $t-2$, so that it is not driven by these correlated income shocks in the pre-periods.
} 
when providing unemployment insurance. The model will clarify how to quantify the degree of adverse selection that would arise if insurers were to offer insurance and to think about whether individuals' willingness to pay for a private UI policy would overcome such barriers. Along the way, the model also provides a framework for thinking about alternative explanations for the absence of a private market, including aggregate risk, biased beliefs, and moral hazard.

\subsection{Setup}

There are a set of individuals, $i$, who face a risk of losing their job in the next year. They choose consumption today, $c_{\text {pre }}$, along with a plan for consumption in the event of not losing and losing her job in the future, $c_{e}$ and $c_{u}$. In addition, individuals also choose a vector of other choices, $a$, which can include spousal labor supply, job search activities, and can be contingent plans for future behavior conditional on other events that may happen in the future. In this sense, the model is both stochastic and dynamic. Let $p$ denote an individuals chance of losing her job in the next 12 months. This chance is allowed to be privately known to the individual (so that it can generate adverse selection). It is also allowed to be affected by the choices of the individual - for example, unemployment insurance may increase the odds of job loss (moral hazard).

Individual $i$ chooses $\left\{c_{p r e}, c_{u}, c_{u}, a, p\right\} \in \Omega_{i}$ to maximize a utility function that satisfies

$$
v\left(c_{\text {pre }}\right)+p u\left(c_{u}\right)+(1-p) v\left(c_{e}\right)+\psi_{i}(p, a)
$$

where $v\left(c_{\text {pre }}\right)$ is the utility over consumption today, $u\left(c_{u}\right)$ and $v\left(c_{e}\right)$ are the utility over consumption if the individual does and does not lose her job next year, and $\psi_{i}(p, a)$ is the (dis)utility from all the other choices $p$ and $a$. The model generalizes the structure in Hendren (2013) in several ways to capture the features operating in the present environment. First, the utility function over consumption is allowed to differ for those who remain employed, $v$, versus those who lose their job, $u$. This allows for state-dependent utility. Second, the probability of job loss is allowed to be a choice, so that the problem incorporates moral hazard: more insurance can increase the cost to the insurer of providing that insurance. Third, the model in principle allows for multiple dimensional heterogeneity (e.g. different individuals, $i$, may have different utility functions, $\psi_{i}$, and face different constraints, $\Omega_{i}$. In the exposition in the main text, I assume heterogeneity can be fully summarized by the choice of $p$ (i.e. it is uni-dimensional); but the modeling in Appendix A illustrates how the analysis readily extends to the case of multi-dimensional heterogeneity.

Finally, the model allows for sources of formal and informal insurance: items such as transfers from friends and family, and the current level of government benefits are embodied in the constraints, $\Omega_{i}$. In particular, the model allows for dynamic responses to under-insurance and thus the ability to match the empirical patterns in Section 3. 
Consumption Responses To see how the general modeling setup captures the patterns of consumption in Figure IV, one can make the assumption that the constraints, $\Omega_{i}$, allow the individual to save today to increase consumption in both states of the world tomorrow. ${ }^{32}$ Optimization then yields the familiar Euler equation:

$$
v^{\prime}\left(c_{\text {pre }}(p)\right)=p u^{\prime}\left(c_{u}(p)\right)+(1-p) v^{\prime}\left(c_{e}(p)\right)
$$

The marginal utility of income today equals the expected marginal utility of income in the future. If the marginal utility of income is higher when unemployed, $u^{\prime}>v^{\prime}$ (i.e. individuals are underinsured), then learning one might lose their job should cause individuals to cut back on current consumption and save for future consumption. In this sense, the ex-ante responses in Figure IV are consistent with individuals being under-insured against the risk of job loss.

Spousal Labor Supply Responses The model also captures the spousal labor supply responses seen in Section 3.3. To see this, write $a=\left(l^{\text {spouse }}, a^{\prime}\right)$ and $\psi_{i}(p, a)=\kappa_{i}\left(p, a^{\prime}\right)-\eta\left(l^{\text {spouse }}(p)\right)$, where $a^{\prime}$ is the vector of all other actions and $\eta$ captures the disutility of spousal labor supply. Let $w^{\text {spouse }} l^{\text {spouse }}$ denote the earnings of the spouse with labor supply $l^{\text {spouse }}$. Then, the intratemporal choice of labor supply implies the marginal disutility of labor is equated to the marginal value of consumption multiplied by the wage, $\eta^{\prime}\left(l^{\text {spouse }}(p)\right)=w^{\text {spouse }} v^{\prime}\left(c_{\text {pre }}(p)\right)$. So, the Euler equation (6) can be re-written as

$$
\frac{1}{w^{\text {spouse }}} \eta^{\prime}\left(l^{\text {spouse }}(p)\right)=p u^{\prime}\left(c_{u}(p)\right)+(1-p) v^{\prime}\left(c_{e}(p)\right)
$$

The marginal disutility of labor divided by the spouse's wage equals the expected marginal utility of income in the future. All else equal, an increase in $p$ should lead to an increase in spousal labor supply. Equation (7) illustrates this logic along the intensive margin; Appendix C.4 illustrates this logic using extensive margin responses. If individuals are under-insured against unemployment risk, $u^{\prime}\left(c_{u}(p)\right)>v^{\prime}\left(c_{e}(p)\right)$, which generates a desire to increase income if job loss becomes more likely. In this sense, the model formalizes the idea that the ex-ante responses signal under-insurance against unemployment, and suggest they would have a desire to purchase a private unemployment insurance contract if it were offered.

\subsection{Existence of Private Markets}

When can a third-party insurance company enter this environment and profitably sell an insurance contract? To be precise, I ask when can a private market arise for additional insurance on top of

\footnotetext{
${ }^{32}$ To be specific, I assume that if $\left\{c_{p r e}, c_{u}, c_{u}, a, p\right\} \in \Omega_{i}$ then $\left\{c_{p r e}-s, c_{u}+s, c_{u}+s, a, p\right\} \in \Omega_{i}$ for all $s$. For simplicity, I assume that the interest rate on savings equals 1 to be consistent with the lack of discounting in equation (5). More generally, this Euler equation is obtained as long as the discount rate on utility equals the interest rate on risk free savings.
} 
what is currently provided by existing formal and informal insurance arrangements. ${ }^{33}$

To begin, imagine an insurer enters and attempts to sell a policy that pays $\$ 1$ in the event the individual loses her job. A type $p$ is willing to pay $\frac{p}{1-p} \frac{u^{\prime}\left(c_{u}(p)\right)}{v^{\prime}\left(c_{e}(p)\right)}$ from the future state of not losing her job to buy this policy, where $u^{\prime}\left(c_{u}(p)\right)$ and $v^{\prime}\left(c_{e}(p)\right)$ are the marginal utilities of consumption in the event of losing and not losing her job.

The actuarially fair cost of providing this $\$ 1$ to a type $p$ is $\frac{p}{1-p}$. If the insurer could sell at this price there would be a profitable insurance market as long as the individual had a higher marginal utility of income when unemployed, $\frac{u^{\prime}\left(c_{u}(p)\right)}{v^{\prime}\left(c_{e}(p)\right)}$. But, since $p$ is unobserved to the insurer, the cost to the insurance company depends on who else prefers such an insurance contract. The natural tendency is that those more likely to obtain the insurance payout (i.e. those with probabilities greater than $p$ ) will prefer this insurance contract. Let $P$ denote the random variable corresponding to the distribution of probabilities chosen by the population. The cost of providing insurance depends on $\frac{E[P \mid P \geq p]}{1-E[P \mid P \geq p]}$, where $P$ is a random variable representing the distribution of risks of job loss. Appendix A shows that a private market cannot exist if and only if

$$
\frac{u^{\prime}\left(c_{u}(p)\right)}{v^{\prime}\left(c_{e}(p)\right)} \leq T(p) \quad \forall p
$$

where $\frac{u^{\prime}\left(c_{u}(p)\right)}{v^{\prime}\left(c_{e}(p)\right)}-1$ is the markup over actuarially fair rates that a type $p$ is willingness to pay for a small amount of insurance and $T(p)=\frac{E[P \mid P \geq p]}{1-E[P \mid P \geq p]} \frac{1-p}{p}$ is the pooled price ratio. Equation (8) is similar to the equation in Hendren (2013), but generalized to the case when the elements of the equation are choices of the individual, instead of exogenously given. As a result, the present formulation incorporate dynamic responses (e.g. consumption responds to learning about future unemployment) and moral hazard (the likelihood of an insurance payout, $p$, depends on behavior). The main result provided in Appendix A is that the objects in equation (8) are sufficient for characterizing when a private market can profitably sell insurance in this rich environment.

Equation (8) is similar to the unraveling condition in Akerlof (1970) and Einav et al. (2010). In those models, the market will fully unravel whenever the average cost curve (average cost of those purchasing the insurance at a given price) lies everywhere below the demand curve (willingness to pay for the marginal purchaser). Online Appendix Figure V presents a graphical illustration that translates the current analysis into their framework. Loosely, equation (8) characterizes when the market unravels for a small amount of insurance, where the "demand curve" is given by $\frac{p}{1-p} \frac{u^{\prime}\left(c_{u}(p)\right)}{v^{\prime}\left(c_{e}(p)\right)}$ and the "average cost curve" is given by $\frac{E[P \mid P \geq p]}{1-E[P \mid P \geq p]}$. The key distinction of the model in this paper is that it does not exogenously restrict the set of insurance contracts traded. Appendix A.2 shows that the no trade condition also rules out menus of contracts and other (e.g. larger) insurance

\footnotetext{
${ }^{33}$ A related question, discussed in Section (7), is whether a private market would arise if the government were to stop providing UI.
} 
contracts. In this sense, when Equation (8) holds, it suggests the market for any insurance contract about the job loss will fully unravel in the sense of Akerlof (1970) and Einav et al. (2010). ${ }^{34}$

While the present model is less restrictive than Einav et al. (2010) in terms of allowing for endogenous contracts, the model is more restrictive in only allowing a single dimension of heterogeneity, $p$. In Appendix A.1, I extend the baseline model in Section 4 to allow two people with the same $p$ to have a different willingness to pay, $\frac{u^{\prime}}{v^{\prime}}$. When people with the same $p$ have different willingness to pay, $\frac{u^{\prime}}{v^{\prime}}$, the left side of Equation (8) is drawn from the interior of the distribution of $\frac{u^{\prime}}{v^{\prime}}$. In this sense, the results are robust to the introduction of multi-dimensional heterogeneity. ${ }^{35}$

Equation (8) provides a theory of how private information can prevent the existence of a UI market. The next two sections focus on translating the empirical evidence in Section 2 and 3 into estimating each side of this equation: the willingness to pay for UI, $\frac{u^{\prime}\left(c_{u}(p)\right)}{v^{\prime}\left(c_{e}(p)\right)}$, and the pooled price ratio, $T(p)$.

\section{Implications for Willingness to Pay}

Because unemployment insurance policies are not traded in a market, it is not straightforward to ascertain the markup individuals would be willing to pay for UI, $\frac{u^{\prime}\left(c_{u}(p)\right)}{v^{\prime}\left(c_{e}(p)\right)}$. This section develops two strategies for estimating properties of this willingness to pay. The first follows previous literature by assuming state-independent utility over consumption and inferring the willingness to pay from the size of the consumption drop caused by job loss. While this is a common strategy employed in the previous literature, I show that this approach underestimates willingness to pay when individuals have ex-ante knowledge about future job loss. In particular, estimates must be scaled upwards to account for the fact that some information about job loss has been revealed at the time lagged consumption is measured in the first difference estimate.

The second strategy exploits the ex-ante behavioral response to learning one might lose their job. Instead of comparing employed to the unemployed, I compare the consumption of individuals who learn today that they might lose their job to those who learn today they will likely not lose their job. Throughout, I compare and contrast the assumptions required for each of these approaches to deliver accurate inferences about individuals' willingness to pay.

\footnotetext{
${ }^{34}$ The model in Akerlof and EFC do allow for richer heterogeneity than the single-dimension allowed in the baseline model. However, Appendix A.1 shows an analogy of equation (8) readily extends to the case of multi-dimensional heterogeneity.

${ }^{35}$ As shown in Appendix A.1, the relevant willingness to pay is not a simple average of the population, but is a more complicated interior quantile of the type space that depends on the joint distribution of the type distribution and willingness to pay.
} 


\subsection{Approach \#1: Consumption when unemployed versus employed}

\subsubsection{Setup}

There is an extensive literature focused on estimating the markup individuals are willing to pay for additional UI benefits by measuring the causal effect of job loss or unemployment on consumption growth. If utility over consumption is state independent $(v(c)=u(c)$ ), one can follow Chetty (2006) by using a third-order Taylor expansion for $u^{\prime}$ around $c_{e}(p)^{36}$, to write the markup individuals are willingness to pay for UI as:

$$
\frac{u^{\prime}\left(c_{u}(p)\right)}{v^{\prime}\left(c_{e}(p)\right)}-1 \approx \sigma \frac{\Delta c}{c}(p)\left[1+\frac{\gamma}{2} \frac{\Delta c}{c}(p)\right]
$$

where $\frac{\Delta c}{c}=\frac{c_{e}(p)-c_{u}(p)}{c_{e}(p)}$ is the causal effect of job loss on type $p$ 's percentage difference in consumption, $\sigma$ is the coefficient of relative risk aversion, $\sigma=-\frac{c_{e}(p) u^{\prime \prime}\left(c_{e}(p)\right)}{u^{\prime}\left(c_{e}(p)\right)}$, and $\gamma=-\frac{c_{e}(p) u^{\prime \prime \prime}\left(c_{e}(p)\right)}{u^{\prime \prime}\left(c_{e}(p)\right)}$ is the coefficient of relative prudence. ${ }^{37}$ For simplicity, I assume constant coefficient of relative risk aversion (e.g. $u(c)=\frac{c^{1-\sigma}}{1-\sigma}$ ) so that the coefficient of relative prudence equals the coefficient of relative risk aversion plus $1, \gamma=\sigma+1$. Following Gruber (1997), it is common to approximate this percentage change using log consumption,

$$
\frac{\Delta c}{c}(p) \approx \log \left(c_{e}(p)\right)-\log \left(c_{u}(p)\right)
$$

When utility over consumption is state independent $(u(c)=v(c))$, the willingness to pay for a type $p$ depends on the causal impact of job loss on their consumption.

\subsubsection{Implementation using Unemployment versus Job Loss}

While equation (10) is the causal effect of job loss, the traditional focus of previous literature is to estimate the causal effect of unemployment on consumption. Indeed, because the consumption

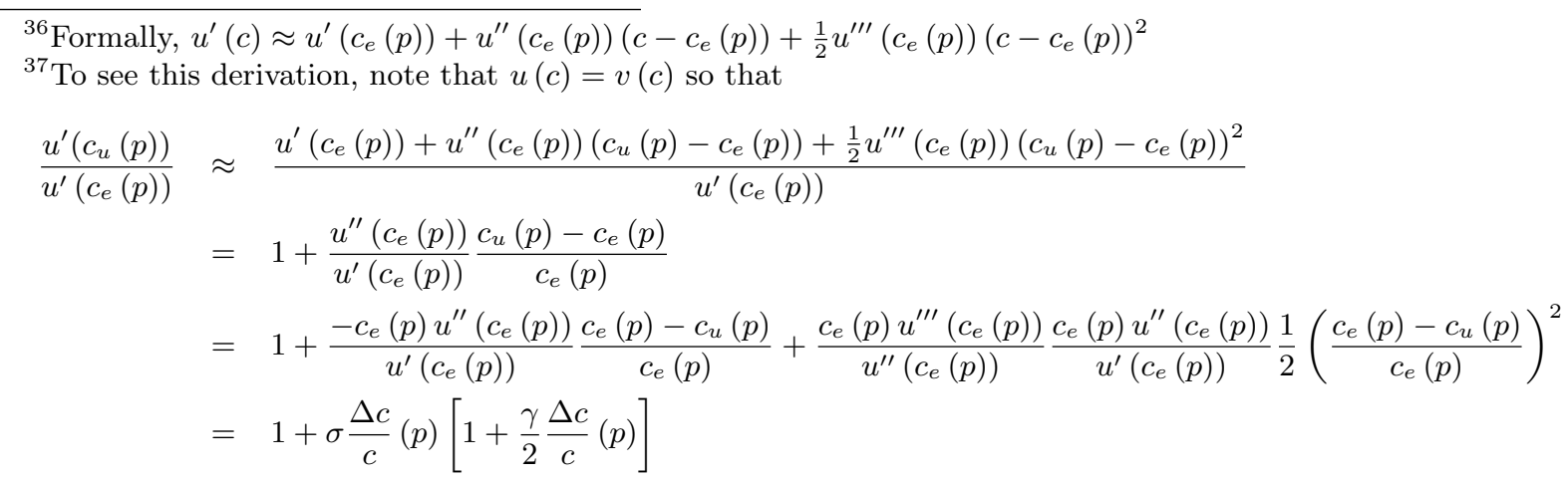

And, under an assumption of constant relative risk aversion, we have $\gamma=\sigma+1$

$$
\begin{aligned}
\frac{u^{\prime}\left(c_{u}(p)\right)}{u^{\prime}\left(c_{e}(p)\right)}-1 & \approx \sigma \frac{\Delta c}{c}(p)\left[1+\frac{\sigma+1}{2} \frac{\Delta c}{c}(p)\right] \\
& =\sigma \frac{\Delta c}{c}(p)+\sigma \frac{\sigma+1}{2}\left(\frac{\Delta c}{c}(p)\right)^{2}
\end{aligned}
$$


data in the PSID is not high-frequency, it is difficult to measure food expenditure at the time of job loss. The subsequent survey provides information about whether the individual lost her job. But it does not provide the consumption levels at the time of losing that job, which is formally what is desired to estimate the willingness to pay for an insurance policy that pays $\$ 1$ in the event of job loss.

Therefore, my baseline analysis to estimate willingness to pay will focus on the causal impact of unemployment on consumption, following the traditional approach in the literature (e.g. Gruber (1997)). This potentially provides an over-estimate of the impact of unemployment on consumption if shocks that lead to unemployment at the time of the next survey are worse than the average job loss shock. I therefore present results below from a complementary approach that estimates the impact of having lost one's job in the past 12 months on current consumption. This will likely under-state the causal impact of job loss on consumption: if those who lose their job are liquidity constrained (Chetty (2008)), consumption will have fallen more at the time of the job loss than what is observed at the time of the subsequent survey. In practice, it will turn out that the impacts of job loss and unemployment on consumption are fairly similar, so that much of this distinction is not important in practice. ${ }^{38}$

\subsubsection{Attenuation Bias in First Difference Estimator}

To estimate the causal impact of unemployment on food expenditure in equation (10), one must account for the fact that those who are unemployed may differ on many other dimensions (e.g. have lower earnings history or less savings) that generate differences in consumption levels. To remove this selection bias, previous literature often focuses on the impact of unemployment on yearly consumption first differences, as in $\Delta_{0}^{F D}$ in Equation 4 (Gruber (1997); Chetty and Szeidl (2007)).

The first row of Table $\mathrm{V}$ presents the estimates for $\Delta_{0}^{F D}$ in Equation 4 using the baseline sample from the PSID. Consistent with Gruber (1997) and Chetty and Szeidl (2007), the event of unemployment leads to a roughly $7-8 \%$ lower food expenditure relative to the previous year. Column (1) presents the results for the baseline sample in the PSID, yielding a coefficient of $7.23 \%$ (s.e. $0.997 \%$ ). The remaining columns report robustness to alternative specifications that I return to below.

The common assumption in previous literature is that this yearly first difference impact on expenditure reflects the causal effect of unemployment. However, the results in Section 3.3 illustrate that lagged consumption may differ between subsequently employed and unemployed, even for those

\footnotetext{
${ }^{38}$ See Appendix Figure III, which replicates the baseline pattern in Figure IV using job loss instead of unemployment as the outcome.
} 
who were ex-ante identical. In this case, one can write the first difference estimate as:

$$
\Delta_{0}^{F D}=\underbrace{E\left[\log \left(c_{e}(p)\right)-\log \left(c_{u}(p)\right)\right]}_{\text {Average Causal Effect }}-\underbrace{\left(E\left[\log \left(c_{\text {pre }}(p)\right) \mid U=0\right]-E\left[\log \left(c_{\text {pre }}(p)\right) \mid U=1\right]\right)}_{\text {Bias from ex-ante response }}(11)
$$

where the bias term equals the difference in consumption in the year prior to the unemployment spell, $c_{\text {pre }}$, between those who subsequently become unemployed and those who do not. If individuals in the previous year have knowledge about future unemployment then one would expect the distribution of $c_{\text {pre }}(p)$ to differ between those who experience versus do not experience unemployment (e.g., those who lose their job on average could have lowered their consumption in previous periods). Therefore, the bias term in equation (11) would be nonzero.

\subsubsection{Correction}

This section provides a two-sample IV strategy to recover the causal effect from the first difference estimator by scaling it by the amount of information revealed over the time elapsed in the first difference (e.g. 1 year prior to unemployment). ${ }^{39}$ The idea is to use the Euler equation (Equation 6) to infer a link between ex-ante consumption driving the bias in equation (11) and ex-post consumption, $c_{e}(p)$ and $c_{u}(p)$. The main intuition is that the impact of learning that unemployment is $1 \%$ more likely (i.e. $p$ increases by $1 \mathrm{pp}$ ) should have an impact on consumption today that equals $1 \%$ of the causal effect of unemployment on consumption. When this is true, one can scale the first difference estimate by the amount of information revealed in the time length of the first difference.

Proposition 1. Suppose that (i) the utility function is state-independent $(u(c)=v(c)$ ), (ii) the Euler equation 6 holds, and (iii) the causal effect of unemployment on consumption is not varying with $p, \frac{d\left[\log \left(c_{e}(p)\right)-\log \left(c_{u}(p)\right)\right]}{d p}=0$. Let “ $\approx$ " denote an equality up to log-linear consumption approximations and third-order Taylor approximations for $u$ and $v$. Then, the average causal effect of unemployment on log consumption is given by

$$
E\left[\log \left(c_{e}(p)\right)-\log \left(c_{u}(p)\right)\right] \approx \frac{\Delta_{0}^{F D}}{1-\kappa(E[P \mid U=1]-E[P \mid U=0])} \equiv \Delta^{I V}
$$

where $\frac{\operatorname{var}(P)}{\operatorname{var}(U)}=E[P \mid U=1]-E[P \mid U=0]$ is the fraction of variance in $U$ that is realized in beliefs $P$ at time $t-1$ and $\kappa=E\left[\frac{1}{1+p \frac{u^{\prime}\left(c_{u}(p)\right)-v^{\prime}\left(c_{e}(p)\right)}{u^{\prime}\left(c_{e}\right)}}\right] \approx 1$.

If the causal effect varies with the unobserved heterogeneity, $p$, then $\Delta^{I V}$ is greater than (less than) $E\left[\log \left(c_{e}(p)\right)-\log \left(c_{u}(p)\right)\right]$ if higher values of $p$ correspond to larger (smaller) consumption

\footnotetext{
${ }^{39}$ An alternative strategy would be to use longer lags instead of 1-year lagged consumption. However, Online Appendix Figure V shows that individuals have (albeit small) predictive information about future unemployment 10 years in advance. This suggests the lags would need to be longer than 10 years to remove the bias in Equation (11).
} 
drops. ${ }^{40}$

Proof. See Appendix C.1.

The average causal effect of unemployment is given by the first difference estimate in equation (4), $\Delta_{0}^{F D}$, scaled by the amount of information that is revealed over the year prior to the unemployment measurement, $1-(E[P \mid U=1]-E[P \mid U=0])$. If individuals have no knowledge about future unemployment, then $E[P \mid U=1]=E[P \mid U=0]$, so that the denominator equals 1 , and the first difference estimate remains valid. But, to the extent to which individuals learn about future unemployment and adjust their behavior accordingly, one needs to inflate the impact of unemployment on the first difference in consumption by the amount of information that is revealed over this time period.

Appendix C.1 shows that the $\kappa$ correction factor in the denominator of $\Delta^{I V}$ accounts for the fact that the ex-ante consumption response is valued using the ex-ante marginal utility, whereas the insurance markup is defined relative to the marginal utility in the ex-post state of employment. Because $p$ is small on average $(E[p]=4 \%)$, this correction is small in practice; if individuals are willing to pay a $25 \%$ markup and $E[p]=4 \%$, then this correction factor is roughly 1.01. Going forward I assume $\kappa \approx 1$.

\subsubsection{2-Sample Implementation}

Because the PSID does not contain belief elicitation information that could be used to formulate the denominator in equation (12), I rely on a two-sample IV strategy. Using the HRS, I regress the subjective probability elicitations on an indicator for subsequent unemployment. This provides an estimate of $E[P \mid U=1]-E[P \mid U=0]$, as long as the measurement error in $Z$ is classical (i.e. $Z-P$ is uncorrelated with $U$ ). Because $P$ and $U$ are bounded variables, the classical measurement error assumption is unlikely to be literally true; yet it provides a natural benchmark case for the analysis. The estimates suggest $E[P \mid U=1]-E[P \mid U=0] \approx 0.197$ (s.e. 0.012 ), which implies roughly $80 \%$ of the uncertainty in unemployment is not known 1 year in advance. Appendix Table I illustrates that the $80 \%$ statistic is quite stable across subgroups of the data.

Baseline Results The second set of rows in Table V scale the first difference estimate, $\Delta_{0}^{F D}$, by this first stage $(1 / 0.803)$ to arrive at an estimate of the average causal impact of unemployment

\footnotetext{
${ }^{40}$ In particular, one can show:

$$
E\left[\log \left(c_{e}(p)\right)-\log \left(c_{u}(p)\right)\right]=\frac{\Delta_{0}^{F D}+\frac{d\left[\log \left(c_{e}(p)\right)-\log \left(c_{u}(p)\right)\right]}{d p}(E[P \mid U=1]-E[P])}{1-\kappa(E[P \mid U=1]-E[P \mid U=0])-E[P] \sigma \frac{d\left[\log \left(c_{e}(p)\right)-\log \left(c_{u}(p)\right)\right]}{d p}}
$$
}

where $\sigma$ is the coefficient of relative risk aversion. 
on consumption. For the baseline sample employed in $t-1$, unemployment causes a $9 \%$ average drop in food expenditure. The remaining rows translate the causal effect into a willingness to pay by following equation (9) for common values of risk aversion (e.g. $\sigma$ ranging from 1 to 3 ). under an assumption of $\sigma=2$ suggests individuals are willing to pay a $20.4 \%$ markup for unemployment insurance. Higher risk aversion (e.g. $\sigma=3$ ) raises the willingness to pay to $31.9 \%$; if individuals are less risk averse (e.g. $\sigma=1$ ), they would be willing to pay a $9.8 \%$ markup for unemployment insurance.

Robustness The baseline analysis in column (1) makes a couple of specification decisions whose robustness are explored in Columns (2)-(6). Column (2) controls for changes in household size and food needs, yielding a similar willingness to pay estimate. Column (3) explores the pattern for those age 50 and under (analogous to Column (3) in Table IV for $\Delta_{-1}^{F D}$ ) and again finds a similar coefficient to the baseline specification. Column (4) re-introduces observations with more than a threefold change in food expenditure, which were dropped to align with the specification of Gruber (1997). Re-introducing these observations increases the first difference estimate to $8.89 \%$ (s.e. 1.23\%). Third, food expenditure sums monthly food spending in the house, out of the house, and - in addition - any spending that occurred through food stamps. While this follows Zeldes (1989); Gruber (1997), there are two concerns with adding food stamp expenditure into the analysis. First, individuals may have already included this spending in their report for in- and out-of-house expenditure (although technically this would not be a correct response). Second, the wording of the food stamp question elicits concurrent expenditure for the previous week, whereas the food expenditure measures elicit a "typical" week. Since unemployment is co-incident with rises in food stamp use, this differential recall window could lead to an under-stating of the impact of unemployment on food consumption. To understand the potential impact of this, Column (5) expands the specification in Column (4) to exclude food stamp expenditure from the food expenditure measure altogether. This yields a larger expenditure drop of $18.2 \%$ (s.e. $1.71 \%$ ), and provides arguably an upper bound on the size of the causal effect of $22.7 \%$. This would suggest individuals are willing to pay a $60.9 \%$ markup for UI with a coefficient of relative risk aversion of 2.

The analysis in Columns (1)-(6) measure how food expenditure varies with whether or not the individual is employed at the time of measurement. As discussed in Section 5.1.2, one would ideally like to estimate the impact of job loss regardless of whether it leads to unemployment. Column (6) shows that food expenditure growth is $4.87 \%$ (s.e. $0.860 \%$ ) lower relative to the previous year if a job loss has occurred relative to the previous year. This is slightly lower than the baseline 
estimate of $7.23 \%$ in Column (1). This is consistent with the idea that the consumption effects are attenuated when looking at job loss because the timing of the consumption measurement does not align with the timing of the event.

Finally, a remaining concern is that equation (8) requires comparing the willingness to pay for all $p$ to the pooled price ratio. Therefore, it is also useful to understand the heterogeneity in the potential willingness to pay across the population. How much might some people be willing to pay for insurance? Estimating a maximum as opposed to an average is always more difficult than estimating a mean. This is compounded by the problem that consumption expenditure is generally measured with error (Zeldes (1989); Meghir and Pistaferri (2011)). Appendix C.2 develops a measurement error model that uses symmetry assumptions to provide an upper bound on the causal effect of unemployment on food expenditure, $\min _{p}\left\{\log \left(c_{u}(p)\right)-c_{e}(p)\right\}$, which can be used to construct a maximum willingness to pay for UI. For brevity, the details of this approach are provided in the Appendix.

Columns (7)-(8) present the results. For the baseline sample in Column (7), the results suggest a maximum causal impact on food expenditure is $13.7 \%$, or roughly twice as large as the mean consumption drop. This rises to $14.6 \%$ on the broader sample that does not drop outliers with greater than a threefold change in measured food expenditure. The lower rows in Table V scale these estimates by various values of risk aversion. With a conservative estimate of 3 , it suggests the maximum markup individuals would be willing to pay is less than $52.6 \%$ on the baseline sample and $56.6 \%$ in the broader sample including outliers.

\subsection{Approach \#2: Exploiting Ex-Ante Responses as Evidence of WTP}

The previous section follows previous literature by inferring the willingness to pay for UI from the causal impact of unemployment on consumption (as measured by food expenditure). While this is a standard approach, it suffers a couple of drawbacks that have been noted in the literature. Most notably, it relies heavily on an assumption of state-independence of the utility function over food expenditure. $^{41}$

Recent literature has highlighted how these assumptions may be problematic. In particular, individuals who are unemployed may have more time to spend searching for lower prices or using time to make food instead of eating at restaurants. In this case, true "consumption" may not fall by as much, suggesting a lower drop in the marginal utility of income. More generally, one might worry about state-dependence of the utility function: even if consumption levels were the same

\footnotetext{
${ }^{41}$ This is often stated as two distinct assumptions: (1) state independence over consumption $(u(c)=v(c)$ for all $c$ ), and (2) food expenditure as a valid proxy for consumption. But, it should be clear that all that matters is how well food expenditure and risk aversion are able to provide a proxy for the marginal utility of consumption.
} 
when employed and unemployed, the marginal value of additional income when unemployed may differ from the marginal value of additional income when employed, $u^{\prime} \neq v^{\prime}$.

This section presents a new strategy for identifying the willingness to pay for UI that avoids these issues. The idea is to exploit the ex-ante behavioral response to learning one might lose their job within the state of currently being employed. The extent to which individuals take actions in response to learning they might lose their job in the future to generate or save financial resources helps reveal their willingness to pay for UI.

\subsubsection{Exploiting Ex-Ante Consumption Responses}

To see how this approach can work using ex-ante consumption responses, recall the Euler equation (6):

$$
v^{\prime}\left(c_{\text {pre }}(p)\right)=p u^{\prime}\left(c_{u}(p)\right)+(1-p) v^{\prime}\left(c_{e}(p)\right)
$$

Individuals who learn today that they will lose their job in the next year will equate their marginal utility of consumption today to the marginal utility of consumption when losing their job, $v^{\prime}\left(c_{\text {pre }}(1)\right)=$ $u^{\prime}\left(c_{u}(1)\right)$. Conversely, those that learn today that they won't lose their job in the next year will have a current marginal utility of consumption equal to the marginal utility of consumption when employed next year, $v^{\prime}\left(c_{\text {pre }}(0)\right)=v^{\prime}\left(c_{e}(0)\right)$. Under the assumption that $c_{e}$ and $c_{u}$ do not vary with $p$, Proposition 2 illustrates how the ex-ante behavioral response can reveal the markup individuals are willing to pay for UI.

Proposition 2. Suppose (a) the Euler equation holds, (b) $c_{e}$ and $c_{u}$ do not vary systematically with $p, \frac{d c_{e}}{d p}=0$ and $\frac{d c_{u}}{d p}=0$, and (c) the coefficient of relative risk aversion in the ex-ante employed state is constant, $\sigma=\frac{-v^{\prime \prime}\left(c_{\text {pre }}(p)\right)}{v^{\prime}\left(c_{\text {pre }}\right)} c_{\text {pre }}(p)$. Then,

$$
\frac{u^{\prime}\left(c_{u}\right)-v^{\prime}\left(c_{e}\right)}{v^{\prime}\left(c_{e}\right)}=\frac{\sigma}{\kappa} E\left[\frac{-d \log \left(c_{p r e}(p)\right)}{d p}\right]
$$

where $\kappa=E\left[\frac{1}{1+p \frac{u^{\prime}\left(c_{u}(p)\right)-u^{\prime}\left(c_{e}(p)\right)}{u^{\prime}\left(c_{e}\right)}}\right] \approx 1$ and $E\left[\frac{-d \log \left(c_{\text {pre }}(p)\right)}{d p}\right]$ is the average relationship between consumption today, $c_{\text {pre }}$, and beliefs about future employment, $p$.

Proof. See Appendix C.3.

Proposition 2 shows that one can identify the markup individuals are willing to pay for UI by scaling the impact of a change in beliefs about future unemployment on consumption today by the coefficient of relative risk aversion over current consumption. In contrast to equation (9), equation 13 no longer compares consumption between the employed and unemployed, but rather studies how consumption today varies with changes in beliefs about the future states of the world. ${ }^{42}$

\footnotetext{
${ }^{42}$ To see how this can differ it is helpful to consider a couple of examples to illustrate how marginal utilities of
} 
2-Sample Implementation To estimate how $c_{p r e}(p)$ varies with $p$ in equation 13 , I follow a methodology similar to that of the two sample IV approach in Section 5.1. While that approach compares the time path of consumption and time path of beliefs, $p$, between $t-1$ and $t$, this approach exploits the differential path of consumption between $t-2$ and $t-1$ for those who do versus those who do not become unemployed at time $t$. Mathematically,

$$
\frac{d \log \left(c_{p r e}\right)}{d p} \approx \frac{E\left[\log \left(c_{t-1}\right)-\log \left(c_{t-2}\right) \mid U_{t}=1\right]-E\left[\log \left(c_{t-1}\right)-\log \left(c_{t-2}\right) \mid U_{t}=0\right]}{E\left[P_{t, t-1}-P_{t, t-2} \mid U_{t}=1\right]-E\left[P_{t, t-1}-P_{t, t-2} \mid U_{t}=0\right]}
$$

where $P_{j, t}$ is the beliefs in period $t$ about job loss in period $j$. The numerator captures the impact of unemployment in year $t$ on food expenditure growth in $t-1$ relative to $t-2$. The denominator equals the amount of information that individuals learn about $U_{t}$ between year $t-2$ and $t-1$. The ratio of these two changes provides an estimate of the impact of changes in beliefs, $p$, on current food expenditure, $c_{\text {pre }}(p)$.

Table IV already reported the numerator in equation (14). Food expenditure growth is $2.71 \%$ lower in the year prior to the unemployment measurement. To estimate the denominator, I follow a similar approach to the estimation of the first stage in Section 5.1. Recall that the average difference in beliefs one year prior to the job loss measure between those who do and do not lose their job is $E\left[P_{t, t-1} \mid U_{t}=1\right]-E\left[P_{t, t-1} \mid U_{t}=0\right]=19.7 \%$ (Appendix Table I, Column (1)). In this sense, $80 \%$ of the information about unemployment is realized between $t-1$ and $t$. Now, one wishes to know how much is revealed between $t-2$ and $t-1$, and thus one needs an estimate of how much individuals know 2 years ante, $E\left[P_{t, t-2} \mid U_{t}=1\right]-E\left[P_{t, t-2} \mid U_{t}=0\right]$.

To obtain this, I regress the elicitation, $Z$, on an indicator for losing one's job in the subsequent 12-24 months after the elicitation. The second row of Appendix Table I reports this value as

additional food expenditure, $u^{\prime}$ and $v^{\prime}$, are conceptually distinct from the level of food expenditure when employed and unemployed. First, it is possible to observe a large expenditure drop, but that individuals do not actually have a willingness to pay for insurance. If unemployed individuals have more time to spend searching for lower priced consumption goods or have more time to cook at home instead of needing to eat at restaurants (as shown in Aguiar and Hurst (2005)), then their marginal utility of additional food expenditure when employed, $v^{\prime}\left(c_{e}\right)$, may be equal to the marginal utility of additional food expenditure when unemployed, $u^{\prime}\left(c_{u}\right)$, even if $c_{e}>c_{u}$.

Conversely, it is also possible to have a case where job loss has no causal effect on consumption, $c_{e}(p)=c_{u}(p)=\bar{c}$, but individuals have significant willingness to pay for insurance, $u^{\prime}(\bar{c})>v^{\prime}(\bar{c})$. For example, perhaps the additional time available when not employed enables a greater value from higher expenditure (e.g. eating at nice restaurants). Hence, there may be a higher utility value of additional spending when unemployed but because of financial liquidity constraints, consumption does not rise as much as a fully insured individual would prefer. In this case, consumption may not be affected by unemployment but individuals can have a willingness to pay for UI.

While the present approach avoids issues of state dependence, Proposition 2 imposes an additional assumption that is not required of the standard approach: ex-post consumption does not vary systematically with $p, \frac{d c_{e}}{d p}=0$ and $\frac{d c_{u}}{d p}=0$. Intuitively, if higher $p$ today decreases (increases) consumption in both states of the world, then the marginal utility of income today will rise more than (less than) would be suggested by just the average gap in marginal utilities between employment and unemployment. In this sense, using the response of $c_{p r e}$ to $p$ to estimate the willingness to pay for UI will lead to an overestimate (underestimate) of the true willingness to pay. I return to a discussion of this in Section 5.3 . 
$E\left[P_{t-2, t} \mid U_{t}=1\right]-E\left[P_{t-2, t} \mid U_{t}=0\right]=9.37 \% .{ }^{43}$ The difference is then $10.31 \%$, which forms an estimate of the amount of information about unemployment in year $t$ is revealed in the second year prior to the unemployment measurement.

Results Table VI takes the estimates for each specification in Table IV (repeated in the first rows of Table VI) and scales them by this first stage of 0.1031 to arrive at an estimate of $\frac{d c_{p r e}}{d p}$. These yield estimates for $\frac{d c_{p r e}}{d p}$ of around 20-30\%. Scaling these by a coefficient of relative risk aversion of $\sigma=2$ suggests individuals are willing to pay around a 50-60\% markup for unemployment insurance. For higher values of risk aversion $(\sigma=3)$ this increases to $70-90 \%$; for lower values $(\sigma=1)$ this decreases to $20-30 \%$.

\subsubsection{Exploiting Spousal Labor Supply Responses}

In addition to exploiting the response of consumption to learning one might lose her job, one can also exploit the ex-ante spousal labor supply responses. One can also use the labor supply version of the Euler equation (equation (7)) to identify the willingness to pay for UI. In addition to illustrating the various methods one can use to estimate willingness to pay, it also provides a willingness to pay estimate for the HRS sample that more closely will correspond to the sample used to measure the pooled price ratio, $T(p)$, in Section 6 .

Mathematically, Appendix C.4 shows that one can re-write $\sigma E\left[\frac{d \log \left(c_{p r e}\right)}{d p}\right]$ in equation 13 as

$$
\sigma E\left[\frac{d \log \left(c_{p r e}\right)}{d p}\right] \approx \frac{E\left[\frac{d L F P}{d p}\right]}{\epsilon^{s e m i}}
$$

where $E\left[\frac{d L F P}{d p}\right]$ is the average response of the female labor participation rate to an increase in beliefs, $p$, and $\epsilon^{s e m i}=\frac{d L F P}{d \log (w)}$ is the response of the female labor participation rate to a $1 \%$ increase in wages (a.k.a. the semi-elasticity of spousal labor supply). Intuitively, one can compare the magnitude of the labor supply response to beliefs to the size of a response to a wage increase to infer individuals' implicit valuation of UI. I use a baseline value of $\epsilon^{\text {semi }}=0.5$, following Kleven et al. (2009). I also consider a range of estimates between 0.33 and 1, loosely consistent with the range of estimates found in Blundell et al. (2016).

From Elicitations, $Z$, to Beliefs, $P$ Figure III and Table III reported a clear relationship between the elicitations, $Z$, and spousal labor entry. However, because these elicitations, $Z$, are

\footnotetext{
${ }^{43}$ Online Appendix Figure I also reports the coefficients for future years of unemployment and obtains estimates of $E\left[Z_{t-j, t} \mid U_{t}=1\right]-E\left[Z_{t-j, t} \mid U_{t}=0\right]$ ranging from 0.1 to 0.05 at $j=8$, which suggests most of the information in $Z$ is about unemployment in the subsequent year. This is consistent with a relatively flat consumption growth profile for years prior to $t-2$ as shown in Figure IV.
} 
likely to be only noisy measures of true beliefs, $p$, this pattern will be an attenuated measure of the relationship between true beliefs and spousal labor entry, $\frac{d L F P}{d p}$.

In particular, to the extent to which the noise in the elicitations is classical the attenuation will be equal to the ratio of total variance to signal variance, $\frac{\operatorname{var}(Z \mid X)}{\operatorname{var}(P \mid X)}$. Therefore, I proceed by scaling the the estimate of $\beta$ in equation (3) by the ratio of total to signal variance $\frac{\operatorname{var}(Z \mid X)}{\operatorname{var}(P \mid X)}$.

I correct for this attenuation bias using two benchmark assumptions: (i) the noise in the elicitations is classical (i.e. $Z-P$ is uncorrelated with $P$ ), and (ii) that true beliefs are unbiased $(\operatorname{Pr}\{U \mid P\}=P)$. The classical measurement error assumption implies that the attenuation will be equal to the ratio of total variance to signal variance, $\frac{\operatorname{var}(Z \mid X)}{\operatorname{var}(P \mid X)}$. Therefore, I proceed by scaling the the estimate of $\beta$ in equation (3) by the ratio of total to signal variance $\frac{\operatorname{var}(Z \mid X)}{\operatorname{var}(P \mid X)}$. The unbiasedness of true beliefs implies that $\operatorname{cov}(Z, U \mid X)=\operatorname{cov}(P, U \mid X)=\operatorname{var}(P \mid X)$. In words, the only reason $Z$ and $U$ will co-vary will be because of their correlation with the underlying beliefs, $P$. Hence, one can recover

$$
\frac{d L F P}{d p}=\frac{\frac{d L F P}{d Z}}{\frac{\operatorname{var}(Z \mid X)}{\operatorname{cov}(Z, U \mid X)}}
$$

The variance of $Z$ given $X$ is estimated as the mean square error of a regression of $Z$ on $X$. The covariance between $Z$ and $U$ is estimated as the covariance between residuals of regressions of $Z$ on $X$ and $U$ on $X$, and adjusting for the degrees of freedom used to estimate the coefficients on $X$ in those regressions. All standard errors are be bootstrapped by household to account for the uncertainty in the estimate of $\frac{\operatorname{var}(Z \mid X)}{\operatorname{cov}(Z, U \mid X)}$.

Results The first row of Table VII reports the coefficients from Table III of the relationship between the elicitations, $Z$, and spousal labor entry. The second set of rows in Table VII reports the results for $\frac{\operatorname{var}(Z \mid X)}{\operatorname{var}(P \mid X)}$ for each of the specifications. The estimated scaling factor is around 11 for the non-placebo specifications in Columns (1)-(3) and (5)-(6).

The third set of rows scales the estimates in the first row by this scaling factor to recover an estimate of $\frac{d L F P}{d p}$. The coefficients range around 0.3 , which suggest that a $10 \mathrm{pp}$ increase in true beliefs will increase LFP by 3pp. The next rows scale this response by the semi-elasticity of labor supply, $\epsilon^{s e m i}$, for values ranging from 0.33 to 1 . For a semi-elasticity of 0.5 , the results suggest individuals would be willing to pay $\sim 60 \%$ markup for unemployment insurance. If labor supply is more elastic (e.g. $\epsilon^{\text {semi }}=1$ ), it suggests a willingness to pay of around $30 \%$; if labor supply is less elastic (e.g. $\epsilon^{\text {semi }}=0.33$ ), it suggests a willingness to pay of $90-95 \%$. 


\subsection{Discussion}

The estimates range from around 10-50\% for the ex-post methods of valuation in Section 5.1 to $30-90 \%$ for the ex-ante methods in Section 5.2. There are two interpretations for why the valuations exploiting ex-ante responses are higher than the ex-post methods. On the one hand, there could be a violation of state independence of the utility function $(u \neq v)$ so that individuals have a higher desire to have income in the state of unemployment than would be gathered from their drop in consumption. In this case, the ex-ante methods provide a more accurate measure of the value of UI. On the other hand, the ex-ante valuation could suffer from a selection bias: types of shocks that generate higher $p$ could be generating lower consumption in both the $c_{u}$ and $c_{e}$ states of the world. For example, perhaps individuals that are more likely to learn they might lose their job they also learn that their own future earnings prospects decline even if they do not end up being the ones that lose their job. In this case, one would expect $\frac{d c_{e}}{d p}<0$ so that the ex-ante responses over-state the willingness to pay for UI. ${ }^{44}$ Going forward, I explore the implications of the broad range of estimates - largely between 10-90\% - for the workings of a private UI market.

\section{Implications for the Pooled Price Ratio}

Individuals appear to be willing to pay a significant markup in order to obtain unemployment insurance. Is this sufficient to overcome the cost of higher risks adversely selecting their insurance contract, $T(p)$ ? This section builds on Hendren (2013) by providing two approaches to measuring properties of the pooled price ratio. I first provide a lower bound on the average pooled price ratio under relatively weak assumptions. Second, I provide a semi-parametric point estimate for the minimum pooled price ratio, $\inf T(p)$ that will require some additional parametric assumptions.

\subsection{Non-parametric Lower Bounds for the Average Pooled Price Ratio, $E[T(P)]$}

To begin, let $P_{Z}$ denote the predicted values from a regression the unemployment event, $U$, on the elicitations, $Z$, controlling for observables that insurers might use to price insurance, $X$,

$$
P_{Z}=\operatorname{Pr}\{U \mid X, Z\}
$$

\footnotetext{
${ }^{44}$ To see how this would lead to an over-statement of the true demand for UI, note that the Euler equation now implies

$$
\frac{d c_{p r e}}{d p} v^{\prime \prime}\left(c_{\text {pre }}(p)\right)=u^{\prime}\left(c_{u}(p)\right)-v^{\prime}\left(c_{e}(p)\right)+(1-p) v^{\prime \prime}\left(c_{e}(p)\right) \frac{d c_{e}}{d p}
$$

so that the consumption drop, $\frac{d c_{p r e}}{d p}$, is larger for two reasons: the value of insurance, $u^{\prime}\left(c_{u}(p)\right)-v^{\prime}\left(c_{e}(p)\right)$, and the higher value of consumption in the future even if employed, $(1-p) v^{\prime \prime}\left(c_{e}(p)\right) \frac{d c_{e}}{d p}$. In this sense, the ex-ante consumption response would over-state the value individuals would have for a privately traded UI policy.
} 
Under a couple of natural assumptions, the distribution of predicted values, $P_{Z}$, forms a distributional lower bound on the distribution of true beliefs, $P$. In particular, Hendren (2013) shows that if (a) elicitations contain no more information about $U$ than does $P: \operatorname{Pr}\{U \mid X, Z, P\}=\operatorname{Pr}\{U \mid X, P\}$ and (b) true beliefs are unbiased $\operatorname{Pr}\{U \mid X, P\}=P,{ }^{45}$ then true beliefs are a mean-preserving spread of the distribution of predicted values:

$$
E[P \mid X, Z]=P_{Z}
$$

Because they contain more information, the true beliefs, $P$, are more dispersed than the distribution of predicted values, $P_{Z}$.

Figure $\mathrm{V}$ illustrates the dispersion in the distribution of predicted values, $P_{Z}$. To do so, I run a logistic regression of $U$ on $X$ and a 3 rd order polynomial in $Z$ along with indicators for $Z=1$, $Z=0.5$, and $Z=0$. I then construct the predicted values, $P_{Z}$. I aggregate across observable variables by subtracting out the predicted unemployment event if only $X$ (not $Z$ ) is included in the regression, $P_{Z}-\operatorname{Pr}\{U \mid X\} .{ }^{46}$

The results indicate a significant degree of dispersion generated by the information in the elicitations. An individual with a mean predicted risk of unemployment, $\operatorname{Pr}\{U \mid X, Z\}=\operatorname{Pr}\{U \mid X\}$ has roughly $25 \%$ of the population with a higher predicted risk of losing their job based on their elicitations, $Z$. The logic of equation(8) can be seen in this graph: would individuals with lower odds of becoming unemployed be willing to pay the pooled cost of those with higher odds of becoming unemployed?

To understand the markup individuals would have to be willing to pay to cover the cost of higher risks, consider a measure analogous to a pooled price ratio using the distribution of predicted values $P_{Z}$, instead of the unobserved distribution of risks, $P$. For each $p$, calculate the average extent to which the predicted values lie above $p, m(p)=E\left[P_{Z}-p \mid P_{Z} \geq p\right]$. Then, construct the average $m(p)$ by drawing $p$ from the distribution of $P_{Z}, E\left[m\left(P_{Z}\right)\right]$. Finally, normalize this by the

\footnotetext{
${ }^{45}$ Assumption (a) is a natural assumption to place on the elicitations, as it is difficult to imagine how someone could report more information than their true beliefs. Assumption (b) is potentially more restrictive, as individuals may have biased beliefs. However, many forms of biased beliefs can be incorporated naturally into the theoretical analysis in Section 4. For example, consider the classic model of Kahneman and Tversky (1979) whereby individuals with true likelihood of unemployment, $p$, behave as if that likelihood is actually $q(p)$. In this case, one can think of the divergence between $q(p)$ and $p$ as a ratio that multiplies the willingness to pay for insurance, as noted in equation (16). The pooled price ratio, $T(p)$, is analogous to the cost of the insurance product to the insurer, which depends on the actual probabilities that satisfy $\operatorname{Pr}\{U \mid X, P\}=P$.

${ }^{46}$ To construct this figure, I use a probit specification in $X$ and $Z$ that includes a second order polynomial in $Z$ to capture the potential nonlinearities, such as the moderately convex relationship illustrated in Figure II, and also indicators for $Z=0, Z=0.5$, and $Z=1$ to capture focal point responses illustrated in Figure I. This produces the predicted values, $P_{Z}$. To construct $\operatorname{Pr}\{U \mid X\}$, I run the same specification but exclude the $Z$ variables. Results are similar using a linear specification (as shown in Appendix Table III), but since the mean probability of becoming unemployed is very close to zero $(3.1 \%)$ the logit specification has a better fit since the specification is not fully saturated in $X$ and $Z$.
} 
probability of job loss in the population, $\operatorname{Pr}\{U\}$, and add 1:

$$
T_{Z}=1+\frac{E\left[m\left(P_{Z}\right)\right]}{\operatorname{Pr}\{U\}}
$$

Loosely speaking, $T_{Z}$ is a pooled price ratio obtained using the distribution of predicted values in place of the unobserved true distribution of risks. Appendix B.1 provides formal conditions under which $T_{Z} \leq E[T(P)]$, so that $T_{Z}$ provides a lower bound on the average pooled price ratio. ${ }^{47}$ So, without making strong assumptions about the presence or nature of the measurement errors in individuals' subjective elicitations, one can form a lower bound on the average pooled price ratio, $E[T(P)]$.

The average pooled price ratio, $E[T(P)]$, contains less information than is required to estimate the no trade condition (which requires the pooled price ratio for all $p$, or in particular its minimum, $\inf T(p)$ ). This shortcoming will motivate a complementary approach in Section 6.2 that will impose a semi-parametric structure to facilitate estimation of the minimum pooled price ratio. However, one can motivate the average pooled price ratio as a reasonable measure of the frictions imposed by private information on the workings of an insurance market. In particular, Appendix B.1 shows the average pooled price ratio characterizes the markup individuals would have to be willing to pay to make it profitable for insurers to be able to sell insurance if they chose their prices randomly along the demand curve, instead of strategically finding the individual who has the lowest pooled price ratio to try to sell insurance. If insurers cannot find the type, $p$, who faces the lowest $T(p)$ when trying to open up an insurance market, then $E[T(P)]$ will characterize the markup individuals would need to be willing to pay in order for insurers to profitably be able to sell insurance.

Results The first set of rows in Table VIII present the estimates of $E\left[T_{Z}\left(P_{Z}\right)\right]-1{ }^{48}$ For the baseline specification with demographic and job characteristic controls, the average markup imposed by the presence of worse risks is at least $77 \%$ (s.e. $5.2 \%$ ), suggesting $E[T(P)] \geq 1.77$. Columns

\footnotetext{
${ }^{47}$ This lower bound builds upon but is distinct from the results in Hendren (2013). Hendren (2013) shows that $E\left[m\left(P_{Z}\right)\right] \leq E[m(P)]$. Appendix B.1 provides conditions under which this also implies $T_{Z} \leq E[T(P)]$. The bound for $E[T(P)]$ is tighter for low probability events, like unemployment and job loss.

${ }^{48}$ As in Hendren (2013), the construction of $E\left[T_{Z}\left(P_{Z}\right)\right]$ and $E\left[m_{Z}\left(P_{Z}\right)\right]$ is all performed by conditioning on $X$. To partial out the predictive content in the observable characteristics, I first construct the distribution of residuals, $P_{Z}-\operatorname{Pr}\{U \mid X\}$. I then construct $m_{Z}(p)=E\left[P_{Z}-p \mid P_{Z} \geq p\right]$ for each value of $X$ as the average value of $P_{Z}-\operatorname{Pr}\{U \mid X\}$ above $p+\operatorname{Pr}\{U \mid X\}$ for those with observable characteristics $X$. In principle, one could estimate this separately for each $X$; but this would require observing a rich set of observations with different values of $Z$ for that given $X$. In practice, I follow Hendren (2013) and specify a partition of the space of observables, $\zeta_{j}$, for which I assume the distribution of $P_{Z}-\operatorname{Pr}\{U \mid X\}$ is the same for all $X \in \zeta_{j}$. This allows the mean of $P_{Z}$ to vary richly with $X$, but allows a more precise estimate of the shape by aggregating across values of $X \in \zeta_{j}$. In principle, one could choose the finest partition, $\zeta_{j}=\left\{X_{j}\right\}$ for all possible values of $X=X_{j}$. However, there is insufficient statistical power to identify the entire distribution of $P_{Z}$ at each specific value of $X$. For the baseline specification, I use an aggregation partition of 5 year age bins by gender. Appendix Table III (Columns (3)-(5)) documents the robustness of the results to alternative aggregation partitions.
} 
(2) and (3) shows that adding health controls or dropping the job characteristic controls do not meaningfully change the results ( $72 \%$ and $80 \%$, respectively). Figure VI, Panel A, graphically illustrates these estimates of $E\left[T_{Z}\left(P_{Z}\right)\right]-1$ plotted against the psuedo-R squared of the model for $\operatorname{Pr}\{U \mid X, Z\}$. Additional job characteristics controls help better predict unemployment entry rates across industry and occupation groups, but they do not reduce the average pooled price ratio. Intuitively, the magnitude of $E\left[P_{Z}-p \mid P_{Z} \geq p\right]$ depends on the thickness of the upper tail of the distribution of predicted values, which does not appear to be significantly altered with these changes in controls, $X .{ }^{49}$ This is consistent with the upper tail being driven by person-specific idiosyncratic knowledge that an individual may have that he or she has a particular chance at losing his or her job. Even if an insurer could use individual fixed effects to price insurance, individuals would still on average have to be willing to pay at least a $40 \%$ markup to cover the pooled cost of worse risks.

The remaining columns of Table VIII and panels of Figure VI explore how the estimated markups vary across subsamples. This provides consistent estimates of $E\left[T_{Z}\left(P_{Z}\right)\right]-1$ in excess of $50 \%$ across occupations (Figure VI, Panel B), age (Panel C), and year (Panel D).

Could insurers mitigate adverse selection by imposing waiting periods or making other modifications to when the insurance policy pays its benefits, $U ?^{50}$ Figure VI (Panel E) shows that requiring a 6-month waiting period (so that the insurance policy pays only if the individual loses his or her job in the subsequent 6-12 months) leads to a lower bound on $E[T(P)]-1$ of $57.9 \%$ $(p<0.001)$. The markups remain high for other potential timelines, such as 0-24 and 6-24 month payout windows, and if an insurer required an individual to also file for government UI. One could also imagine that the insurer pays out an insurance payment proportional to the amount of time the individual spends unemployed. Although duration is not perfectly observed in the HRS, a potential proxy for unemployment duration and severity is whether individuals are unemployed and looking for work in the next survey wave (24 months later). Figure VI (Panel E) shows that this continues to have a significant amount of private information, with the lower bound on the average pooled price ratio above $40 \%$. In short, changing the definition of $U$ through waiting periods and attachment to government UI programs does not appear to remove or significantly reduce the barriers

\footnotetext{
${ }^{49}$ Appendix Table III explores robustness to various specifications, including linear versus probit error structures, alternative aggregation windows for constructing $E\left[m_{Z}\left(P_{Z}\right)\right]$, and alternative polynomials for $Z$. All estimates are quite similar to the baseline and yield lower bounds of $E\left[T_{Z}\left(P_{Z}\right)\right]-1$ of around $70 \%$.

${ }^{50}$ Fortunately, the lower bound result does not require that $Z$ be an elicitation that perfectly corresponds to an event, $U$. Hence, to explore whether such modifications would be profitable one can simply alter the construction of $U$ and use the same elicitation to construct lower bounds on $E[T(P)]$ for this alternative event.

I abstract from the ability of an individual to change the timing of their unemployment. Such claim timing could impose additional adverse selection costs. In principle, if such timing responses are costly to the worker, they would be a behavioral response that would not affect the insurer's costs for the first dollar of insurance when $b=\tau=0$. But, this could be an additional cost factor with non-marginal contracts, as has been noted in other market contexts such as dental insurance (Cabral (2013)).
} 
imposed by private information.

Perhaps insurers could sell insurance only to observably low risks, such as those with longer job tenure? ${ }^{51}$ Figure VI (Panel F) presents the lower bound estimates on subsamples with high job tenure and steady work histories. In contrast to the idea that restricting to low risks would help open up an insurance market, if anything the opposite is true: lower risk populations have higher markups. Indeed, for those with greater than 5 years of job tenure, the data suggest a lower bound of $110 \%$ despite having a less than $2 \%$ chance of losing their job in the subsequent 12 months. Loosely, the data is consistent with there always being at least one bad apple in every bunch that knows s/he has a decent chance of losing his/her job. This presents an especially high burden on a sample that on average have a low risk of job loss.

\subsection{Semi-parametric Point Estimates of inf $T(p)$}

To move from lower bounds on $E[T(P)]$ to a point estimate of the minimum pooled price ratio, $\inf T(p)$, one requires an estimate of the distribution of beliefs, $P$. To obtain this, I follow Hendren (2013) by making additional assumptions about the distribution of measurement error in the elicitations. Note that the observed density (p.d.f./p.m.f.) of $Z$ and $U$ can be written as

$$
f_{Z, U}(Z, U \mid X)=\int_{0}^{1} p^{U}(1-p)^{1-U} f_{Z \mid P, X}(Z \mid P=p, X) f_{P}(p \mid X) d p
$$

where $f_{Z \mid P, X}$ is the distribution of elicitations given true beliefs (i.e. elicitation error) and $f_{P}$ is the distribution of true beliefs in the population (which can be used to construct $T(p)$ at each $p) .{ }^{52}$ As shown in Hendren (2013), the key additional assumption required to move from lower bounds to point estimates is to place some structure on the distribution of elicitations given beliefs, $f_{Z \mid P, X}$, to reduce its dimensionality. I assume elicitations are equal to beliefs plus a noise term, $Z=P+\epsilon$, where $\epsilon$ is drawn from a mixture of an ordered probit structure to capture the excess mass at focal point values. Appendix B.2 provides the precise details of the specification and the estimation of the minimum pooled price ratio.

Results The second set of rows in Table VIII report the results. I estimate a value of inf $T(p)-1$ of 3.36 in the baseline specification with demographic and job characteristic controls. This suggests that unless people are willing to pay a $336 \%$ (s.e. 20\%) markup in order to obtain unemployment

\footnotetext{
${ }^{51}$ For example, health-related insurance markets generally exclude those with pre-existing conditions. Hendren (2013) shows this is consistent with those risks having private information but healthy individuals not. Loosely, those results suggest that there's one way to be healthy, but many unobservable ways to be sick. This pattern prevents the existence of insurance markets for those with pre-existing conditions, but the ability of insurers to limit such risks from risk pools allows for insurance markets for the healthy that are less afflicted by problems of private information.

${ }^{52}$ This is obtained by first taking the conditional expectation with respect to $p$ and then using the assumption that $\operatorname{Pr}\{U \mid Z, X, P\}=P$.
} 
insurance, the results are consistent with the absence of a private market. Including health controls reduces this markup slightly to $323 \%$ (s.e. $26.8 \%$ ), and using only demographic controls increases the markup to $530 \%$ (s.e. $65.5 \%) .{ }^{53}$

The results are also quite robust across subsamples, as illustrated in Columns (4)-(9) of Table VIII. Consistent with the findings in the lower bound analysis, I find larger barriers to trade imposed by private information for those with longer tenure backgrounds (and hence lower unemployment probabilities on average), with values of $\inf T(p)-1$ of $474 \%$. The results are similar across age groups (333\% for ages at or below 55 and $344 \%$ for ages above 55); and they are slightly higher for below-median wage earners (436\%) than above-median wage earners (316\%). The estimates are all well above the estimated markups individuals are willing to pay for UI. In this sense, private information provides a theory of the absence of a private market.

\section{Discussion}

Although Section 5 suggests larger demand for UI than found in previous literature, estimates of the pooled price ratio generally lie above these willingness to pay estimates. This suggests private information provides a rationale for the absence of the private market: if an insurer were to try to sell a policy, the results suggest it would not deliver a positive profit at any price. Here, I provide a brief discussion of alternative theories of market non-existence.

Government UI To begin, one might wonder whether government UI is crowding out the provision of a private market. Here, my estimates suggest individuals continue to have an unsatisfied willingness to pay for UI in the status quo world with the current level of government and other formal/informal sources of insurance. They are willing to pay a premium for additional UI, but it is insufficient to overcome adverse selection. Another interesting question is whether a private market would arise if the government were to decrease its benefit levels. Extrapolating evidence from Gruber (1997) suggests the willingness to pay could increase by a factor of 3 (Table I, p196), but this would still be smaller than the estimated $300 \%$ markups individuals would need to be willing to pay to overcome adverse selection. This suggests a private market would not arise even in the absence of government provision of UI.

Moral Hazard Moral hazard is another common explanation for market non-existence. However, the model in Section 4 allowed for moral hazard and showed it does not affect market non-existence.

\footnotetext{
${ }^{53}$ Appendix Table IV presents the raw point estimates for $\alpha_{i}$ and $\xi_{i}$. It suggests there is a small (e.g. 10\%) sub-sample of the population that has a very high chance of losing their job. The presence of this upper tail drives these high estimated markups.
} 
Although behavior may change when individuals obtain insurance, the behavioral response to a small amount of insurance will be small; and the impact of the small response on the cost of a small insurance policy is second-order - analogous to the logic that the deadweight loss of a tax varies with the square of the tax rate. This insight, initially noted by Shavell (1979), suggests moral hazard does not affect whether insurers' first dollar of insurance is profitable. ${ }^{54}$ In this sense, moral hazard can limit the size of the gains to trade, but does not provide a singular theoretical explanation for the absence of a market. In contrast, the first dollar of insurance can be adversely selected by strictly worse risks, so that private information can explain the absence of a market.

Government Regulation Another theory of market non-existence is overly burdensome government regulation. For example, Cochrane (1995) suggests off-hand this is a reason one does not see markets for "reclassification risk" in health insurance markets. ${ }^{55}$ Translating this idea to UI, perhaps individuals are willing to pay for UI, but the reason such demand is not satisfied is because the government prevents it from being so. Here, the empirical results in Section 5 and 6.2 reject this theory as a singular explanation of market non-existence. Because of adverse selection, firms have no ability to profitably enter the market even without any regulatory constraints.

Aggregate Risk The baseline model in Section 4 assumes that the insurer would have access to risk-neutral insurance markets. If there is aggregate risk, the cost to the insurer of transferring dollars from employed to unemployed states for a type $p$ may be higher than the ex-ante risk-neutral cost of $\frac{p}{1-p}$ because the marginal cost of capital is higher in states where people are unemployed. In the limit where unemployment is perfectly correlated across individuals and all individuals have the same willingness to pay for UI, there may be no scope for a profitable insurance market.

However, unemployment is not purely an aggregate shock. The world does not oscillate between full unemployment and full employment. To be sure, unemployment rates vary across years; but the R-squared of a regression of unemployment on year dummies yields an R-squared of 0.0019. As long as the risk of unemployment has an idiosyncratic component, there will be first order gains to risk pooling and an insurance company should be able to profitably sell UI. If insurers did not want to absorb any aggregate risk, they could in principle condition their insurance contract on the aggregate unemployment rate and fully insure themselves against the portion that reflects aggregate

\footnotetext{
${ }^{54}$ If insurers are unable to sell small insurance contracts, perhaps because of fixed costs, then the moral hazard response could limit the gains to trade and prevent them from covering their fixed costs. In this sense, moral hazard plus fixed costs could prevent market existence. In contrast, private information provides a singular explanation for market non-existence that does not require an existence of fixed costs.

${ }^{55}$ This theory is made suggestively, and the paper does not provide direct evidence of an impact of government regulation.
} 
risk. However, my results suggest that the market for insuring the idiosyncratic risk would be too heavily adversely selected. ${ }^{56}$

Biased beliefs The baseline model above assumes individuals have accurate beliefs. This is at odds with existing literature suggesting individuals may have biased beliefs about their unemployment and job prospects (e.g. Stephens (2004); Spinnewijn (2015)).

To extend the model in Section 4 to include biased beliefs, suppose $p$ is the objective belief for a given individual but their decisions over financial assets utilize a re-weighted probability function, $q(p)$ as in Kahneman and Tversky (1979). It is straightforward to show that the no trade condition becomes:

$$
\beta(p) \frac{u^{\prime}\left(c_{u}(p)\right)}{v^{\prime}\left(c_{e}(p)\right)} \leq T(p) \quad \forall p
$$

where $\beta(p)=\frac{p}{q} \frac{1-q}{1-p}$ is the distortion in individuals' marginal rate of substitution arising from biases in beliefs (as opposed to differential marginal utilities of income, $\frac{u^{\prime}}{v^{\prime}}$ ). Biased beliefs generate a second reason individuals would be willing to pay for UI: they may over (or under) state of the likelihood of job loss, $\beta(p)$.

One can use the estimates above to ask how biased must beliefs be to overcome the frictions imposed by private information. With a pooled price ratio of $330 \%$ and markup individuals are willing to pay less than $75 \%$, a market would not be profitable unless individuals believe that job loss is 4.4 -times more likely to occur than in reality $(330 / 75=4.4)$. So, one requires incredibly large biases to sufficiently inflate demand to overcome the hurdles that would be imposed by adverse selection.

\section{Conclusion}

This paper argues that private information prevents the existence of a robust private market for unemployment or job-loss insurance. I show that traditional approaches using first differences under-estimate individuals' valuations of UI when individuals possess knowledge of future job loss. I provide corrections for this bias that accounts for the information that has been realized at the time one measures the lagged value in the first difference estimate. I also provide conditions under which one can exploit the impact of learning unemployment is $1 \mathrm{pp}$ more likely on consumption today to infer a willingness to pay for UI. Despite these generally higher willingness to pay estimates, they still fall well below the frictions imposed by private information. If insurers were to attempt to sell such policies, they would be too heavily adversely selected to delivers positive profit.

\footnotetext{
${ }^{56}$ The fact that the vast majority of unemployment risk is idiosyncratic perhaps also explains why there is not a large private market for households to insure against fluctuations in the aggregate unemployment rate.
} 
While this paper has focused on the positive question of why do markets exist, the paper has not explored the normative implications. In particular, the presence of ex-ante knowledge of future job loss suggests individuals may have demand not only for insurance against losing their job tomorrow; but also demand for insurance against learning today that they might lose their job tomorrow. Additionally, one might also expect that much of the information that prevents third-parties from selling UI policies is jointly known to the firm and worker. If this is the case, then one might ask why firms don't provide additional UI or severance ${ }^{57}$ and, in particular whether additional government UI introduces externalities on the firm's contracting decisions. The implications of such patterns for optimal UI design are an interesting direction for future work.

Figure VII places these estimates in the context of other insurance markets studied in Hendren (2013), which uses a similar empirical strategy to study private information in long-term care insurance, life insurance, and disability insurance. Those results suggest no statistically significant amounts of private information for those with observable characteristics that allow them to purchase insurance. However, for individuals with pre-existing conditions that would cause them to be rejected by an insurance company, the estimated markups are $42 \%$ for life, $66 \%$ for disability, and $83 \%$ for long-term care. The patterns are consistent with the idea that the frictions imposed by private information are forming the boundary to the existence of insurance markets. In settings with sufficiently high pooled price ratios, private markets cannot exist.

Figure VII also places the degree of private information about job loss in context. The frictions to creating a private market are quite large - this perhaps explains why one does not even observe subsegments of the population in which this market exists. In every subgroup, there's a "bad apple" with a decent chance of job loss, making it difficult to profitably sell insurance.

\section{References}

Acemoglu, D. and R. Shimer (1999). Efficient unemployment insurance. Journal of Political. 7

Acemoglu, D. and R. Shimer (2000). Productivity gains from unemployment insurance. European Economic Review 44(7), 1195-1224. 7

Aguiar, M. and E. Hurst (2005). Consumption versus expenditure. Journal of Political Economy 113(5), 919-948. 1, 10, 42

Akerlof, G. (1970). The market for lemons: Qualitative uncertainty and the market mechanism. Quarterly Journal of Economics 84(3), 488-500. 4.2, A

\footnotetext{
${ }^{57}$ This could be due to a moral hazard problem (severence reduces effort), or a screening problem (an adverse selection of the type of workers attracted to firms with high severance payments).
} 
Bach, K. (1998). Negativauslese und tarifdifferenzierung im versicherungs-sektor. DUV, Schesslitz. 7

Baily, M. (1976). Some aspects of optimal unemployment insurance. Journal of Public Economics 10, 379-402. 1, 6, 7

Barceló, C. and E. Villanueva (2010). The response of household wealth to the risk of losing the job: Evidence from differences in firing costs. 8

Basten, C. C., A. Fagereng, and K. Telle (2012). Saving and portfolio allocation before and after job loss. KOF Swiss Economic Institute Working Paper (298). 8

Bloemen, H. G. and E. G. Stancanelli (2005). Financial wealth, consumption smoothing and income shocks arising from job loss. Economica 72(287), 431-452. 8

Blundell, R., M. Costa Dias, C. Meghir, and J. Shaw (2016, Feb). Female labour supply, human capital and welfare reform. 5.2.2

Blundell, R., L. Pistaferri, and I. Preston (2008). Consumption inequality and partial insurance. The American Economic Review, 1887-1921. 7

Blundell, R., L. Pistaferri, and I. Saporta-Eksten (2012). Consumption inequality and family labor supply. National Bureau of Economic Research Working Paper No. 18445. 1

Bollinger, C. R. (1998). Measurement error in the current population survey: A nonparametric look. Journal of Labor Economics 16(3), 576-594. 68

Brown, J. and D. A. Matsa (2015). Boarding a sinking ship? an investigation of job applications to distressed firms. Journal of Finance (Forthcoming). 8

Browning, M. and T. Crossley (2001). Unemployment insurance levels and consumption changes. Journal of Public Economics 80, 1-23. 1

Cabral, M. (2013). Claim timing and ex post adverse selection. Working Paper. 50

Campos, R. G. and I. Reggio (2015). Consumption in the shadow of unemployment. European Economic Review. 8

Carroll, C. D., K. E. Dynan, and S. D. Krane (2003). Unemployment risk and precautionary wealth: Evidence from households' balance sheets. Review of Economics and Statistics 85(3), 586-604. 8

Carroll, C. D. and A. A. Samwick (1997). The nature of precautionary wealth. Journal of Monetary Economics 40(1), 41-71. 8

Carroll, C. D. and A. A. Samwick (1998). How important is precautionary saving? Review of Economics and Statistics 80(3), 410-419. 8

Chetty, R. (2006). A general formula for the optimal level of social insurance. Journal of Public Economics 90(10), 1879-1901. 6, 7, 5.1.1

Chetty, R. (2008). Moral hazard vs. liquidity and optimal unemployment insurance. Journal of Political Economy 116(2), 173-234. 1, 7, 5.1.2 
Chetty, R. and A. Szeidl (2007). Consumption commitments and risk preferences. Quarterly Journal of Economics 122(2). 2.2, 3.3, 5.1.3

Chiappori, P. and B. Salanié (2000). Testing for asymmetric information in insurance markets. Journal of Political Economy, 56-78. 1

Cochrane, J. H. (1995). Time-consistent health insurance. Journal of Political Economy, 445-473. 7

Davis, S. J. and T. M. von Wachter (2011). Recessions and the cost of job loss. NBER Working Paper. 31

Dynan, K. E. (1993). How prudent are consumers? Journal of Political Economy, 1104-1113. 8

Einav, L., A. Finkelstein, and M. Cullen (2010). Estimating welfare in insurance markets using variation in prices. The Quarterly Journal of Economics 125(3), 877-921. 4.2

Einav, L., A. Finkelstein, and J. Levin (2010, Sep). Beyond testing: Empirical models of insurance markets. Annual Review of Economics 2(1), 311-336. 1

Engen, E. M. and J. Gruber (2001). Unemployment insurance and precautionary saving. Journal of Monetary Economics 47(3), 545-579. 8

Finkelstein, A. and K. McGarry (2006). Multiple dimensions of private information: Evidence from the long-term care insurance market. American Economic Review 96(4), 938-958. 2.1

Finkelstein, A. and J. Poterba (2004, Jan). Adverse selection in insurance markets: Policyholder evidence from the UK annuity market. Journal of Political Economy. 1

Gallen, Y. (2013). Anticipating unemployment: Savings evidence from denmark. Northwestern University. 8

Gan, L., M. Hurd, and D. McFadden (2005, Aug). Individual subjective survival curves. Analyses in the Economics of Aging, ed. D Wise. 2.1, B.2

Gruber, J. (1997). The consumption smoothing benefits of unemployment insurance. American Economic Review 87(1), 192-205. 1, 1, 6, 1, 2.2, 3.3, 5.1.1, 5.1.2, 5.1.3, 5.1.5, 7

Gruber, J. and J. B. Cullen (1996). Spousal labor supply as insurance: Does unemployment insurance crowd out the added worker effect? NBER Working Paper. 23

Guariglia, A. and B.-Y. Kim (2004). Earnings uncertainty, precautionary saving, and moonlighting in russia. Journal of Population Economics 17(2), 289-310. 8

Guiso, L., T. Jappelli, and D. Terlizzese (1992). Earnings uncertainty and precautionary saving. Journal of Monetary Economics 30(2), 307-337. 8

He, D. (2009, Jan). The life insurance market: Asymmetric information revisited. Journal of Public Economics. 2.1

Hendren, N. (2013). Private information and insurance rejections. Econometrica 81(5), 1713-1762. $1,5,1,2.1,2.1,4,4.1,4.2,6,6.1,47,48,6.2,51,8, \mathrm{~A}, \mathrm{~A} .2$, B.1.2, B.2, B.2

$\mathrm{Hu}, \mathrm{Y}$. and S. Schennach (2008). Instrumental variable treatment of nonclassical measurement error models. Econometrica 76(1), 195-216. 68 
Hubbard, R. G., J. Skinner, and S. P. Zeldes (1994). Precautionary saving and social insurance. NBER Working Paper. 8

Hurd, M. (2009). Subjective probabilities in household surveys. Annual Review of Economics, 543-562. 2.3

Kahneman, D. and A. Tversky (1979). Prospect theory: An analysis of decision under risk. Econometrica: Journal of the Econometric Society, 263-291. 45, 7

Kleven, H. J., C. T. Kreiner, and E. Saez (2009). The optimal income taxation of couples. Econometrica $77(2), 537-560.5 .2 .2$

Landais, C., P. Michaillat, and E. Saez (2010). Optimal unemployment insurance over the business cycle. 7

Lusardi, A. (1997). Precautionary saving and subjective earnings variance. Economics Letters $57(3), 319-326.8$

Lusardi, A. (1998). On the importance of the precautionary saving motive. American Economic Review, 449-453. 8

Manski, C. F. (2004). Measuring expectations. Econometrica, 1329-1376. 1

Manski, C. F. and F. Molinari (2010). Rounding probabilistic expectations in surveys. Journal of Business and Economic Statistics 28(2), 219-231. B.2, 63

Meghir, C. and L. Pistaferri (2011). Earnings, consumption and life cycle choices. Handbook of Labor Economics 4, 773-854. 5.1.5, C.2

Pistaferri, L. (2001). Superior information, income shocks, and the permanent income hypothesis. Review of Economics and Statistics 83(3), 465-476. 1

Savage, L. J. (1954). The Foundations of Statistics. John Wiley \& Sons Inc., New York. 2.1

Shavell, S. (1979). On moral hazard and insurance. The Quarterly Journal of Economics, 541-562. $5,7, \mathrm{~A}$

Shimer, R. and I. Werning (2007). Reservation wages and unemployment insurance. The Quarterly Journal of Economics, 1145-1185. 7

Shimer, R. and I. Werning (2008). Liquidity and insurance for the unemployed. The American Economic Review 98(5), 1922-1942. 7

Spinnewijn, J. (2015). Unemployed but optimistic: Optimal insurance design with biased beliefs. Journal of the European Economic Association 13(1), 130-167. 7

Stephens, M. (2001). The long-run consumption effects of earnings shocks. Review of Economics and Statistics 83(1), 28-36. 1, 3.3, 31

Stephens, M. (2004). Job loss expectations, realizations, and household consumption behavior. Review of Economics and statistics 86(1), 253-269. 1, 21, 7

Stephens Jr, M. (2002). Worker displacement and the added worker effect. Journal of Labor Economics 20(3), 504-537. 1, 23

Zeldes, S. P. (1989). Consumption and liquidity constraints: an empirical investigation. The Journal of Political Economy, 305-346. 5.1.5, C.2 


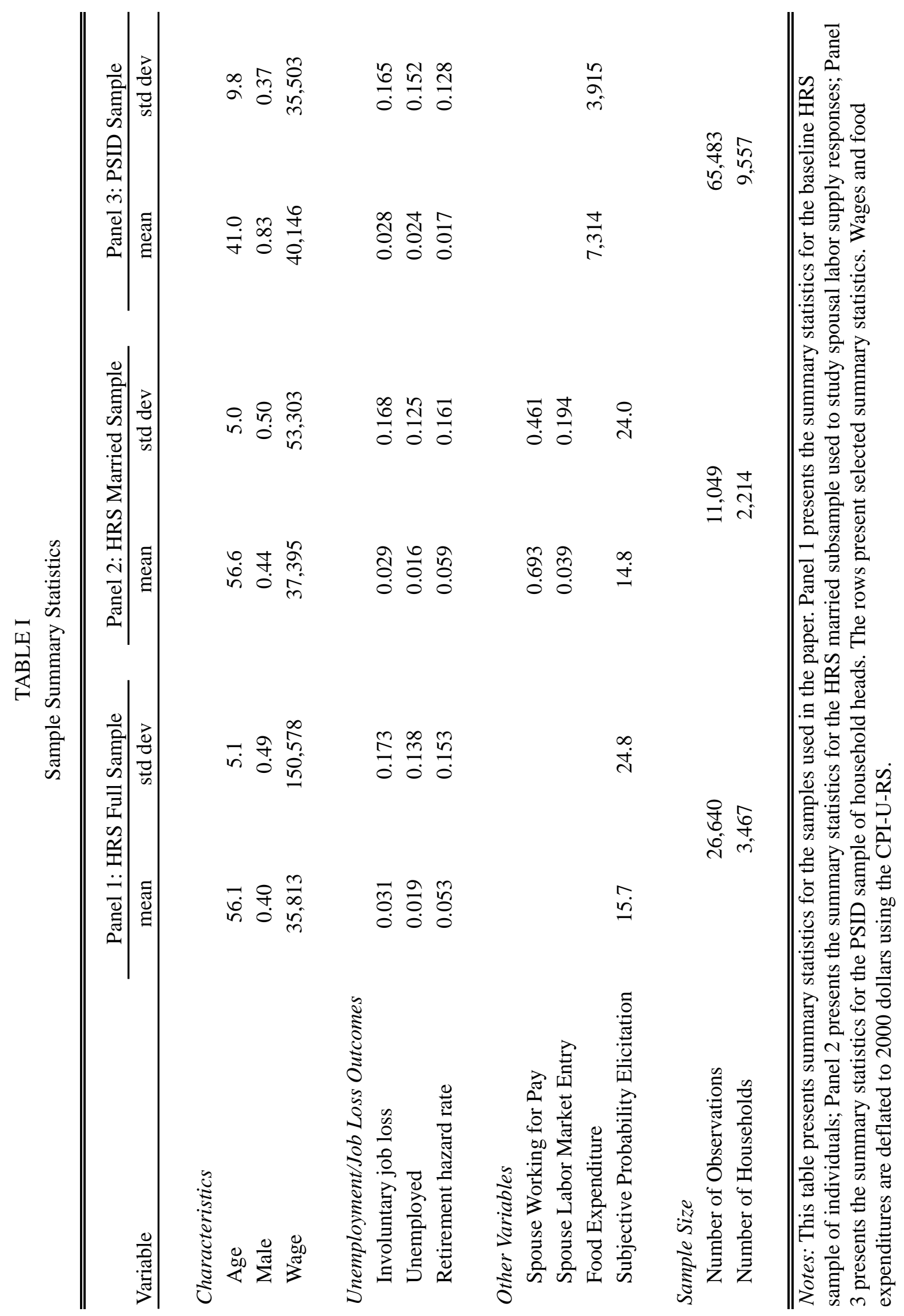




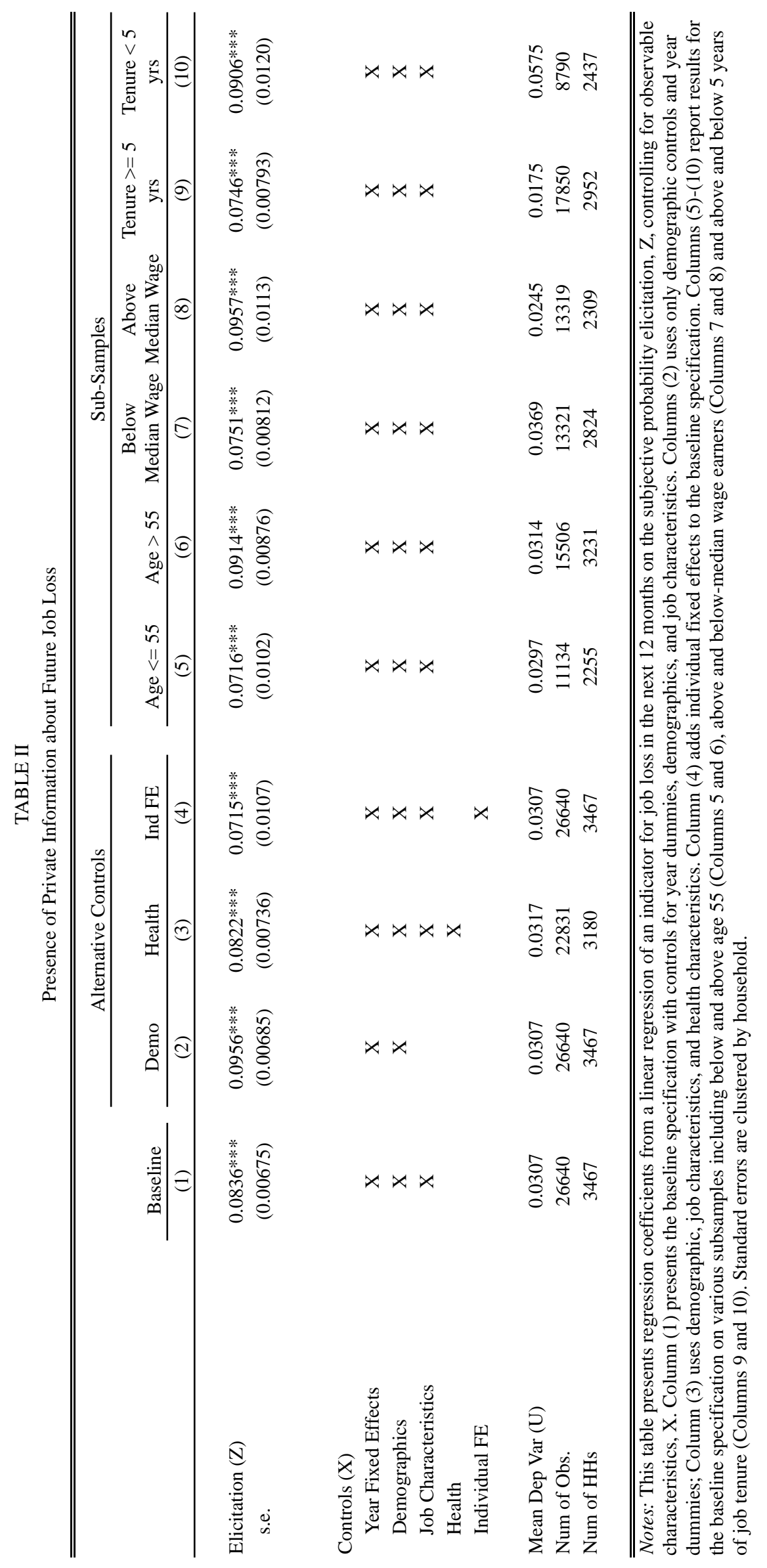




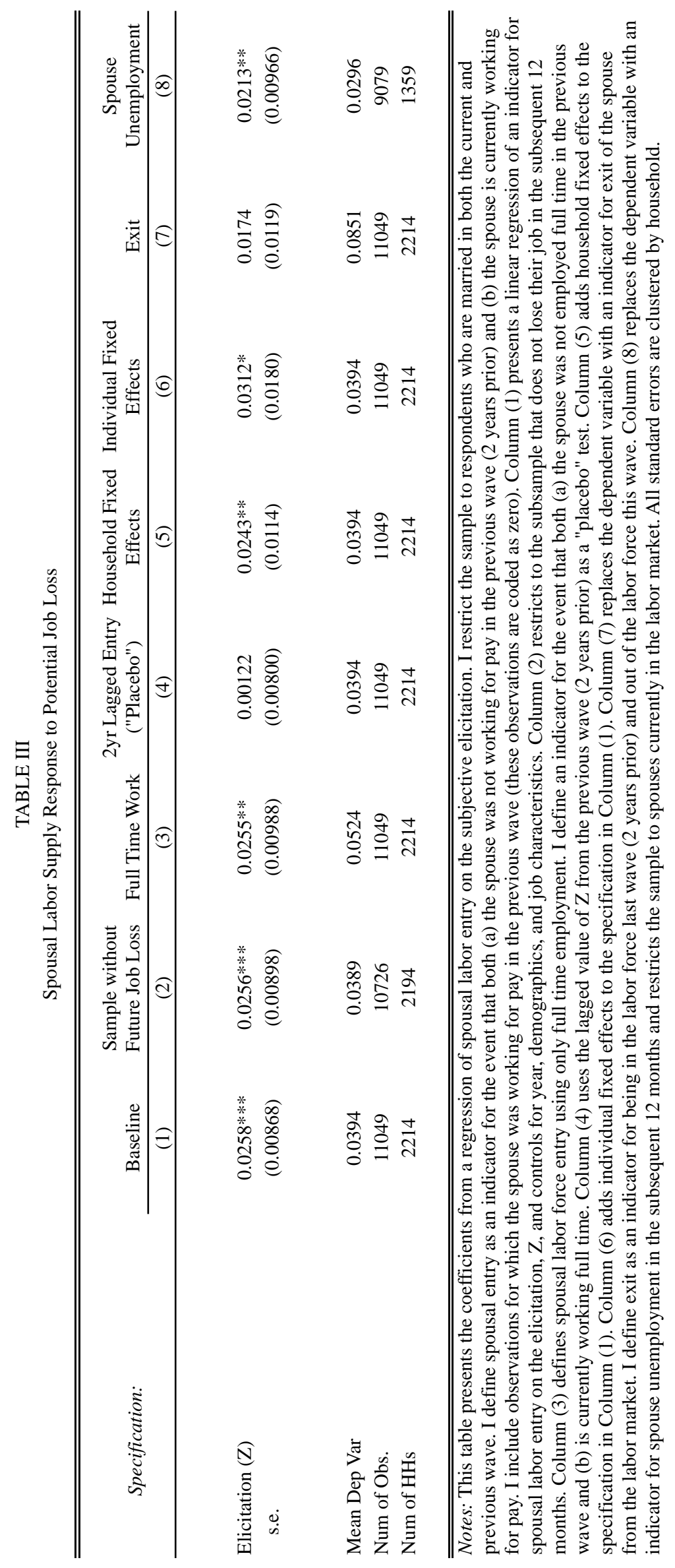




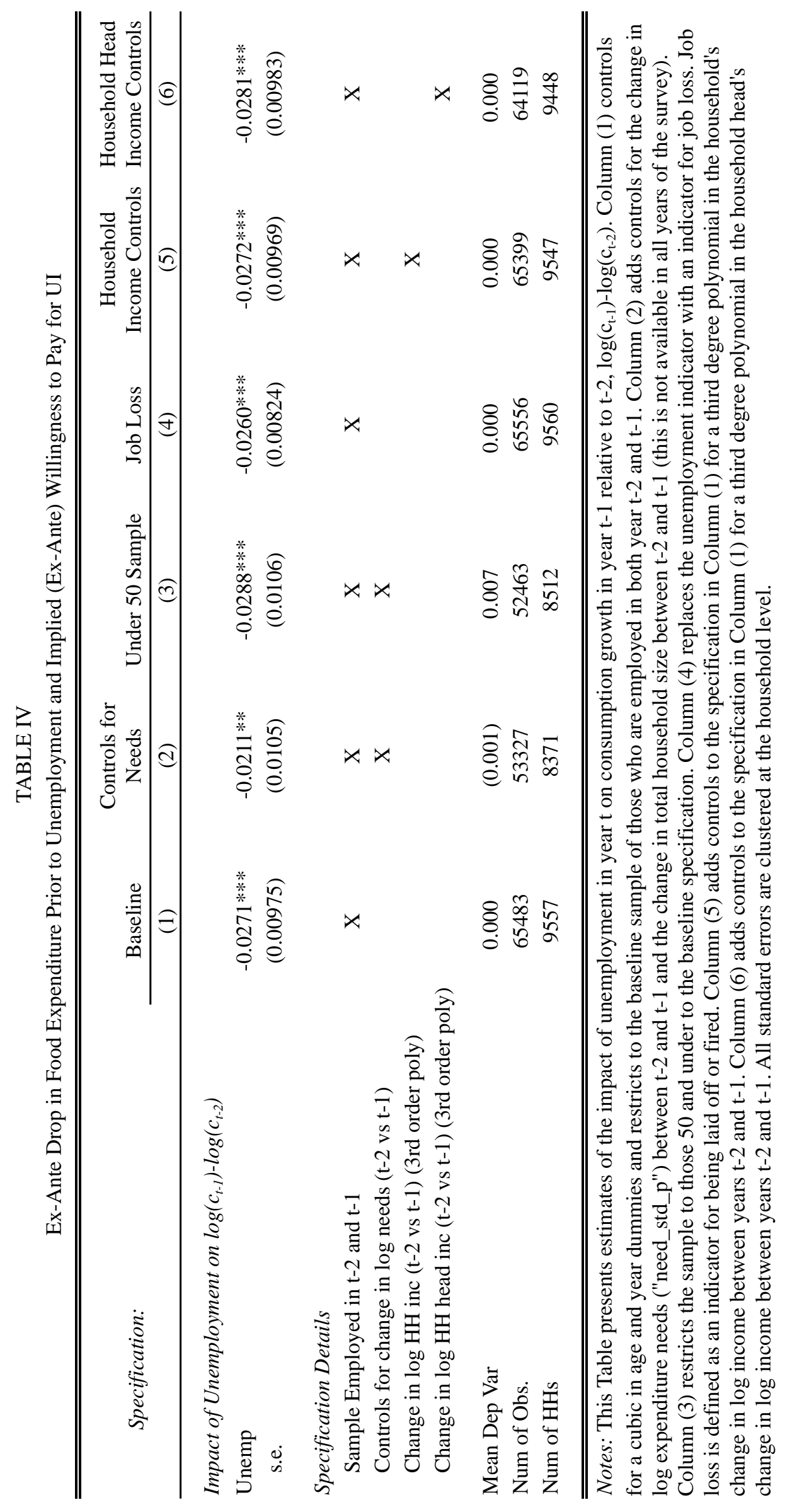




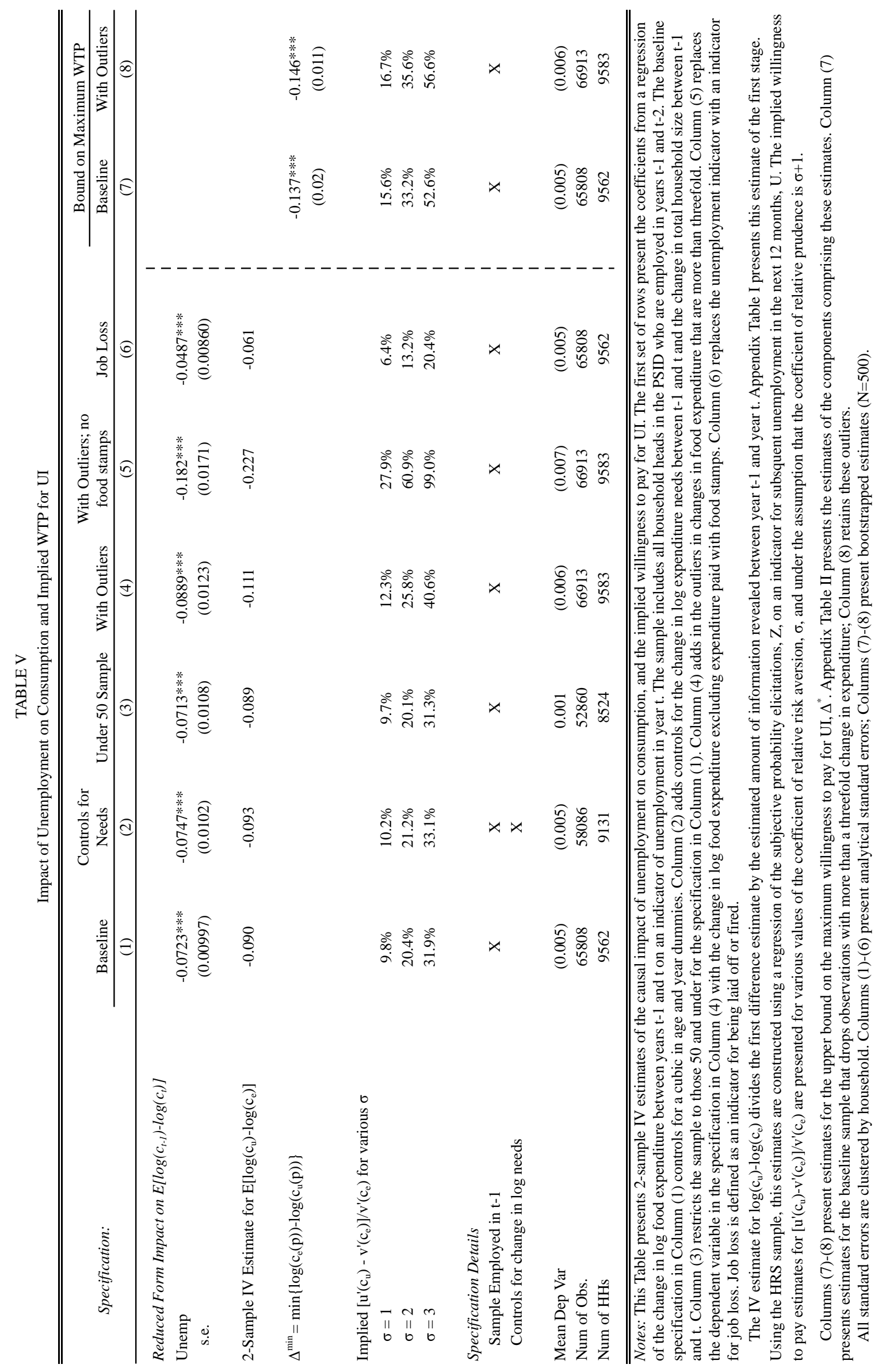




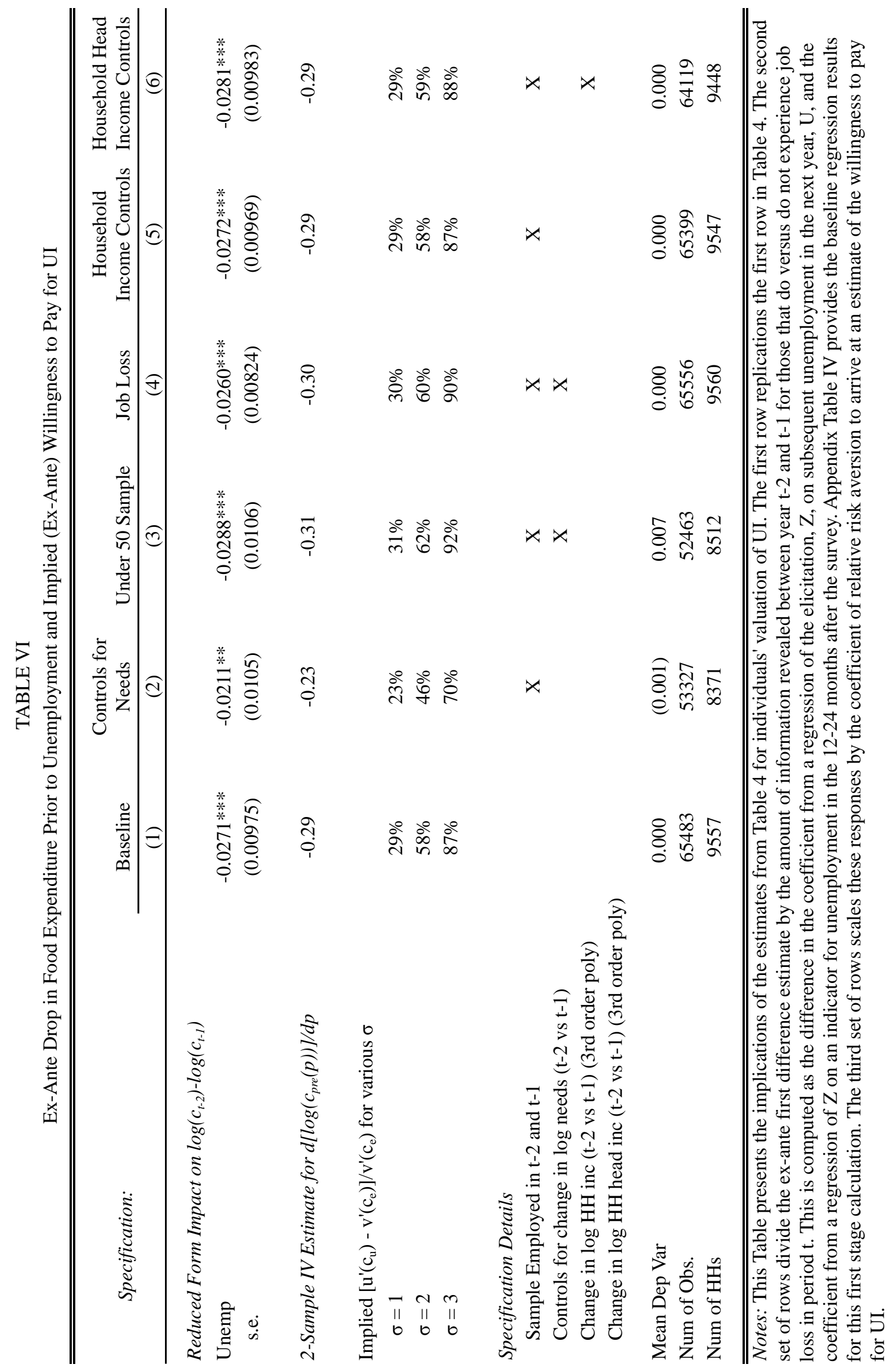




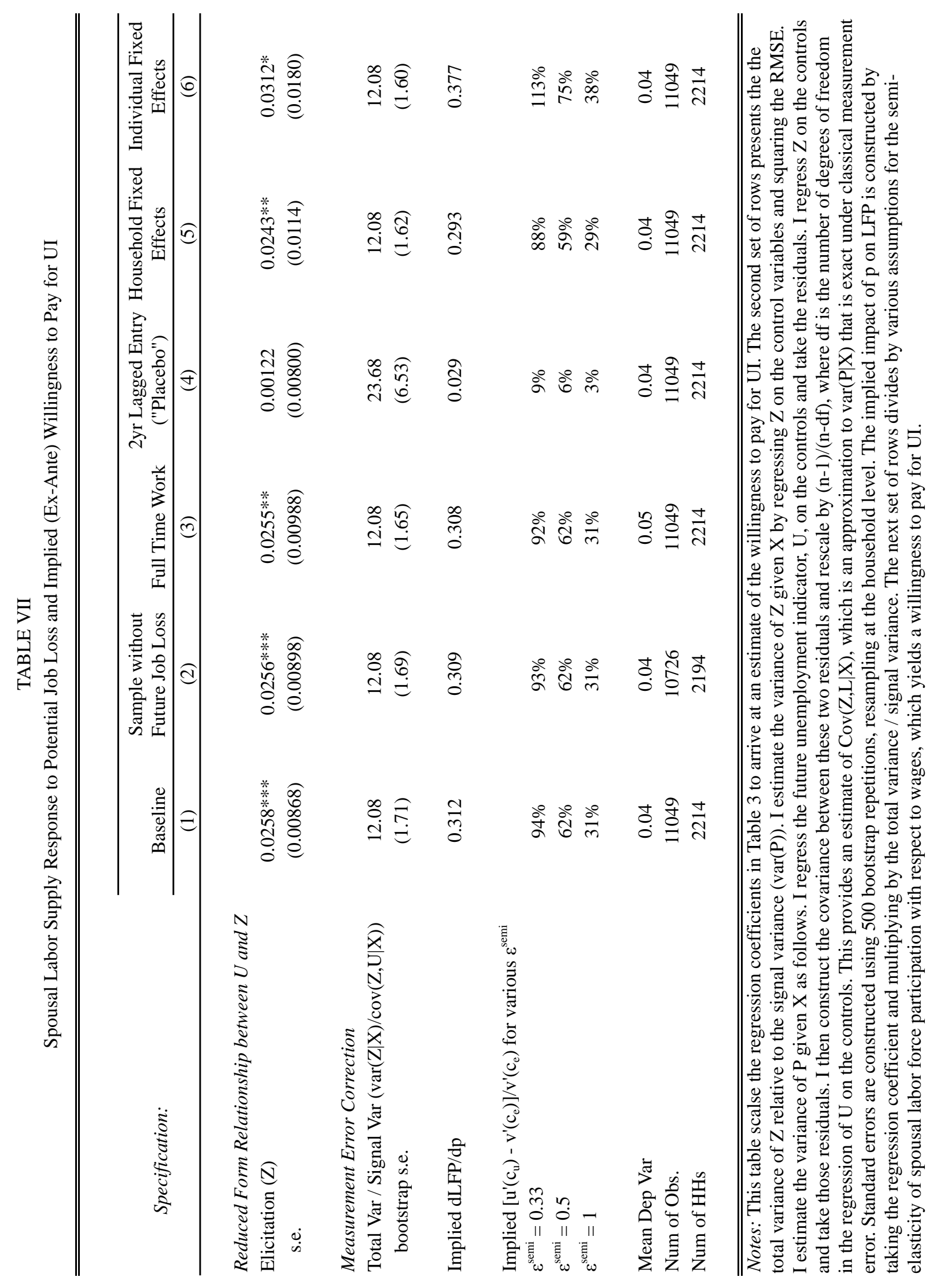




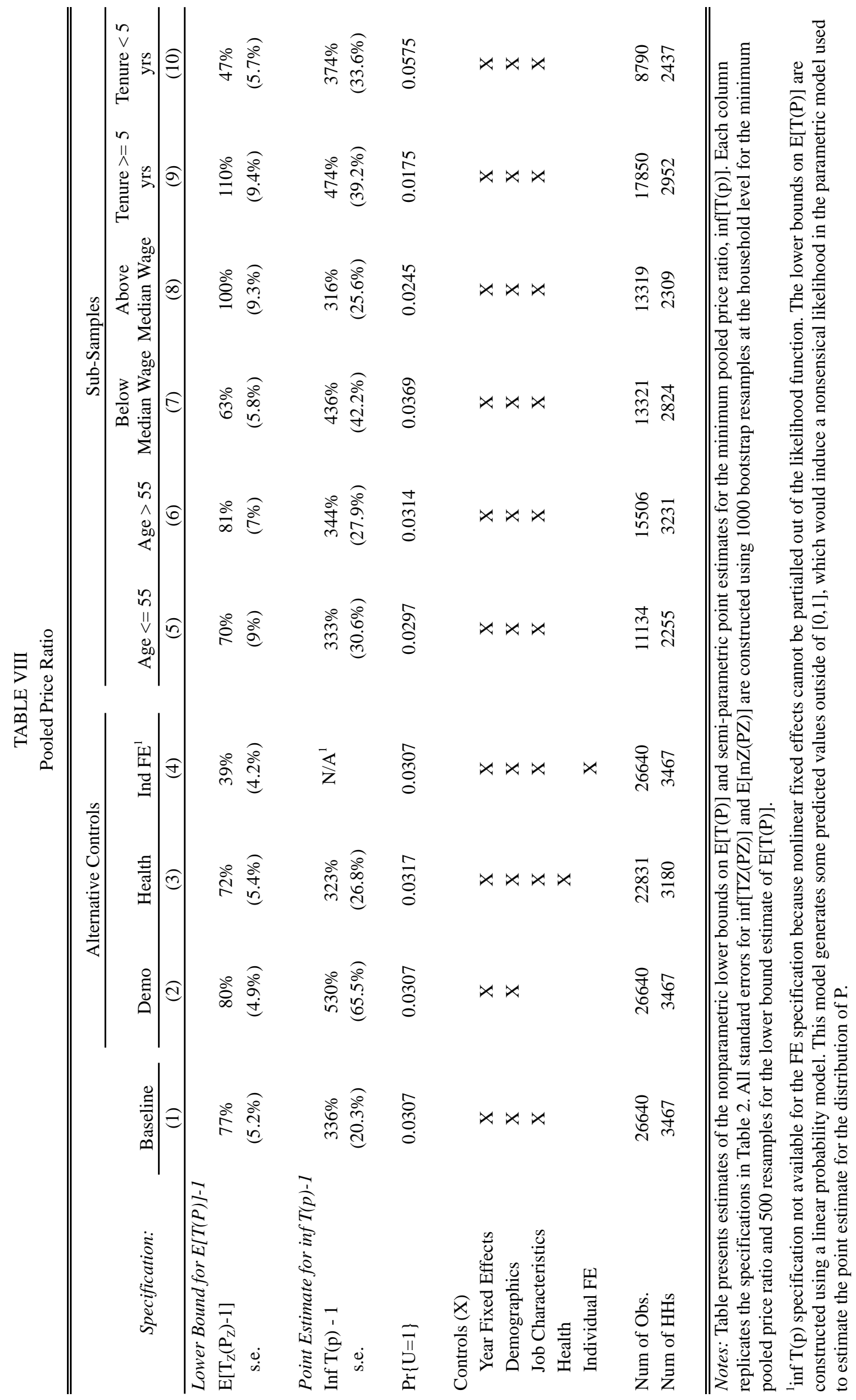


FIGURE I: Histogram of Subjective Probability Elicitations

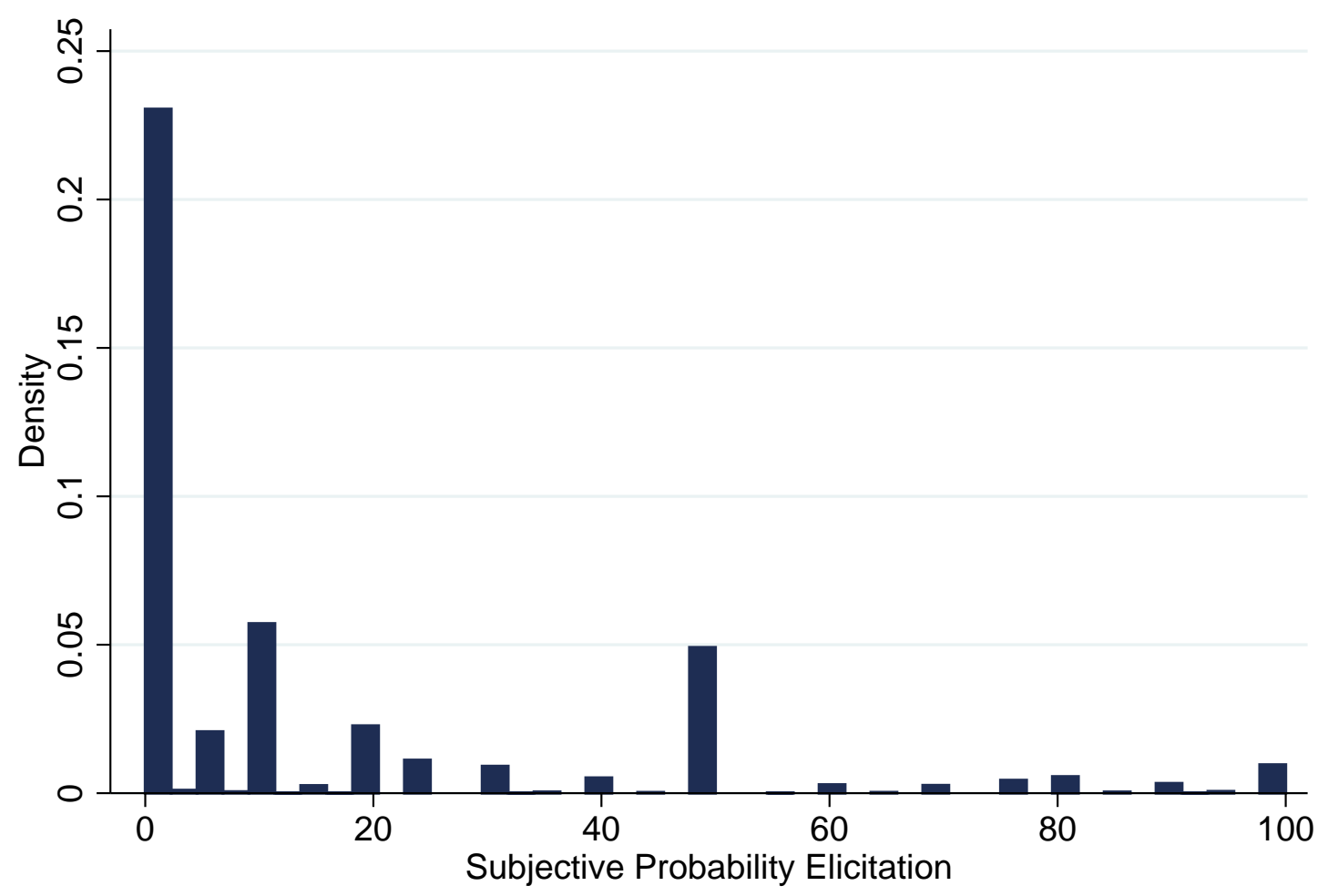

Notes: This figure presents a histogram of responses to the question "What is the percent chance (0-100) that you will lose your job in the next 12 months?". The figure reports the histogram of responses for the baseline sample (corresponding to Column (1) in Table 1)). As noted in previous literature, responses tend to concentrate on focal point values, especially $Z=0$. 
FIGURE II: Predictive Content of Subjective Probability Elicitations: Binned Scatterplot of $U$ versus $Z$, conditional on $X$

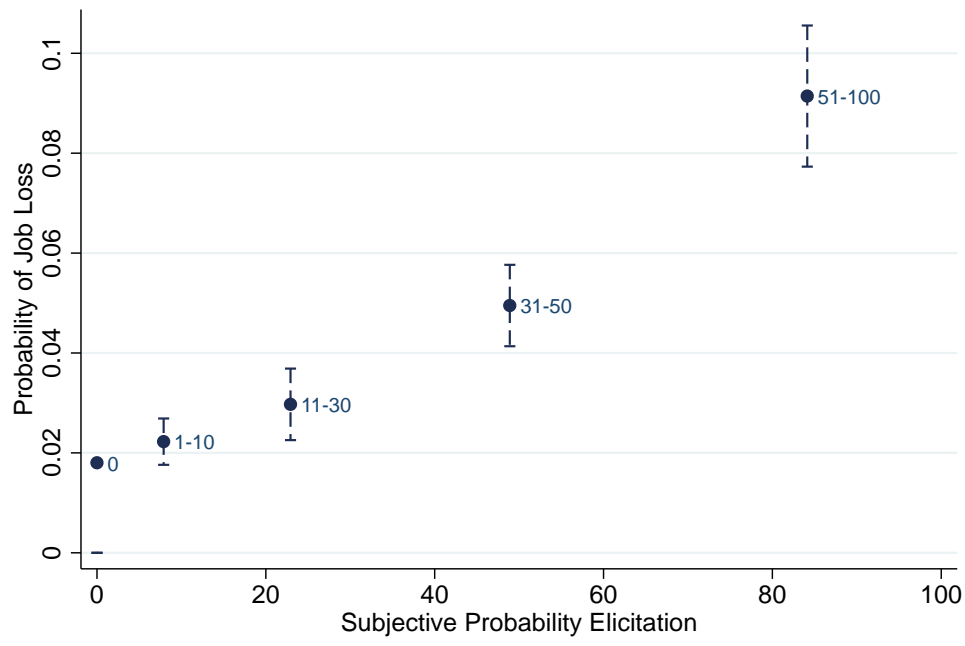

Notes: This figure reports mean unemployment rate in each elicitation category controlling for demographics, job characteristics, and year controls. To construct this figure, I run the regression in Equation (1). The figure plots the coefficients on bins of the elicitations. I omit the lowest bin (corresponding to $Z=0$ ) and add back the mean job loss of $1.9 \%$ to all coefficients. The $5 / 95 \%$ confidence intervals are constructed using the standard errors of the regression coefficients, clustering by household. 
FIGURE III: Relationship between Potential Job Loss and Spousal Labor Supply

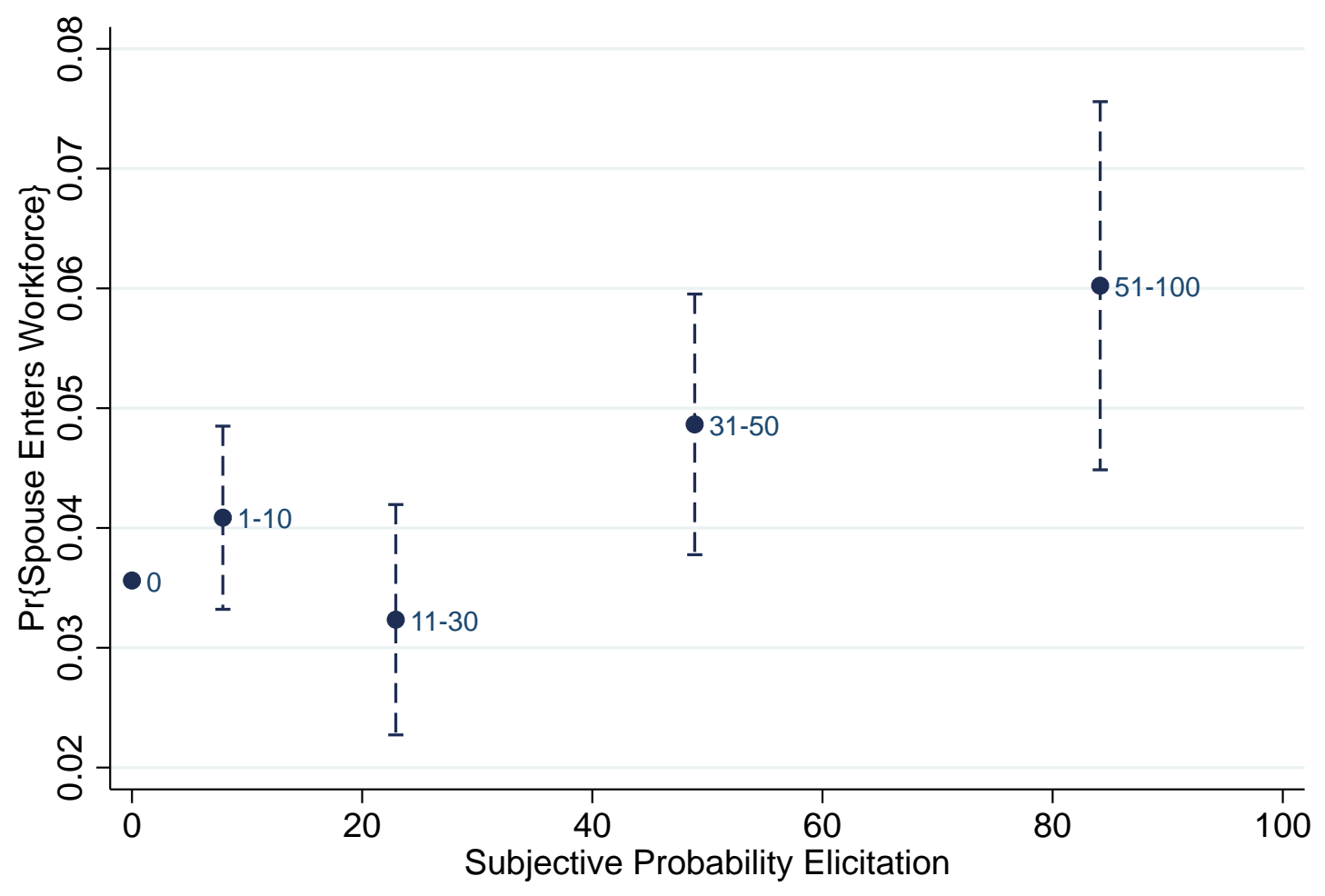

Notes: The figure present coefficients from a regression of an indicator for a spouse entering the labor force, defined as an indicator for not working in the previous wave and working in the current wave, on category indicators for the subjective probability elicitations, $Z$, controlling for demographics, job characteristics, and year controls. Figure reports $5 / 95 \%$ confidence intervals for each category indicator which are computed by clustering standard errors by household. 


\section{FIGURE IV: Impact of Unemployment on Consumption Growth}

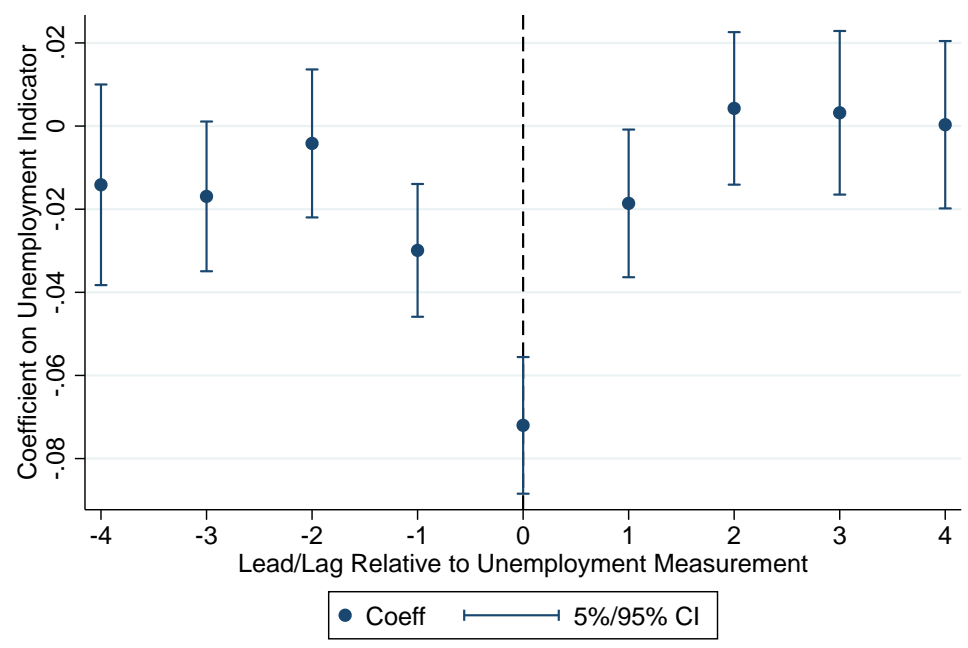

Notes: These figures present coefficients from separate regressions of leads and lags of the log change in food expenditure on an indicator of unemployment, along with controls for year indicators and a cubic in age. Data is from the PSID with one observation per household per year. Unemployment is defined as an indicator for the household head being unemployed. Following Gruber (1997) and Chetty et al. (2005), food expenditure is the sum of food in the home, food outside the home, and food stamps. The horizontal axis presents the years of the lead/lag for the consumption expenditure growth measurement (i.e. 0 corresponds to consumption growth in the year of the unemployment measurement relative to the year prior to the unemployment measurement). The sample is restricted to household heads who are employed in $t-1$ or $t-2$. 


\section{FIGURE V: Cumulative Distribution of $\operatorname{Pr}\{U \mid Z, X\}-\operatorname{Pr}\{U \mid X\}$}

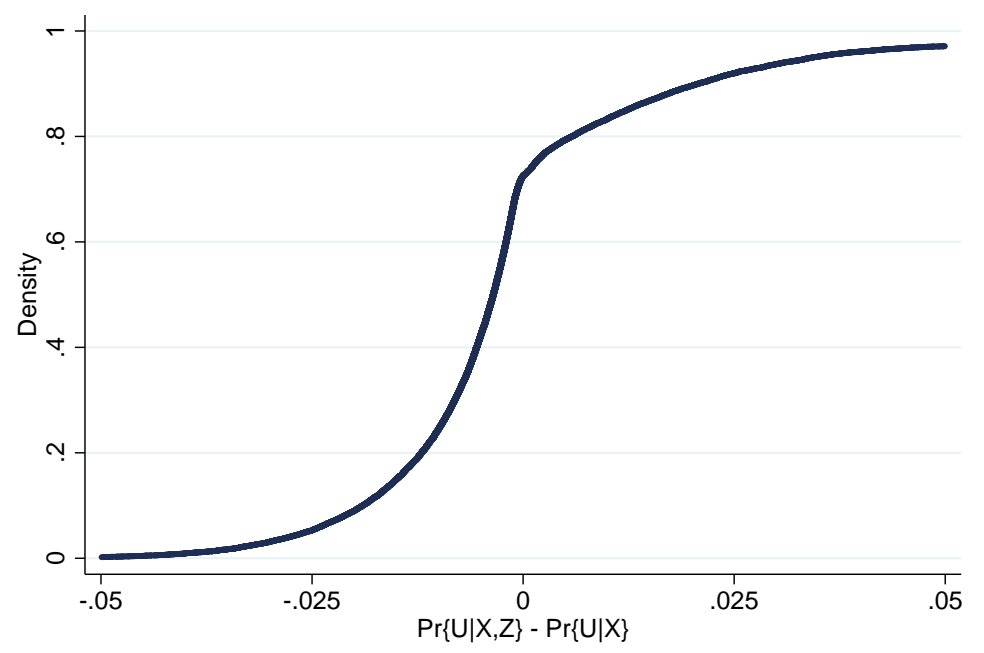

Notes: This figure presents the cumulative distribution of $\operatorname{Pr}\{U \mid X, Z\}-\operatorname{Pr}\{U \mid X\}$. To construct $\operatorname{Pr}\{U \mid X, Z\}, \mathrm{I}$ use the baseline sample in the HRS and regress job loss in the next 12 months, $U$, on both the observable characteristics (year dummies, demographics, and job characteristics) and the elicitations (a cubic in $Z$ combined with indicators for $Z=0, Z=0.5$, $Z=1$ to capture focal point responses). I use a logit specification and construct the predicted values to form an estimate of $\operatorname{Pr}\{U \mid X, Z\}$ for each observation in the baseline sample. For $\operatorname{Pr}\{U \mid X\}$, I repeat this process but exclude the elicitation variables. These predicted values provide an estimate of $\operatorname{Pr}\{U \mid X\}$. I then construct the difference, $\operatorname{Pr}\{U \mid X, Z\}-\operatorname{Pr}\{U \mid X\}$ for each observation, and plot its cumulative distribution. 
FIGURE VI: Lower Bounds for Average Pooled Price Ratio, $E[T(P)]-1$

A. Controls

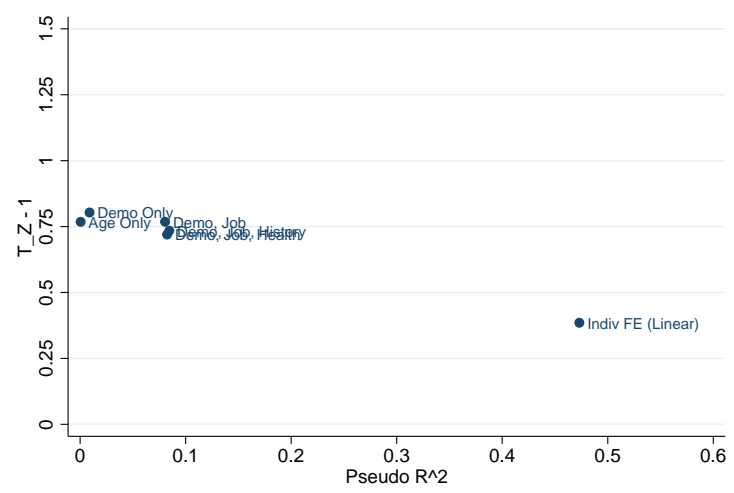

C. By Age

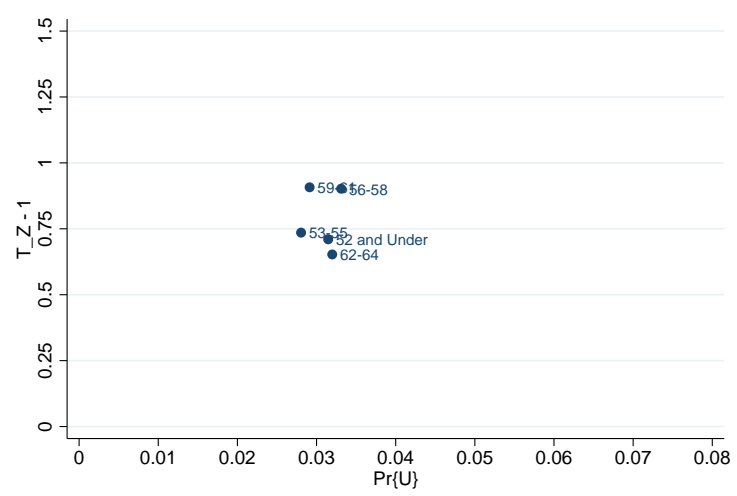

E. Alternative $U$ Definitions

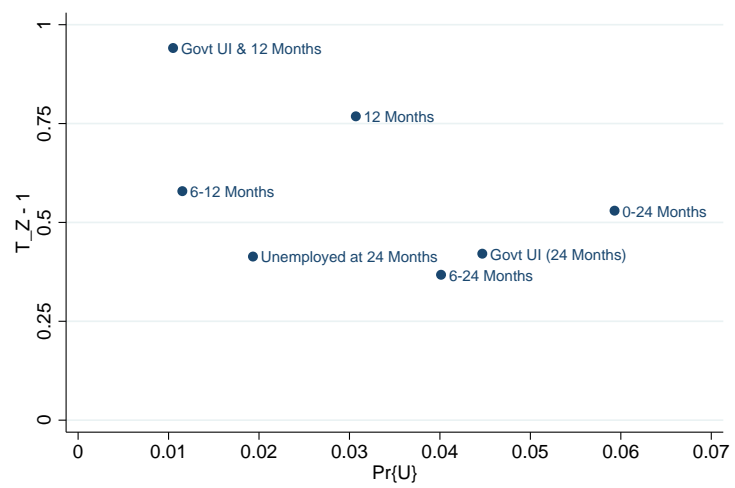

B. By Occupation

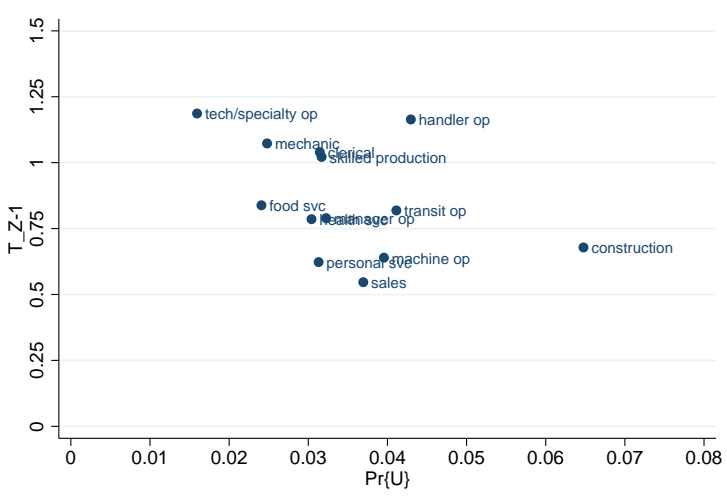

D. By Year

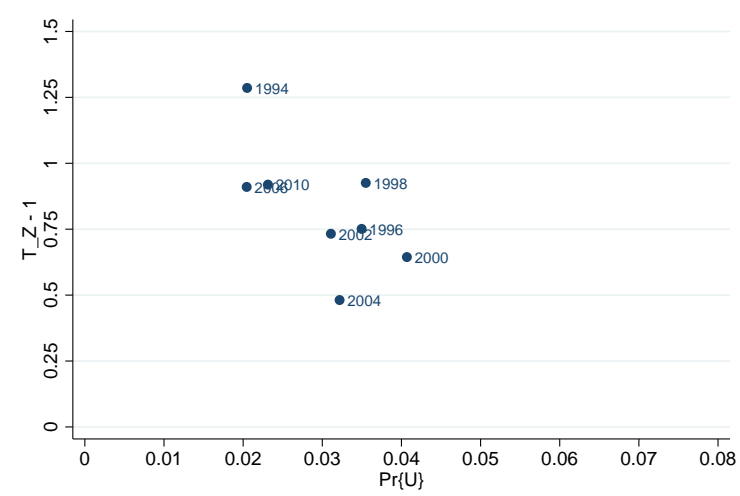

F. Low Risk Sub-samples

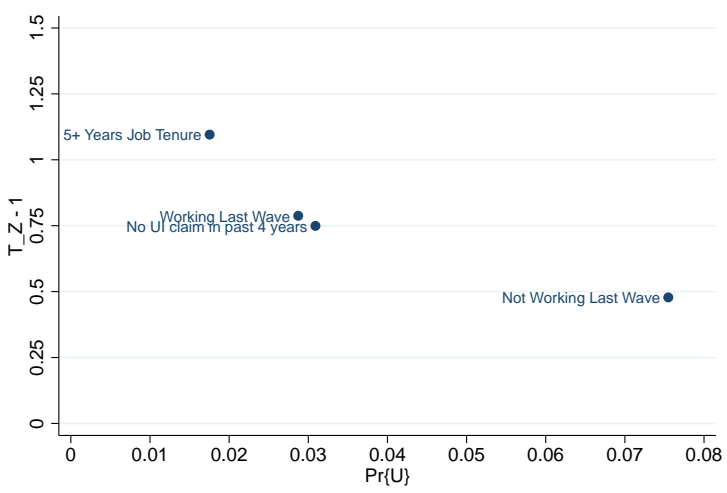

Notes: These figures present estimates of the lower bounds on the average pooled price ratio, $E\left[T_{Z}\left(P_{Z}\right)\right]$, using a range of subsamples and controls. Panel A reports estimates of $E\left[T_{Z}\left(P_{Z}\right)\right]$ for a range of control variables, including a specification with individual fixed effects. All specifications use a probit link specification for $\operatorname{Pr}\{U \mid X, Z\}$ except for the fixed effects specification in Panel A, which uses a linear specification because of the presence of fixed effects. The horizontal axis presents the Psuedo- $R^{2}$ of the specification for $\operatorname{Pr}\{U \mid X, Z\}$. Panel B constructs separate estimates by occupation. Panel C constructs estimates by age group. Panel D constructs separate estimates for each wave of the survey. Panel E reports specifications for alternative definitions of $U$. These include whether the individual loses her job in the subsequent 6-12 months, 6-24 months, or 0-24 months (instead of 0-12 months). Panel $\mathrm{F}$ restricts the sample to varying sub-samples, analyzing the relationship between $E\left[T_{Z}\left(P_{Z}\right)\right]$ and restrictions to lower-risk subsamples. The horizontal axis in Panels B-F report the mean unemployment probability, $\operatorname{Pr}\{U\}$, for each sub-sample. 
FIGURE VII: Comparison of $\inf T(p)-1$ to Other (Non-)Existing Insurance Markets

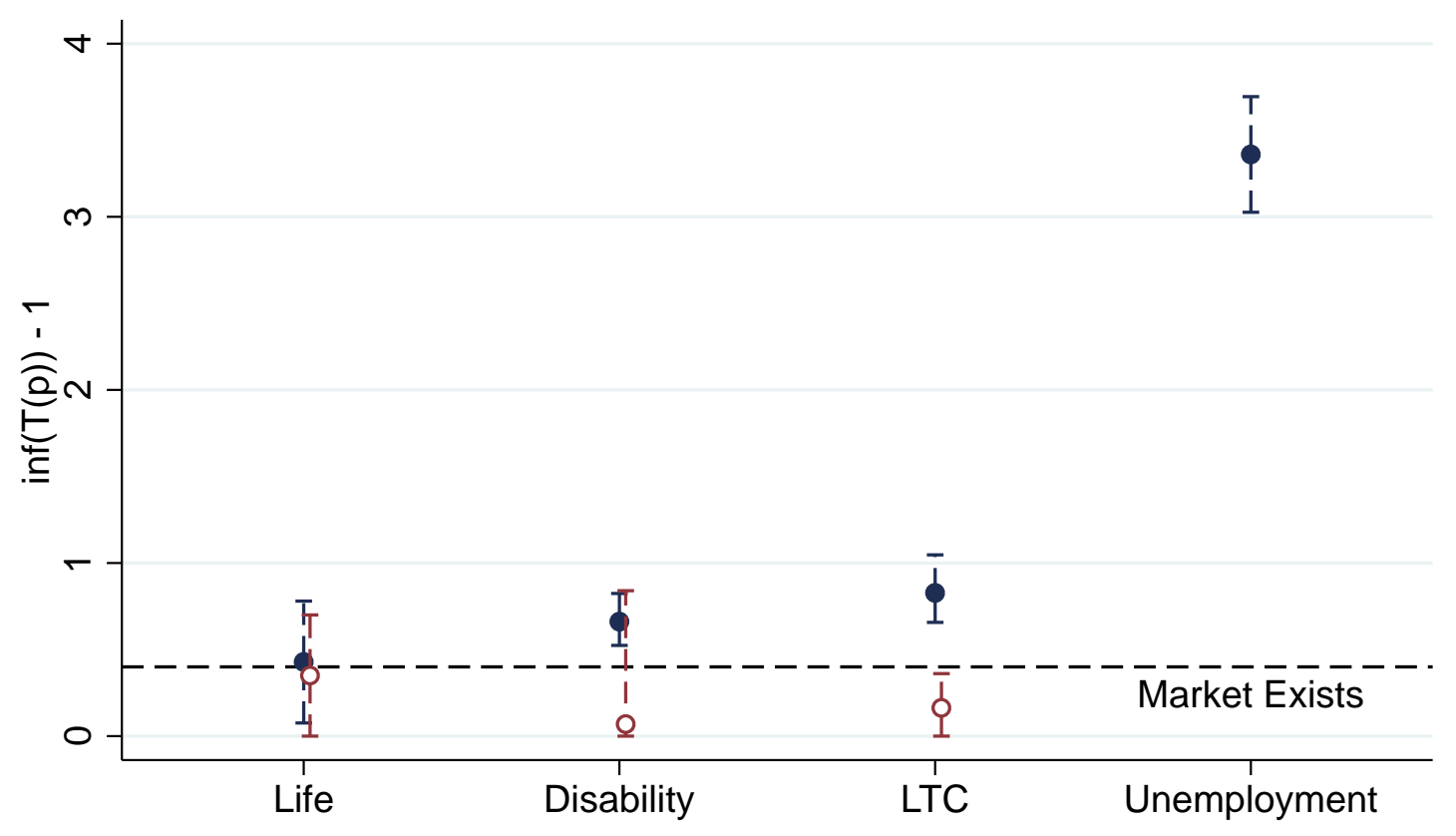

- reject $\vdash---\dashv$ noreject_low/noreject_high

Notes: Hendren (2013) argues private information prevents people with pre-existing conditions from purchasing insurance in LTC, Life, and Disability insurance markets. This figure compares the estimates of inf $T(p)-1$ for the baseline specification in the unemployment context to the estimates in Hendren (2013) for the sample of individuals who are unable to purchase insurance due to a pre-existing condition (blue circles) and those whose observables would allow them to purchase insurance in each market (red hollow circles). Figure reports the confidence interval and the $5 / 95 \%$ confidence interval for each estimate in each sample. For the sub-samples in LTC, Life, and Disability for which the market exists, one cannot reject the null hypothesis of no private information, $\inf T(p)=0$. In contrast, sub-samples whose observables would prevent them from purchasing insurance tend to involve larger estimates of the minimum pooled price ratio, which suggests the frictions imposed by private information form the boundary of the existence of insurance markets. 


\section{ONLINE APPENDIX: Not For Publication}

\section{A No Trade Condition}

This section provides a more formal exposition of the no trade condition in Section 4. To provide a general treatment, I begin by relaxing the condition of uni-dimensional heterogeneity in the population. Individuals are indexed by a heterogeneity parameter, $\theta$, and make choices $\left\{c_{p r e}(\theta), c_{u}(\theta), c_{e}(\theta), a(\theta), p(\theta)\right\} \in \Omega_{\theta}$, where the constraint set varies arbitrarily across types.

Consider a policy that provides a small payment, $d b$, in the event of being unemployed and is financed with a small payment in the event of being employed, $d \tau$, offered to those with observable characteristics $X$. By the envelope theorem, the utility impact to type $\theta$ of buying such a policy will be given by

$$
d U=-(1-p(\theta)) v^{\prime}\left(c_{e}(\theta)\right) d \tau+p(\theta) u^{\prime}\left(c_{u}(\theta)\right) d b
$$

which will be positive if and only if

$$
\frac{p(\theta) u^{\prime}\left(c_{u}(\theta)\right)}{(1-p(\theta)) v^{\prime}\left(c_{e}(\theta)\right)} \geq \frac{d \tau}{d b}
$$

The LHS of equation (17) is a type $\theta$ 's willingness to pay (i.e. marginal rate of substitution) to move resources from the event of being employed to the event of being unemployed. ${ }^{58}$ The RHS of equation (17), $\frac{d \tau}{d b}$, is the cost per dollar of benefits of the insurance policy.

Let $\bar{\Theta}\left(\frac{d \tau}{d b}\right)$ denote the set of all individuals, $\theta$, who prefer to purchase the additional insurance at price $\frac{d \tau}{d b}$ (i.e. those satisfying equation (17)). An insurer's profit from a type $\theta$ is given by $(1-p(\theta)) \tau-p(\theta) b$. Hence, the insurer's marginal profit from trying to sell a policy with price $\frac{d \tau}{d b}$ is given by

$$
d \Pi=\underbrace{E\left[1-p(\theta) \mid \theta \in \bar{\Theta}\left(\frac{d \tau}{d b}\right)\right] d \tau}_{\text {Premiums Collected }}-\underbrace{E\left[p(\theta) \mid \theta \in \bar{\Theta}\left(\frac{d \tau}{d b}\right)\right] d b}_{\text {Benefits Paid }}-\underbrace{\left(d E\left[p(\theta) \mid \theta \in \bar{\Theta}\left(\frac{d \tau}{d b}\right)\right]\right)(\tau+b)}_{\text {Moral Hazard }}
$$

The first term is the amount of premiums collected, the second term is the benefits paid out, and the third term is the impact of additional insurance on its cost. If more insurance increases the probability of unemployment, $d E[p(\theta)]>0$, then it reduces premiums collected, $\tau$, and increases benefits paid, $b .{ }^{59}$

However, for the first dollar of insurance when $\tau=b=0$, the moral hazard cost to the insurer is zero. This insight, initially noted by Shavell (1979), suggests moral hazard does not affect whether insurers' first dollar of insurance is profitable - a result akin to the logic that deadweight loss varies with the square of the tax rate.

The first dollar of insurance will be profitable if and only if

$$
\frac{d \tau}{d b} \geq \frac{E\left[p(\theta) \mid \theta \in \bar{\Theta}\left(\frac{d \tau}{d b}\right)\right]}{E\left[1-p(\theta) \mid \theta \in \bar{\Theta}\left(\frac{d \tau}{d b}\right)\right]}
$$

If inequality (18) does not hold for any possible price, $\frac{d \tau}{d b}$, then providing private insurance will not be profitable at any price. The market will unravel a la Akerlof (1970). Under the natural assumption ${ }^{60}$ that profits are concave in $b$ and $\tau$, the inability to profitably sell a small amount of insurance also rules out the inability to sell larger insurance contracts.

To this point, the model allows for an arbitrary dimensionality of unobserved heterogeneity, $\theta$. To provide a clearer expression of how demand relates to underlying fundamentals, such as marginal rates of substitution and beliefs, it is helpful to impose a dimensionality reduction on the unobserved heterogeneity.

Assumption A1. (Uni-dimensional Heterogeneity) Assume the mapping $\theta \rightarrow p(\theta)$ is $1-1$ and continuously differentiable in $b$ and $\tau$ in an open ball around $b=\tau=0$. Moreover, the marginal rate of substitution, $\frac{p}{1-p} \frac{u^{\prime}\left(c_{u}(p)\right)}{v^{\prime}\left(c_{e}(p)\right)}$, is increasing in $p$.

\footnotetext{
${ }^{58}$ Note that, because of the envelope theorem, the individual's valuation of this small insurance policy is independent of any behavioral response. While these behavioral responses may impose externalities on the insurer or government, they do not affect the individuals' willingness to pay.

${ }^{59}$ To incorporate observable characteristics, one should think of the expectations as drawing from the distribution of $\theta$ conditional on a particular observable characteristic, $X$.

${ }^{60}$ See Appendix A.3 for a micro-foundation of this assumption.
} 
Assumption A1 states that the underlying heterogeneity can be summarized by ones' belief, $p(\theta)$. In this case, the adverse selection will take a particular threshold form: the set of people who would be attracted to a contract for which type $p(\theta)$ is indifferent will be the set of higher risks whose probabilities exceed $p(\theta)$. Let $P$ denote the random variable corresponding to the distribution of probabilities chosen in the population in the status quo world without a private unemployment insurance market, $b=\tau=0 .{ }^{61}$ And, let $c_{u}(p)$ and $c_{e}(p)$ denote the consumption of types $p(\theta)$ in the unemployed and employed states of the world. Under Assumption A1, equation (18) can be re-written as:

$$
\frac{u^{\prime}\left(c_{u}(p)\right)}{v^{\prime}\left(c_{e}(p)\right)} \leq T(p) \quad \forall p
$$

where $T(p)$ is given by

$$
T(p)=\frac{E[P \mid P \geq p]}{E[1-P \mid P \geq p]} \frac{1-p}{p}
$$

which is the pooled cost of worse risks, termed the "pooled price ratio" in Hendren (2013). The market can exist only if there exists someone who is willing to pay the markup imposed by the presence of higher risk types adversely selecting her contract. Here, $\frac{u^{\prime}\left(c_{u}(p)\right)}{v^{\prime}\left(c_{e}(p)\right)}-1$ is the markup individual $p$ would be willing to pay and $T(p)-1$ is the markup that would be imposed by the presence of risks $P \geq p$ adversely selecting the contract. This suggests the pooled price ratio, $T(p)$, is the fundamental empirical magnitude desired for understanding the frictions imposed by private information.

The remainder of this Appendix further discusses the generality of the no trade condition. A.1 discusses multidimensional heterogeneity. Appendix A.3 illustrates that while in principle the no trade condition does not rule out non-marginal insurance contracts (i.e. $b$ and $\tau>0$ ), in general a monopolist firm's profits will be concave in the size of the contract; hence the no trade condition also rules out larger contracts. Appendix A.2 also discusses the ability of the firm to potentially offer menus of insurance contracts instead of a single contract to screen workers.

\section{A.1 Multi-Dimensional Heterogeneity and Robustness to Outlier Willingness to Pay}

In reality, there are many reasons beyond one's chance of job loss that drive differences in willingness to pay. As a result, a potential concern with the robustness of the no trade condition is that one may expect that at least one person in the population is likely willing to pay the pooled cost of the risks worse than them, even if the majority of those with similar likelihood of job loss, $p$, have lower demand for UI. To understand the potential validity of this concern, this section solves for the no-trade condition in the case where there is an (unbounded) distribution of $\frac{u^{\prime}\left(c_{u}(\theta)\right)}{v^{\prime}\left(c_{e}(\theta)\right)}$ among the set of those with the same risk type, $p(\theta)$. In this case, there is heterogeneous willingness to pay for additional UI for different types $\theta$ with the same $p(\theta)$.

I show that there exists a mapping, $f(p): A \rightarrow \Theta$, that maps $A \subset[0,1]$ into the interior of the type space, $\Theta$, such that the no trade condition reduces to testing

$$
\frac{u^{\prime}\left(c_{u}(f(p))\right)}{u^{\prime}\left(c_{e}(f(p))\right)} \leq T(p) \quad \forall p
$$

In this sense, even though some types are willing to pay an unboundedly high amount for UI, their extreme willingness to pay does not directly affect the no trade condition. Rather, one needs to search through an interior subset of the type space. Hence, if there are sufficiently many people of risk type $p$ with very high willingness to pay, then one would expect the type $f(p)$ to be willing to pay the pooled cost of worse risks, so that equation (20) will not hold. But, the results illustrate that a simple addition of individuals with outlier willingness to pay for UI will not open up a market unless there are sufficiently many other types with the similar risk type that are also willing to pay the pooled cost of worse risks.

I prove this result as follows. First, I assume for simplicity that the distribution of $p(\theta)$ has full support on $[0,1]$ and the distribution of $\frac{u^{\prime}\left(c_{u}(\theta)\right)}{v^{\prime}\left(c_{e}(\theta)\right)}$ has full support on $[0, \infty)$ (this is not essential, but significantly shortens the proof - note this allows for some individuals with unboundedly high willingness to pay). Now, fix a particular policy, $\frac{d \tau}{d b}$, and consider the set of $\theta$ that are willing to pay for this policy:

$$
E\left[p(\theta) \mid \theta \in \bar{\Theta}\left(\frac{d \tau}{d b}\right)\right]
$$

\footnotetext{
${ }^{61}$ In other words, the random variable $P$ is simply the random variable generated by the choices of probabilities, $p(\theta)$, in the population.
} 
Without loss of generality, there exists a function $\tilde{p}\left(\frac{d \tau}{d b}\right)$ such that

$$
E\left[p(\theta) \mid \theta \in \bar{\Theta}\left(\frac{d \tau}{d b}\right)\right]=E\left[p(\theta) \mid p(\theta) \geq \tilde{p}\left(\frac{d \tau}{d b}\right)\right]
$$

so that the average probability of the types selecting $\frac{d \tau}{d b}$ is equal to the average cost of all types above $\tilde{p}\left(\frac{d \tau}{d b}\right)$. Without loss of generality, one can assume that $\tilde{p}$ is strictly increasing in $\frac{d \tau}{d b}$ so that $\tilde{p}^{-1}$ exists. ${ }^{62}$

I construct $f(p): A \rightarrow \Theta$ as follows. Define $A$ to be the range of $\tilde{p}$ when taking values of $\frac{d \tau}{d b}$ ranging from 0 to $\infty$. For each $p$, define $f(p)$ to be a value(s) of $\theta$ such that the willingness to pay equals $\tilde{p}^{-1}(p)$ :

$$
\frac{p}{1-p} \frac{u^{\prime}\left(c_{e}(f(p))\right)}{v^{\prime}\left(c_{u}(f(p))\right)}=\tilde{p}^{-1}(p)
$$

Now, suppose $\tilde{p}^{-1}(p) \leq T(p)$ for all $p$. One needs to establish that inequality (18) does not hold for any $\frac{d \tau}{d b}$ :

$$
\frac{d \tau}{d b} \leq \frac{E\left[p(\theta) \mid \theta \in \bar{\Theta}\left(\frac{d \tau}{d b}\right)\right]}{E\left[1-p(\theta) \mid \theta \in \bar{\Theta}\left(\frac{d \tau}{d b}\right)\right]}
$$

To see this, note that

$$
\frac{E\left[p(\theta) \mid \theta \in \bar{\Theta}\left(\frac{d \tau}{d b}\right)\right]}{E\left[1-p(\theta) \mid \theta \in \bar{\Theta}\left(\frac{d \tau}{d b}\right)\right]}=\frac{E\left[p(\theta) \mid p(\theta) \geq \tilde{p}\left(\frac{d \tau}{d b}\right)\right]}{1-E\left[p(\theta) \mid p(\theta) \geq \tilde{p}\left(\frac{d \tau}{d b}\right)\right]}
$$

so that we wish to show that

$$
\frac{E\left[p(\theta) \mid p(\theta) \geq \tilde{p}\left(\frac{d \tau}{d b}\right)\right]}{1-E\left[p(\theta) \mid p(\theta) \geq \tilde{p}\left(\frac{d \tau}{d b}\right)\right]} \geq \frac{d \tau}{d b}
$$

for all $\frac{d \tau}{d b}$. Note that the set $A$ is generated by the variation in $\frac{d \tau}{d b}$, so that testing equation (21) is equivalent to testing this equation for all $p$ in the range of $A$ :

$$
\frac{E[p(\theta) \mid p(\theta) \geq p]}{1-E[p(\theta) \mid p(\theta) \geq p]} \geq \tilde{p}^{-1}(p) \quad \forall p \in A
$$

which is equivalent to

$$
\frac{E[p(\theta) \mid p(\theta) \geq p]}{1-E[p(\theta) \mid p(\theta) \geq p]} \geq \frac{p}{1-p} \frac{u^{\prime}\left(c_{e}(f(p))\right)}{v^{\prime}\left(c_{u}(f(p))\right)} \quad \forall p \in A
$$

which proves the desired result.

Intuitively, it is sufficient to check the no trade condition for the set of equivalent classes of types with the same willingness to pay for $\frac{d \tau}{d p}$. Within this class, there exists a type that one can use to check the simple uni-dimensional no trade condition.

\section{A.2 Robustness to Menus}

Here, I illustrate how to nest the model into the setting of Hendren (2013), then apply the no trade condition in Hendren (2013) to rule out menus in this more complex setting with moral hazard. I assume here that there are no additional choices, $a$, other than the choice $p$, although the presence of such additional choices should not alter the proof as long as they are not observable to the insurer. With this simplification, the only distinction relative to Hendren (2013) is the introduction of the moral hazard problem in choosing $p$. This section shows that allowing $p$ to be a choice doesn't make trade any easier than in a world where $p(\theta)$ is exogenous and not affected by the insurer's contracts; hence the no trade condition results from Hendren (2013) can be applied to rule out menus.

I consider the maximization program of a monopolist insurer offering a menu of insurance contracts. Whether there exists any implementable allocations other than the endowment corresponds to whether there exists any allocations other than the endowment which maximize the profit, $\pi$, subject to the incentive and participation constraints.

Without loss of generality, the insurer can offer a menu of contracts to screen types, $\{\nu(\theta), \Delta(\theta)\}_{\theta \in \Gamma}$ where $\nu(\theta)$ specifies a total utility provided to type $\theta, v(\theta)=p(\theta) u\left(c_{u}(\theta)\right)+(1-p(\theta)) v\left(c_{e}(\theta)\right)-\Psi(p ; \theta)$, and $\Delta(\theta)$ denotes the difference in utilities if the agent becomes unemployed, $\Delta(\theta)=u\left(c_{u}(\theta)\right)-v\left(c_{e}(\theta)\right)$. Note that $\nu(\theta)$ implicitly contains the disutility of effort.

Given the menu of contracts offered by the insurer, individuals choose their likelihood of unemployment. Let $\hat{q}(\Delta, \theta)$ denote the choice of probability of employment for a type $\theta$ given the utility difference between employment

\footnotetext{
${ }^{62}$ If $\tilde{p}$ is not strictly increasing (e.g. because of "advantageous selection"), it will be strictly more profitable to an insurance company to sell the insurance at a higher price. Hence, one need not test the no trade condition for such intermediate values of $\frac{d \tau}{d b}$ where $\tilde{p}$ is decreasing in $p$.
} 
and unemployment, $\Delta$, so that the agent's effort cost is $\Psi(\hat{q}(\Delta ; \theta) \theta)$. Note that a type $\theta$ that accepts a contract containing $\Delta$ will choose a probability of employment $\hat{q}(\Delta ; \theta)$ that maximizes their utility. I assume that $\hat{q}$ is weakly increasing in $\Delta$ for all $\theta$.

Let $C_{u}(x)=u^{-1}(x)$ and $C_{e}(x)=v^{-1}(x)$ denote the consumption levels required in the employed and unemployed state to provide utility level $x$. Let $\pi(\Delta, \nu ; \theta)$ denote the profits obtained from providing type $\theta$ with contract terms $\nu$ and $\Delta$, given by

$$
\pi(\Delta, \nu ; \theta)=\hat{q}(\Delta ; \theta)\left(c_{e}^{e}-C_{e}(v-\Psi(\Delta ; \theta))\right)+(1-\hat{q}(\Delta ; \theta))\left(c_{u}^{e}-C_{u}(\nu-\Delta-\Psi(\Delta ; \theta))\right)
$$

Note that the profit function takes into account how the agents' choice of $p$ varies with $\Delta$.

Throughout, I maintain the assumption that profits of the monopolist are concave in $(\nu, \Delta)$. Such concavity can be established in the general case when $u$ is concave and individuals do not choose $p$ (see Hendren (2013)). But, allowing individuals to make choices, $p$, introduces potential non-convexities into the analysis. However, it is natural to assume that if a large insurance contract would be profitable, then so would a small insurance contract. In Section A.3 below, I show that global concavity of the firm's profit function follows from reasonable assumptions on the individuals' utility function. Intuitively, what ensures global concavity is to rule out a case where small amounts of insurance generate large increases in marginal utilities (and hence increase the demand for insurance).

I prove the sufficiency of the no trade condition for ruling out trade by mapping it into the setting of Hendren (2013). To do so, define $\tilde{\pi}(\nu, \Delta ; \theta)$ to be the profits incurred by the firm in the alternative world in which individuals choose $p$ as if they faced their endowment (i.e. face no moral hazard problem). Now, in this alternative world, individuals still obtain total utility $\nu$ by construction, but must be compensated for their lost utility from effort because they can't re-optimize. But, note this compensation is second-order by the envelope theorem. Therefore, the marginal profitability for sufficiently small insurance contracts is given by

$$
\pi(\nu, \Delta ; \theta) \leq \tilde{\pi}(\nu, \Delta ; \theta)
$$

Now, define the aggregate profits to an insurer that offers menu $\{\nu(\theta), \Delta(\theta)\}_{\theta}$ by

$$
\Pi(\nu(\theta), \Delta(\theta))=\int \pi(\nu(\theta), \Delta(\theta) ; \theta) d \mu(\theta)
$$

and in the world in which $p$ is not affected by $\Pi$,

$$
\tilde{\Pi}(\nu(\theta), \Delta(\theta))=\int \pi(\nu(\theta), \Delta(\theta) ; \theta) d \mu(\theta)
$$

So, for small variations in $\nu$ and $\Delta$, we have that

$$
\Pi(\nu(\theta), \Delta(\theta)) \leq \tilde{\Pi}(\nu(\theta), \Delta(\theta))
$$

because insurance causes an increase in $p$. Now, Hendren (2013) shows that the no trade condition implies that $\tilde{\Pi} \leq 0$ for all menus, $\{\nu(\theta), \Delta(\theta)\}$. Therefore, the no trade condition also implies $\Pi \leq 0$ for local variations in the menu $\{\nu(\theta), \Delta(\theta)\}$ around the endowment. Combining with the concavity assumption, this also rules out larger deviations.

Conversely, if the no trade condition does not hold, note that the behavioral response is continuous in $\Delta$, so that sufficiently small values of insurance allow for a profitable insurance contract to be traded.

\section{A.3 Concavity Assumption and Sufficient Conditions for Concavity}

The presence of moral hazard in this multi-dimensional screening problem induces the potential for non-convexities in the constraint set. Such non convexities could potentially limit the ability of local variational analysis to characterize the set of implementable allocations. To be specific, let $\pi(\Delta, \mu ; \theta)$ denote the profit obtained from type $\theta$ if she is provided with total utility $\mu$ and difference in utilities $\Delta$,

$$
\pi(\Delta, \mu ; \theta)=(1-\hat{p}(\Delta ; \theta))\left(c_{e}^{e}-C_{v}(\mu-\Psi(1-\hat{p}(\Delta ; \theta)))\right)+\hat{p}(\Delta ; \theta)\left(c_{u}^{e}-C_{u}(\mu-\Delta-\Psi(1-\hat{p}(\Delta ; \theta)))\right)
$$

To guarantee the validity of our variational analysis for characterizing when the endowment is the only implementable allocation, it will be sufficient to require that $\pi(\Delta, \mu ; \theta)$ is concave in $(\Delta, \mu)$.

Assumption. $\pi(\Delta, \mu ; \theta)$ is concave in $(\Delta, \mu)$ for each $\theta$

This assumption requires the marginal profitability of insurance to decline in the amount of insurance provided. If the agents choice of $p$ is given exogenously (i.e. does not vary with $\Delta$ ), then concavity of the utility functions, $u$ and $v$, imply concavity of $\pi(\Delta, \mu ; \theta)$. Assumption A.3 ensures that this extends to the case when $p$ is a choice and can respond to $\theta$. 
Claim. If $\Psi^{\prime \prime \prime}(q ; \theta)>0$ for all $\theta$ and $\frac{u^{\prime}\left(c_{u}^{e}\right)}{v^{\prime}\left(c_{e}^{e}\right)} \leq 2$ then $\pi$ is globally concave in $(\mu, \Delta)$.

For simplicity, we consider a fixed $\theta$ and drop reference to it. Profits are given by

$$
\pi(\Delta, \mu)=\hat{q}(\Delta)\left(c_{e}^{e}-C_{e}(\mu-\Psi(\hat{q}(\Delta)))\right)+(1-\hat{q}(\Delta))\left(c_{u}^{e}-C_{u}(\mu-\Delta-\Psi(\hat{q}(\Delta)))\right)
$$

The goal is to show the Hessian of $\pi$ is negative semi-definite. I proceed in three steps. First, I derive conditions which guarantee $\frac{\partial^{2} \pi}{\partial \Delta^{2}}<0$. Second, I show that, in general, we have $\frac{\partial^{2} \pi}{\partial \mu^{2}}<0$. Finally, I show the conditions provided to guarantee $\frac{\partial^{2} \pi}{\partial \Delta^{2}}<0$ also imply the determinant of the Hessian is positive, so that both eigenvalues of the Hessian must be negative and thus the matrix is negative semi-definite.

\section{A.3.1 Conditions that imply $\frac{\partial^{2} \pi}{\partial \Delta^{2}}<0$}

Taking the first derivative with respect to $\Delta$, we have

$$
\begin{aligned}
\frac{\partial \pi}{\partial \Delta}= & \frac{\partial \hat{q}}{\partial \Delta}\left(c_{e}^{e}-c_{u}^{e}+C_{u}(\mu-\Delta-\Psi(\hat{q}(\Delta)))\right) \\
& -(1-\hat{q}(\Delta)) C_{u}^{\prime}(\mu-\Delta-\Psi(\hat{q}(\Delta)))-\hat{q}(\Delta) C_{e}^{\prime}(\mu-\Psi(\hat{q}(\Delta)))
\end{aligned}
$$

Taking another derivative with respect to $\Delta$, applying the identity $\Delta=\Psi^{\prime}(\hat{p}(\Delta))$, and collecting terms yields

$$
\begin{aligned}
\frac{\partial^{2} \pi}{\partial \Delta^{2}}= & -\left[(1-\hat{q}(\Delta))(1+\Delta)^{2} C_{u}^{\prime \prime}(\mu-\Delta-\Psi(\hat{q}(\Delta)))+\hat{q}(\Delta)\left(\Delta \hat{q}^{\prime}(\Delta)\right)^{2} C^{\prime \prime}(\mu-\Psi(\hat{q}(\Delta)))\right] \\
& +\frac{\partial \hat{q}}{\partial \Delta}\left[(1-\hat{q}(\Delta)) C^{\prime}(\mu-\Delta-\Psi(\hat{q}(\Delta)))+\hat{q}(\Delta) C^{\prime}(u-\Psi(\hat{q}(\Delta)))-\left(2+2 \Delta \hat{q}^{\prime}(\Delta)\right) C^{\prime}(\mu-\Delta-\Psi(\hat{q}(\Delta)))\right] \\
& +\frac{\partial^{2} \hat{q}}{\partial \Delta^{2}}\left[c_{e}^{e}-c_{u}^{e}+C(\mu-\Delta-\Psi(\hat{q}(\Delta)))-C(\mu-\Psi(\hat{q}(\Delta)))+(1-\hat{q}(\Delta)) \Delta C^{\prime}(\mu-\Delta-\Psi(\hat{q}(\Delta)))+\hat{q}(\Delta) C^{\prime}(\mu-\Psi(\hat{q}(\Delta)\right.
\end{aligned}
$$

We consider these three terms in turn. The first term is always negative because $C^{\prime \prime}>0$. The second term, multiplying $\frac{\partial \hat{q}}{\partial \Delta}$, can be shown to be positive if

$$
(1+\hat{q}(\Delta)) C^{\prime}(\mu-\Delta-\Psi(\hat{q}(\Delta))) \geq \hat{q}(\Delta) C^{\prime}(\mu-\Delta)
$$

which is necessarily true whenever

$$
\frac{u^{\prime}\left(c_{u}^{e}\right)}{v^{\prime}\left(c_{e}^{e}\right)} \leq 2
$$

This inequality holds as long as people are willing to pay less than a $100 \%$ markup for a small amount of insurance, evaluated at their endowment.

Finally, the third term is positive as long as $\Psi^{\prime \prime \prime}>0$. To see this, one can easily verify that the term multiplying $\frac{\partial^{2} \hat{q}}{\partial \Delta^{2}}$ is necessarily positive. Also, note that $\frac{\partial^{2} \hat{q}}{\partial \Delta^{2}}=\frac{-\Psi^{\prime \prime \prime}}{\left(\Psi^{\prime \prime}\right)^{2}}$. Therefore, if we assume that $\Psi^{\prime \prime \prime}>0$, the entire last term will necessarily be negative. In sum, it is sufficient to assume $\frac{u^{\prime}\left(c_{u}^{e}\right)}{v^{\prime}\left(c_{e}^{e}\right)} \leq 2$ and $\Psi^{\prime \prime \prime}>0$ to guarantee that $\frac{\partial^{2} \pi}{\partial \Delta^{2}}<0$.

\section{A.3.2 Conditions that imply $\frac{\partial^{2} \pi}{\partial \mu^{2}}<0$}

Fortunately, profits are easily seen to be concave in $\mu$. We have

$$
\frac{\partial \pi}{\partial \mu}=-(1-\hat{q}(\Delta)) C^{\prime}(\mu-\Delta-\Psi(\hat{q}(\Delta)))-\hat{q}(\Delta) C^{\prime}(\mu-\Psi(\hat{q}(\Delta)))
$$

so that

$$
\frac{\partial^{2} \pi}{\partial \mu^{2}}=-(1-\hat{q}(\Delta)) C^{\prime \prime}(\mu-\Delta-\Psi(\hat{q}(\Delta)))-\hat{q}(\Delta) C^{\prime \prime}(\mu-\Psi(\hat{q}(\Delta)))
$$

which is negative because $C^{\prime \prime}>0$.

\section{A.3.3 Conditions to imply $\frac{\partial^{2} \pi}{\partial \Delta^{2}} \frac{\partial^{2} \pi}{\partial \mu^{2}}-\left(\frac{\partial^{2} \pi}{\partial \Delta \partial \mu}\right)>0$}

Finally, we need to ensure that the determinant of the Hessian is positive. To do so, first note that

$$
\frac{\partial^{2} \pi}{\partial \mu \partial \Delta}=(1-\hat{q}(\Delta)) C^{\prime \prime}(\mu-\Delta-\Psi(\hat{q}(\Delta)))\left(1+\Delta \hat{q}^{\prime}(\Delta)\right)+\hat{q}(\Delta) C^{\prime \prime}(\mu-\Psi(\hat{q}(\Delta))) \Delta \hat{q}^{\prime}(\Delta)
$$


Also, we note that under the assumptions $\Psi^{\prime \prime \prime}>0$ and $\frac{u^{\prime}\left(c_{u}^{e}\right)}{v^{\prime}\left(c_{e}^{e}\right)} \leq 2$, we have the inequality

$$
\frac{\partial^{2} \pi}{\partial \Delta^{2}}<-\left[(1-\hat{q}(\Delta))(1+\Delta)^{2} C_{u}^{\prime \prime}(\mu-\Delta-\Psi(\hat{q}(\Delta)))+\hat{q}(\Delta)\left(\Delta \hat{q}^{\prime}(\Delta)\right)^{2} C^{\prime \prime}(\mu-\Psi(\hat{q}(\Delta)))\right]
$$

Therefore, we can ignore the longer terms in the expression for $\frac{\partial^{2} \pi}{\partial \Delta^{2}}$ above. We multiply the RHS of the above equation with the value of $\frac{\partial^{2} \pi}{\partial \mu^{2}}$ and subtract $\left(\frac{\partial^{2} \pi}{\partial \Delta \partial \mu}\right)^{2}$. Fortunately, many of the terms cancel out, leaving the inequality

$$
\begin{aligned}
\frac{\partial^{2} \pi}{\partial \Delta^{2}} \frac{\partial^{2} \pi}{\partial \mu^{2}}-\left(\frac{\partial^{2} \pi}{\partial \Delta \partial \mu}\right)^{2} \geq & (1-\hat{q}(\Delta)) \hat{q}(\Delta)\left(1+\Delta \hat{q}^{\prime}(\Delta)\right)^{2} C^{\prime \prime}(\mu-\Delta-\Psi(\hat{q}(\Delta))) C^{\prime \prime}(\mu-\Psi(\hat{q}(\Delta))) \\
& +\hat{q}(\Delta)(1-\hat{q}(\Delta))\left(\Delta \hat{q}^{\prime}(\Delta)\right)^{2} C^{\prime \prime}(\mu-\Psi(\hat{q}(\Delta))) C^{\prime \prime}(\mu-\Delta-\Psi(\hat{q}(\Delta))) \\
& -2(1-\hat{q}(\Delta)) \hat{q}(\Delta)\left(1+\Delta \hat{q}^{\prime}(\Delta)\right) \Delta \hat{q}^{\prime}(\Delta) C^{\prime \prime}(\mu-\Delta-\Psi(\hat{q}(\Delta))) C^{\prime \prime}(\mu-\Psi(\hat{q}(\Delta)))
\end{aligned}
$$

which reduces to the inequality

$$
\frac{\partial^{2} \pi}{\partial \Delta^{2}} \frac{\partial^{2} \pi}{\partial \mu^{2}}-\left(\frac{\partial^{2} \pi}{\partial \Delta \partial \mu}\right)^{2} \geq \hat{q}(\Delta)(1-\hat{q}(\Delta)) C^{\prime \prime}(\mu-\Delta-\Psi(\hat{q}(\Delta))) C^{\prime \prime}(\mu-\Psi(\hat{q}(\Delta))) K(\mu, \Delta)
$$

where

$$
\begin{aligned}
K(\mu, \Delta) & =\left(1+\Delta \hat{q}^{\prime}(\Delta)\right)^{2}+\left(\Delta \hat{q}^{\prime}(\Delta)\right)^{2}-2 \Delta \hat{q}^{\prime}(\Delta)-2\left(\Delta \hat{q}^{\prime}(\Delta)\right)^{2} \\
& =1
\end{aligned}
$$

So, since $C^{\prime \prime}>0$, we have that the determinant must be positive. In particular, we have

$$
\frac{\partial^{2} \pi}{\partial \Delta^{2}} \frac{\partial^{2} \pi}{\partial \mu^{2}}-\left(\frac{\partial^{2} \pi}{\partial \Delta \partial \mu}\right)^{2} \geq \hat{q}(\Delta)(1-\hat{q}(\Delta)) C^{\prime \prime}(\mu-\Delta-\Psi(\hat{q}(\Delta))) C^{\prime \prime}(\mu-\Psi(\hat{q}(\Delta)))
$$

\section{A.3.4 Summary}

As long as $\Psi^{\prime \prime \prime}>0$ and $\frac{u^{\prime}\left(c_{u}^{e}\right)}{v^{\prime}\left(c_{e}^{e}\right)} \leq 2$, the profit function is globally concave. Empirically, I find that $\frac{u^{\prime}\left(c_{u}^{e}\right)}{v^{\prime}\left(c_{e}^{e}\right)} \leq 2$. Therefore, the unsubstantiated assumption for the model is that the convexity of the effort function increases in $p, \Psi^{\prime \prime \prime}>0$. An alternative statement of this assumption is that $\frac{\partial^{2} \hat{q}}{\partial \Delta^{2}}<0$, so that the marginal impact of $\Delta$ on the employment probability is declining in the size of $\Delta$. Put differently, it is an assumption that providing utility incentives to work has diminishing returns.

Future work can derive the necessary conditions when individuals can make additional actions, $a(\theta)$, in response to unemployment. I suspect the proofs can be extended to such cases, but identifying the necessary conditions for global concavity would be an interesting direction for future work.

\section{B Details of Empirical Approach}

\section{B.1 Details on Lower Bounds on Average Pooled Price Ratio}

This section provides details on the estimation of the lower bounds on the average pooled price ratio. I begin by providing theoretical motivation for the average pooled price ratio by showing it characterizes when an insurer can earn positive profits if it enters with a particular random pricing strategy. Then, I provide conditions under which the average pooled price defined by the predicted values provides a lower bound on the average pooled price ratio, $T_{Z} \leq E[T(P)]$

\section{B.1.1 Motivating the Average Pooled Price Ratio when Insurers don't know $P$}

To see the theoretical relevance of $E[T(P)]$, suppose an insurer seeks to start an insurance market by randomly drawing an individual from the population and, perhaps through some market research, learns exactly how much this individual is willing to pay. The insurer offers a contract that collects $\$ 1$ in the event of being employed and pays an amount in the unemployed state that makes the individual perfectly indifferent to the policy. If $p$ is the probability 
this individual will become unemployed, then all risks $P \geq p$ will choose to purchase the policy as well. The profit per dollar of revenue will be

$$
r(p)=\frac{u^{\prime}\left(c_{u}(p)\right)}{v^{\prime}\left(c_{e}(p)\right)}-T(p)
$$

So, if the original individual was selected at random from the population, the expected profit per dollar would be positive if and only if

$$
E\left[\frac{u^{\prime}\left(c_{u}(p)\right)}{v^{\prime}\left(c_{e}(p)\right)}\right] \geq E[T(P)]
$$

If the insurer is randomly choosing contracts to try to sell, the average pooled price ratio, $E[T(P)]$, provides information on whether or not a UI market would be profitable.

\section{B.1.2 Conditions under which $T_{Z} \leq E[T(P)]$}

Here, I provide conditions under which $T_{Z}$, defined in equation (15), provides a lower bound on the average pooled price ratio, $E[T(P)]$. To begin, assume that (a) the elicitations, $Z$, have no more information about $U$ than do true beliefs, $P$. Stated formally: $\operatorname{Pr}\{U \mid X, Z, P\}=\operatorname{Pr}\{U \mid X, P\}$. Second, assume that beliefs are unbiased, so that $\operatorname{Pr}\{U \mid X, P\}=P$. Hendren (2013) shows that these two assumptions imply that $E\left[m\left(P_{Z}\right)\right] \leq E[m(P)]$. This suggests that $T_{Z} \leq 1+\frac{E[m(P)]}{\operatorname{Pr}\{U\}}$. So, what remains to show is that $1+\frac{E[m(P)]}{\operatorname{Pr}\{U\}} \leq E[T(P)]$. For this, we make one additional assumption that $\operatorname{cov}\left(\frac{m(P)}{P}, P\right) \leq 0$. This is a natural assumption because $m(p)$ is, on average, a decreasing function in $p$ (because $m(1)=0$ ), so dividing by $P$ renders it an even more strongly decreasing function in $P$. Indeed, I have been unable to find a random variable $P$ for which $\operatorname{cov}\left(\frac{m(P)}{P}, P\right)>0$.

Given these assumptions note that

$$
\begin{aligned}
E[T(P)] & =E_{p}\left[\frac{E[P \mid P \geq p]}{p} \frac{1-p}{1-E[P \mid P \geq p]}\right] \\
& \geq E_{p}\left[1+\frac{m(p)}{p}\right] \\
& \geq 1+E\left[\frac{m(P)}{P}\right]
\end{aligned}
$$

where $E_{p}$ represents the expectation with respect to drawing $p$ from the distribution of $P$. Note the second line follows from the fact that $E[P \mid P \geq p] \geq p$.

So, it suffices to show that $E\left[\frac{m(P)}{P}\right] \geq \frac{E[m(P)]}{E[P]}$. Clearly

$$
E[m(P)]=E\left[\frac{m(P)}{P}\right] E[P]+\operatorname{cov}\left(P, \frac{m(P)}{P}\right)
$$

so that

$$
E\left[\frac{m(P)}{P}\right]=\frac{E[m(P)]-\operatorname{cov}\left(P, \frac{m(P)}{P}\right)}{E[P]}
$$

Imposing $\operatorname{cov}\left(\frac{m(P)}{P}, P\right) \leq 0$ yields $E[T(P)] \geq 1+\frac{E[m(P)]}{E[P]}$, which in turn implies $E[T(P)] \geq T_{Z}$.

\section{B.2 Specification for Point Estimation}

I follow Hendren (2013) by assuming that $Z=P+\epsilon$, where $\epsilon$ has the following structure. With probability $\lambda$, individuals report a noisy measure of their true belief $P$ that is drawn from a $[0,1]$-censored normal distribution with mean $P+\alpha(X)$ and variance $\sigma^{2}$. With this specification, $\alpha(X)$ reflects potential bias in elicitations and $\sigma$ represents the noise. While this allows for general measurement error in the elicitations, it does not produce the strong focal point concentrations shown in Figure 1 and documented in existing work (Gan et al. (2005); Manski and Molinari (2010)). To capture these, I assume that with probability $1-\lambda$ individuals take their noisy report with the same bias $\alpha(X)$ and variance $\sigma^{2}$, but censor it into a focal point at 0,50 , or 100 . If their elicitation would have been below $\kappa$, they report zero. If it would have been between $\kappa$ and $1-\kappa$, they report 50 ; and if it would have been above $1-\kappa$, 
they report 1. Hence, I estimate four elicitation error parameters: $(\sigma, \lambda, \kappa, \alpha(X))$ that capture the patterns of noise and bias in the relationship between true beliefs, $P$, and the elicitations reported on the surveys, $Z{ }^{63}$

Ideally, one would flexibly estimate the distribution of $P$ given $X$ at each possible value of $X$. This would enable separate estimates of the minimum pooled price ratio for each value of $X$. However, the dimensionality of $X$ prevents this in practice. Instead, I again follow Hendren (2013) and adopt an index assumption on the cumulative distribution of beliefs, $F(p \mid X)=\int_{0}^{p} f_{P}(\tilde{p} \mid X) d \tilde{p}$,

$$
F(p \mid X)=\tilde{F}(p \mid \operatorname{Pr}\{U \mid X\})
$$

where I assume $\tilde{F}(p \mid q)$ is continuous in $q$ (where $q \in\{0,1\}$ corresponds to the level of $\operatorname{Pr}\{U \mid X\}$ ). This assumes that the distribution of private information is the same for two observable values, $X$ and $X^{\prime}$, that have the same observable unemployment probability, $\operatorname{Pr}\{U \mid X\}=\operatorname{Pr}\left\{U \mid X^{\prime}\right\}$. Although one could perform different dimension reduction techniques, controlling for $\operatorname{Pr}\{U \mid X\}$ is particularly appealing because it nests the null hypothesis of no private information $(F(p \mid X)=1\{p \leq \operatorname{Pr}\{U \mid X\}\}) .{ }^{64}$

A key difficulty with using functions to approximate the distribution of $P$ is that much of the mass of the distribution is near zero. Continuous probability distribution functions, such as the Beta distributions used in Hendren (2013), require very high degrees for the shape parameters to acquire a good fit. Therefore, I approximate $P$ as a sum of discrete point-mass distributions. ${ }^{65}$ Formally, I assume

$$
\tilde{F}(p \mid q)=w 1\{p \leq q-a\}+(1-w) \Sigma_{i} \xi_{i} 1\left\{p \leq \alpha_{i}\right\}
$$

where $\alpha_{i}$ are a set of point masses in $[0,1]$ and $\xi_{i}$ is the mass on each point mass. I estimate these point mass parameters using maximum likelihood estimation. For the baseline results, I use 3 mass points, which generally provides a decent fit for the data. I then compute the pooled price ratio at each mass point and report the minimum across all values aside from the largest mass point. Mechanically, this has a value of $T(p)=1$. As noted in Hendren (2013), estimation of the minimum $T(p)$ across the full support of the type distribution is not feasible because of an extremal quantile estimation problem. To keep the estimates "in-sample", I report values for the mean value of $q=\operatorname{Pr}\{U\}=0.031$; but estimates at other values of $q$ are similarly large.

\section{Willingness to Pay Metrics}

\section{C.1 Proof of Proposition 1}

Note under state independence, the Euler equation implies

$$
u^{\prime}\left(c_{\text {pre }}(p)\right)=p u^{\prime}\left(c_{u}(p)\right)+(1-p) u^{\prime}\left(c_{e}(p)\right)
$$

${ }^{63}$ Specifically, the p.d.f./p.m.f. of $Z$ given $P$ is given by

$$
f(Z \mid P, X)=\left\{\begin{array}{ccc}
(1-\lambda) \Phi\left(\frac{-P-\alpha(X)}{\sigma}\right)+\lambda \Phi\left(\frac{\kappa-P-\alpha(X)}{\sigma}\right) & \text { if } & Z=0 \\
\lambda\left(\Phi\left(\frac{1-\kappa-P-\alpha(X)}{\sigma}\right)-\Phi\left(\frac{\kappa-P-\alpha(X)}{\sigma}\right)\right) & \text { if } & Z=0.5 \\
(1-\lambda) \Phi\left(\frac{1-P-\alpha(X)}{\sigma}\right)+\lambda\left(1-\Phi\left(\frac{1-\kappa-P-\alpha(X)}{\sigma}\right)\right) & \text { if } & Z=1 \\
\frac{1}{\sigma} \phi\left(\frac{Z-P-\alpha(X)}{\sigma}\right) & \text { if } & \text { o.w. }
\end{array}\right.
$$

where $\phi$ denotes the standard normal p.d.f. and $\Phi$ the standard normal c.d.f. I estimate four elicitation error parameters: $(\sigma, \lambda, \kappa, \alpha(X)) . \sigma$ captures the dispersion in the elicitation error, $\lambda$ is the fraction of focal point respondents, $\kappa$ is the focal point window. I allow the elicitation bias term, $\alpha(X)$, to vary with the observable variables, $X$. This allows elicitations to be biased, but maintains the assumption that true beliefs are unbiased.

This approach builds upon Manski and Molinari (2010) by thinking of the focal point responses as "interval data" (i.e. 50/50 corresponds to some region around 50\%, but not exactly 50\%). However, the present approach differs from Manski and Molinari (2010) by allowing the response to be a noisy and potentially biased measure of this response (as 50/50 corresponds to a region around $50 \%$ for the noisy $Z$ measure, not the true $P$ measure).

${ }^{64}$ Moreover, it allows the statistical model to easily impose unbiased beliefs, so that $\operatorname{Pr}\{U \mid X\}=E[P \mid X]$ for all $X$.

${ }^{65}$ This has the advantage that it does not require integrating over high degree of curvature in the likelihood function. In practice, it will potentially under-state the true variance in $P$ in finite sample estimation. As a result, it will tend to produce lower values for $T(p)$ than would be implied by continuous probability distributions for $P$ since the discrete approximation allows all individuals at a particular point mass to be able to perfectly pool together when attempting to cover the pooled cost of worse risks. 
so that

$$
u^{\prime \prime}\left(c_{p r e}(p)\right) \frac{d c_{p r e}}{d p}=u^{\prime}\left(c_{u}(p)\right)-u^{\prime}\left(c_{e}(p)\right)+p u^{\prime \prime}\left(c_{u}(p)\right) \frac{d c_{u}}{d p}+(1-p) u^{\prime \prime}\left(c_{e}(p)\right) \frac{d c_{e}}{d p}
$$

Dividing,

$u^{\prime}\left(c_{\text {pre }}(p)\right) \frac{u^{\prime \prime}\left(c_{\text {pre }}(p)\right)}{u^{\prime}\left(c_{\text {pre }}(p)\right)} \frac{d c_{\text {pre }}}{d p}=u^{\prime}\left(c_{e}\right) \frac{u^{\prime}\left(c_{u}(p)\right)-u^{\prime}\left(c_{e}(p)\right)}{u^{\prime}\left(c_{e}(p)\right)}+p u^{\prime}\left(c_{u}(p)\right) \frac{u^{\prime \prime}\left(c_{u}(p)\right)}{u^{\prime}\left(c_{u}(p)\right)} \frac{d c_{u}}{d p}+(1-p) u^{\prime}\left(c_{e}(p)\right) \frac{u^{\prime \prime}\left(c_{e}(p)\right)}{u^{\prime}\left(c_{e}(p)\right)} \frac{d c_{e}}{d p}$

or

$u^{\prime}\left(c_{\text {pre }}(p)\right) \sigma \frac{-d \log \left(c_{p r e}\right)}{d p}=u^{\prime}\left(c_{e}\right) \sigma\left[\log \left(c_{e}\right)-\log \left(c_{u}\right)\right]+p u^{\prime}\left(c_{u}(p)\right) \sigma \frac{-d \log \left(c_{u}(p)\right)}{d p}+(1-p) u^{\prime}\left(c_{e}(p)\right) \sigma \frac{-d \log \left(c_{e}(p)\right)}{d p}$

So, dividing by $u^{\prime}\left(c_{e}(p)\right)$ yields:

$$
\frac{u^{\prime}\left(c_{\text {pre }}(p)\right)}{u^{\prime}\left(c_{e}\right)} \sigma \frac{-d \log \left(c_{\text {pre }}\right)}{d p}=\sigma\left[\log \left(c_{e}\right)-\log \left(c_{u}\right)\right]+p \frac{u^{\prime}\left(c_{u}(p)\right)}{u^{\prime}\left(c_{e}(p)\right)} \sigma \frac{-d \log \left(c_{u}(p)\right)}{d p}+(1-p) \sigma \frac{-d \log \left(c_{e}(p)\right)}{d p}
$$

And, using the Euler equation, $p u^{\prime}\left(c_{u}(p)\right)+(1-p) u^{\prime}\left(c_{e}(p)\right)=u^{\prime}\left(c_{\text {pre }}(p)\right)$,

$$
\begin{aligned}
\frac{p u^{\prime}\left(c_{u}(p)\right)+(1-p) u^{\prime}\left(c_{e}(p)\right)}{u^{\prime}\left(c_{e}(p)\right)} \sigma \frac{-d \log \left(c_{p r e}(p)\right)}{d p} & =\frac{u^{\prime}\left(c_{u}(p)\right)-u^{\prime}\left(c_{e}(p)\right)}{u^{\prime}\left(c_{e}(p)\right)}+p \frac{u^{\prime}\left(c_{u}(p)\right)}{u^{\prime}\left(c_{e}(p)\right)} \sigma \frac{-d \log \left(c_{u}(p)\right)}{d p}+(1-p) \sigma \frac{-d \log \left(c_{e}(p)\right)}{d p} \\
\left(p \frac{u^{\prime}\left(c_{u}(p)\right)}{u^{\prime}\left(c_{e}(p)\right)}+1-p\right) \sigma \frac{-d \log \left(c_{p r e}(p)\right)}{d p} & =\frac{u^{\prime}\left(c_{u}(p)\right)-u^{\prime}\left(c_{e}(p)\right)}{u^{\prime}\left(c_{e}(p)\right)}+\left(p \frac{u^{\prime}\left(c_{u}(p)\right)}{u^{\prime}\left(c_{e}(p)\right)}+1-p\right) \sigma \frac{-d \log \left(c_{e}(p)\right)}{d p}+p \frac{u^{\prime}\left(c_{u}(p)\right)}{u^{\prime}\left(c_{e}(p)\right)} \sigma\left(\frac{d\left[\log \left(c_{e}\right)-\log \left(c_{u}\right)\right]}{d p}\right)
\end{aligned}
$$

so that

$$
\sigma \frac{-d \log \left(c_{p r e}\right)}{d p}=\frac{\frac{u^{\prime}\left(c_{u}(p)\right)}{u^{\prime}\left(c_{e}(p)\right)}-1}{1+p\left(\frac{u^{\prime}\left(c_{u}(p)\right)}{u^{\prime}\left(c_{e}(p)\right)}-1\right)}+\sigma \frac{-d \log \left(c_{e}(p)\right)}{d p}+\frac{p \frac{u^{\prime}\left(c_{u}(p)\right)}{u^{\prime}\left(c_{e}(p)\right)}}{p \frac{u^{\prime}\left(c_{u}(p)\right)}{u^{\prime}\left(c_{e}(p)\right)}+1-p} \sigma\left(\frac{d\left[\log \left(c_{e}\right)-\log \left(c_{u}\right)\right]}{d p}\right)
$$

or

$$
\frac{-d \log \left(c_{p r e}\right)}{d p}=\frac{\frac{1}{\sigma}\left(\frac{u^{\prime}\left(c_{u}(p)\right)}{u^{\prime}\left(c_{e}(p)\right)}-1\right)}{1+p\left(\frac{u^{\prime}\left(c_{u}(p)\right)}{u^{\prime}\left(c_{e}(p)\right)}-1\right)}+\frac{-d \log \left(c_{e}(p)\right)}{d p}+\frac{p \frac{u^{\prime}\left(c_{u}(p)\right)}{u^{\prime}\left(c_{e}(p)\right)}}{p \frac{u^{\prime}\left(c_{u}(p)\right)}{u^{\prime}\left(c_{e}(p)\right)}+1-p}\left(\frac{d\left[\log \left(c_{e}\right)-\log \left(c_{u}\right)\right]}{d p}\right)
$$

Note that the assumption is maintained that $\log \left(c_{p r e}\right)$ is linear in $p$, in addition to $\log \left(c_{e}\right)$ and $\log \left(c_{u}\right)$ being linear in $p$. This is of course an approximation in practice, as the equation above illustrates this cannot simultaneously be true for all $p$. Therefore, I assume it is true only in expectation, so that

$$
\frac{-d \log \left(c_{p r e}\right)}{d p}=\frac{1}{\sigma}\left(\frac{u^{\prime}\left(c_{u}(p)\right)}{u^{\prime}\left(c_{e}(p)\right)}-1\right) E\left[\frac{1}{1+p\left(\frac{u^{\prime}\left(c_{u}(p)\right)}{u^{\prime}\left(c_{e}(p)\right)}-1\right)}\right]+\frac{-d \log \left(c_{e}(p)\right)}{d p}+E\left[\frac{p \frac{u^{\prime}\left(c_{u}(p)\right)}{u^{\prime}\left(c_{e}(p)\right)}}{p \frac{u^{\prime}\left(c_{u}(p)\right)}{u^{\prime}\left(c_{e}(p)\right)}+1-p}\left(\frac{d\left[\log \left(c_{e}\right)-\log \left(c_{u}\right)\right]}{d p}\right)\right]
$$

which if it holds for all $p$ must also hold for the expectation taken with respect to $p$. Let $\kappa=E\left[\frac{1}{1+p\left(\frac{u^{\prime}\left(c_{u}(p)\right)}{u^{\prime}\left(c_{e}(p)\right)}-1\right)}\right]$.

Note also that

$$
\frac{u^{\prime}\left(c_{u}(p)\right)}{u^{\prime}\left(c_{e}(p)\right)}-1 \approx \sigma E\left[\log \left(c_{e}(p)\right)-\log \left(c_{u}(p)\right)\right]
$$

which implies

$$
\frac{-d \log \left(c_{p r e}\right)}{d p}=E\left[\log \left(c_{e}(p)\right)-\log \left(c_{u}(p)\right)\right] \kappa+\frac{-d \log \left(c_{e}(p)\right)}{d p}+E\left[\frac{p \frac{u^{\prime}\left(c_{u}(p)\right)}{u^{\prime}\left(c_{e}(p)\right)}}{p \frac{u^{\prime}\left(c_{u}(p)\right)}{u^{\prime}\left(c_{e}(p)\right)}+1-p}\left(\frac{d\left[\log \left(c_{e}\right)-\log \left(c_{u}\right)\right]}{d p}\right)\right]
$$

Now, consider the impact of unemployment on the first difference of consumption. Define $\Delta^{F D}$ as the estimated impact on the first difference in consumption:

$$
\Delta^{F D}=E\left[\log (c)-\log \left(c_{-1}\right) \mid U=1\right]-E\left[\log (c)-\log \left(c_{-1}\right) \mid U=0\right]
$$

Adding and subtracting $E\left[\log \left(c_{e}\right) \mid U=1\right]$ yields

$\Delta^{F D}=E[\log (c) \mid U=1]-E\left[\log \left(c_{e}\right) \mid U=1\right]+E\left[\log \left(c_{e}\right) \mid U=1\right]-E[\log (c) \mid U=0]-\left(E\left[\log \left(c_{-1}\right) \mid U=1\right]-E\left[\log \left(c_{-1}\right) \mid U=0\right]\right)$

Note that $c=c_{u}$ for those with $U_{t}=1$ and $c=c_{e}$ for those with $U=0$. The following three equations help expand $\Delta^{F D}$ :

$$
E\left[\log \left(c_{-1}\right) \mid U=1\right]-E\left[\log \left(c_{-1}\right) \mid U=0\right]=\frac{d \log \left(c_{\text {pre }}\right)}{d p} \frac{\operatorname{var}(P)}{\operatorname{var}(U)}
$$


and

$$
\begin{aligned}
E[\log (c) \mid U=1]-E\left[\log \left(c_{e}\right) \mid U=0\right] & =E\left[\log \left(c_{u}\right) \mid U=1\right]-E\left[\log \left(c_{e}\right) \mid U=1\right] \\
& =E\left[\log \left(c_{u}\right)-\log \left(c_{e}\right)\right]+\frac{d\left[\log \left(c_{u}\right)-\log \left(c_{e}\right)\right]}{d p}(E[P \mid U=1]-E[P])
\end{aligned}
$$

and

$$
\begin{aligned}
E\left[\log \left(c_{e}\right) \mid U=1\right]-E[\log (c) \mid U=0] & =E\left[\log \left(c_{e}\right) \mid U=1\right]-E\left[\log \left(c_{e}\right) \mid U=0\right] \\
& =\frac{d \log \left(c_{e}\right)}{d p} \frac{\operatorname{var}(P)}{\operatorname{var}(U)}
\end{aligned}
$$

So, substituting these into $\Delta^{F D}$ yields:

$\Delta^{F D}=E\left[\log \left(c_{u}\right)-\log \left(c_{e}\right)\right]-\frac{\operatorname{var}(P)}{\operatorname{var}(U)}\left[\kappa\left(E\left[\log \left(c_{e}\right)-\log \left(c_{u}\right)\right]\right)+E[P] \frac{u^{\prime}\left(c_{u}\right)}{u^{\prime}\left(c_{e}\right)} \frac{d\left[\log \left(c_{e}\right)-\log \left(c_{u}\right)\right]}{d p}\right]+\left[\frac{d\left[\log \left(c_{e}\right)-\log \left(c_{u}\right)\right]}{d p}\right](E[P \mid U=1]-E[P])$

Let $\frac{d \Delta}{d p}=\frac{d\left[\log \left(c_{e}\right)-\log \left(c_{u}\right)\right]}{d p}$ denote how the consumption drop varies with $p$. Solving for $E\left[\log \left(c_{e}\right)-\log \left(c_{e}\right)\right]$ yields

$$
E\left[\log \left(c_{u}\right)-\log \left(c_{e}\right)\right]=\frac{\Delta^{F D}+\frac{d \Delta}{d p}(E[P \mid U=1]-E[P])}{1-\frac{\operatorname{var}(P)}{\operatorname{var}(U)} \kappa-\bar{p} \sigma \frac{d \Delta}{d p}}
$$

where $\kappa=$ which yields the desired result. Note that if the consumption drop does not vary with $p$, then this reduces to

$$
E\left[\log \left(c_{u}\right)-\log \left(c_{e}\right)\right]=\frac{\Delta^{F D}}{1-\frac{\operatorname{var}(P)}{\operatorname{var}(U)} \kappa} \equiv \Delta^{I V}
$$

More generally, if the size of the consumption drop is increasing with $p$, then $E\left[\log \left(c_{u}\right)-\log \left(c_{e}\right)\right]>\Delta^{I V}$.

\section{C.2 Maximum Willingness to Pay}

While the analysis to this point estimates the average causal effect of unemployment, Equation (8) requires comparing the willingness to pay for all $p$ to the pooled price ratio. Therefore, it is also useful to understand the heterogeneity in the potential willingness to pay across the population. How much might some people be willing to pay for insurance?

Estimating minima and maxima is always more difficult than estimating means; but this section attempts to make a bit of progress to help shed light on this important question. Let $\Delta^{\text {min }}$ denote the largest causal effect of unemployment in the population,

$$
\Delta^{\min }=\min _{p}\left[\log \left(c_{u}(p)\right)-\log \left(c_{e}(p)\right)\right]
$$

Following equation (9), note that the willingness to pay satisfies

$$
\frac{u^{\prime}\left(c_{u}\right)-u^{\prime}\left(c_{e}\right)}{u^{\prime}\left(c_{e}\right)} \geq \sigma\left(-\Delta^{\min }\right)\left(1+\frac{\gamma}{2}\left(-\Delta^{\min }\right)\right)
$$

Therefore, $\Delta^{\text {min }}$ generates a upper bound on the willingness to pay (note that $\Delta^{\text {min }}<0$ ).

This motivates the question: How big can the causal impact of unemployment be? To address this, note that one can write the causal effect as the sum of two first differences:

$$
\log \left(c_{u}(p)\right)-\log \left(c_{e}(p)\right)=\log \left(c_{u}(p)\right)-\log \left(c_{t-1}(p)\right)-\left(\log \left(c_{e}(p)\right)-\log \left(c_{t-1}(p)\right)\right)
$$

where the first term captures consumption change if unemployed and the second term is the consumption change if employed. Let $\Delta_{e}^{\max }=\max _{p}\left\{\log \left(c_{e}(p)\right)-\log \left(c_{t-1}(p)\right)\right\}$ denote the maximum consumption change experienced by those who did not lose their job. And, let $\Delta_{u}^{\min }=\min _{p}\left\{\log \left(c_{u}(p)\right)-\log \left(c_{t-1}(p)\right)\right\}$ denote the minimum consumption change experienced by those who lose their job. Note that we expect $\Delta_{e}^{\max }>0$ and $\Delta_{u}^{\min }<0$. The Euler equation $((6))$ combined with the assumption of CRRA preferences implies that $c_{t-1}$ lies between $c_{u}(p)$ and $c_{e}(p), c_{t-1}(p) \in\left[c_{u}(p), c_{e}(p)\right]$ for all $p$. Under this natural assumption, the causal impact of unemployment is bounded below by the difference between these drops:

$$
\Delta^{\min } \geq \Delta_{u}^{\min }-\Delta_{e}^{\max }
$$

Therefore, one can bound the causal effect of unemployment on consumption by the largest consumption drop minus the smallest consumption increase. The question now becomes: how large can the consumption drop upon 
unemployment be, $\Delta_{u}^{\text {min }}$ ? And, how large can the consumption increase upon learning that you didn't lose your job be, $\Delta_{e}^{\max }$ ?

If one observed consumption directly, one could estimate the full distribution of first differences in consumption for those who become unemployed, $\log \left(c_{u}(p)\right)-\log \left(c_{t-1}(p)\right)$, and remain employed, $\log \left(c_{e}(p)\right)-\log \left(c_{t-1}(p)\right)$. Then, one could in principle find $\Delta_{u}^{\min }$ and $\Delta_{e}^{\max }$ directly from the data.

However, consumption data in the PSID and other datasets is quite noisy in practice (see for example Zeldes (1989); Meghir and Pistaferri (2011)). ${ }^{66}$ Therefore, I proceed as follows. Note that the Euler equation implies that $c_{t-1}(p) \in\left[c_{u}(p), c_{e}(p)\right]$ for all $p$. In particular, this implies that the log consumption change should always drop for those who lose their job, $c_{t-1}(p) \geq c_{u}(p)$. Therefore, I use the extent to which one observes consumption increases for those who become unemployed to provide information about how the consumption change distribution and its minimum, $\Delta_{u}^{\text {min }}$, is affected by measurement error.

I begin by removing systematic variation in consumption changes due to life cycle and year effects. In particular, I regress the consumption change on the observables, $X$, in Equation (4) (an age cubic and year dummies) and let $\Delta_{i t}^{*}$ denote the residuals. ${ }^{67}$ Online Appendix Figure VI plots the distributions of $\Delta_{i t}^{*}$ for those with $U_{i t}=1$ and $U_{i t}=0$. As one can see, the wide dispersion is suggestive of considerable measurement error, as noted in previous literature.

Let $Q(\alpha, U)$ denote the $\alpha$-quantile of the distribution of $\Delta_{i t}^{*}$ as a function of unemployment status, $U_{t}$. Appendix Table II reports that $41.7 \%$ of the sample who become unemployed have $\Delta_{i t}^{*}>0$ (i.e. $Q(58.3,1)=0$ ), even after controlling for age and year effects. Because the Euler equation suggests consumption changes should not be positive, it suggests the excess dispersion is the result of measurement error. The key assumption I impose is that the impact of measurement error is symmetric across the distribution of consumption changes. In particular, I assume that the probability that the observed consumption change lies above the maximum plausible consumption change of 0 is less than or equal to the probability that the observed consumption change is below the minimum actual consumption change, $\operatorname{Pr}\left\{\Delta_{i t}^{*} \leq \Delta_{u}^{m i n} \mid U_{i t}=1\right\} \geq \operatorname{Pr}\left\{\Delta_{i t}^{*} \geq 0 \mid U_{i t}=1\right\}$, where $\operatorname{Pr}\left\{\Delta_{i t}^{*} \geq 0 \mid U_{i t}=1\right\}=41.7 \%$. Appendix Figure V shows that the observed distribution of consumption changes is fairly symmetric, which would be consistent with the underlying assumptions needed for Equation (25) to hold. ${ }^{68}$ With this assumption,

$$
\Delta_{u}^{\min } \geq Q\left(\operatorname{Pr}\left\{\Delta_{i t}^{*} \geq 0 \mid U_{i t}=1\right\}, 1\right)
$$

Because $\operatorname{Pr}\left\{\Delta_{i t}^{*} \geq 0 \mid U_{i t}=1\right\}=41.7 \%$, one can bound the consumption drop by the 41.7th quantile of the observed consumption drop distribution. This equals $-13.7 \%$, as shown in Appendix Table II.

Similarly, one can impose an analogous assumption on the distribution of consumption changes for the employed that the observed fraction of the population that experiences a consumption decline when remaining employed is less than or equal to the fraction who experience a consumption increase that is above $\Delta_{e}^{\max }, \operatorname{Pr}\left\{\Delta_{i t}^{*} \leq 0 \mid U_{i t}=0\right\}=$ $\operatorname{Pr}\left\{\Delta_{i t}^{*} \geq \Delta_{e}^{\max } \mid U_{i t}=0\right\}$. Under this assumption,

$$
\Delta_{e}^{\max } \leq Q\left(\operatorname{Pr}\left\{\Delta_{i t}^{*} \leq \mid U_{i t}=0\right\}, 0\right)
$$

Appendix Table II shows this maximal consumption increase equals 0.5\%. Combining equations (25) and (26) yields the lower bound on the causal impact of unemployment on consumption:

$$
\Delta^{\text {min }} \geq Q\left(\operatorname{Pr}\left\{\Delta_{i t}^{*} \geq 0 \mid U_{i t}=1\right\}, 1\right)-Q\left(\operatorname{Pr}\left\{\Delta_{i t}^{*} \leq \mid U_{i t}=0\right\}, 0\right)
$$

where the right hand side equals $-13.7 \%-0.5 \%=14.2 \%$ (s.e. $1.1 \%$ ), as reported in Table V, Column (7). Therefore, the maximum causal impact on food expenditure is $14.2 \%$, or roughly twice as large as the mean consumption drop. The lower rows in Table $\mathrm{V}$ scale this estimate by various values of risk aversion. With a conservative estimate of 3 , it suggests the maximum markup individuals would be willing to pay is $54.7 \%$.

\footnotetext{
${ }^{66}$ This "left-hand-side" measurement error was necessarily not a problem for estimating the mean consumption impact of unemployment (assuming the error is classical). But, for estimating properties of the distribution of consumption changes such as minima and maxima, this measurement error becomes a significant limitation.

${ }^{67}$ This residualization can be formalized by assuming there are known time and year preference shocks affecting the marginal utility of consumption that are common across individuals. Note the residuals now satisfy the ex-ante Euler equation, $E\left[\Delta_{i t}^{*}\right]=0$. But, the means of the residuals will differ for those who do and do not experience unemployment, $E\left[\Delta_{i t}^{*} \mid U_{i t}=1\right] \leq 0$ and $E\left[\Delta_{i t}^{*} \mid U_{i t}=0\right] \geq 0$.

${ }^{68}$ While the symmetry assumption is not directly testable, it can be micro-founded from many common assumptions on measurement error distributions. For example, if the true distribution of consumption changes is symmetric and the distribution of measurement error is symmetric and unbiased, then it is straightforward to show that $\operatorname{Pr}\left\{\Delta_{i t}^{*} \leq \Delta_{u}^{\min } \mid U_{i t}=1\right\} \geq \operatorname{Pr}\left\{\Delta_{i t}^{*} \geq x \mid U_{i t}=1\right\}$, where $x \leq 0$ is the maximum consumption change for those who become unemployed. Symmetric and median-unbiasedness is a common assumption measurement error models (see, e.g., Bollinger (1998); Hu and Schennach (2008)).
} 


\section{C.3 Proof of Proposition 2}

Differentiating the Euler equation under assumption (b) yields

$$
u^{\prime}\left(c_{u}\right)-v^{\prime}\left(c_{e}\right)=v^{\prime \prime}\left(c_{\text {pre }}(p)\right) \frac{d c_{p r e}}{d p}
$$

Now, dividing by $v^{\prime}\left(c_{e}\right)$ yields

$$
\frac{u^{\prime}\left(c_{u}\right)-v^{\prime}\left(c_{e}\right)}{v^{\prime}\left(c_{e}\right)}=\frac{v^{\prime \prime}\left(c_{p r e}(p)\right)}{v^{\prime}\left(c_{e}\right)} \frac{d c_{p r e}}{d p}
$$

and expanding the RHS yields

$$
\frac{u^{\prime}\left(c_{u}\right)-v^{\prime}\left(c_{e}\right)}{v^{\prime}\left(c_{e}\right)}=\frac{v^{\prime}\left(c_{\text {pre }}(p)\right)}{v^{\prime}\left(c_{e}\right)} \frac{c_{\text {pre }}(p) v^{\prime \prime}\left(c_{\text {pre }}(p)\right)}{v^{\prime}\left(c_{\text {pre }}(p)\right)} \frac{1}{c_{\text {pre }}(p)} \frac{d c_{\text {pre }}}{d p}
$$

And, imposing the Euler equation to replace $v^{\prime}\left(c_{\text {pre }}(p)\right)$ in the numerator on the RHS $\left(v^{\prime}\left(c_{p r e}(p)\right)=p u^{\prime}\left(c_{u}\right)+\right.$ $\left.(1-p) v^{\prime}\left(c_{e}\right)\right)$ yields,

$$
\frac{u^{\prime}\left(c_{u}\right)-v^{\prime}\left(c_{e}\right)}{v^{\prime}\left(c_{e}\right)}=\left[p \frac{u^{\prime}\left(c_{u}\right)}{v^{\prime}\left(c_{e}\right)}+(1-p)\right] \frac{c_{\text {pre }}(p) v^{\prime \prime}\left(c_{\text {pre }}(p)\right)}{v^{\prime}\left(c_{\text {pre }}(p)\right)} \frac{1}{c_{\text {pre }}(p)} \frac{d c_{\text {pre }}}{d p}
$$

Dividing by $p \frac{u^{\prime}\left(c_{u}\right)}{v^{\prime}\left(c_{e}\right)}+(1-p)$ and taking expectations over $p$ yields

$$
\kappa \frac{u^{\prime}\left(c_{u}\right)-v^{\prime}\left(c_{e}\right)}{v^{\prime}\left(c_{e}\right)}=E\left[\frac{c_{\text {pre }}(p) v^{\prime \prime}\left(c_{\text {pre }}(p)\right)}{v^{\prime}\left(c_{\text {pre }}(p)\right)} \frac{1}{c_{\text {pre }}(p)} \frac{d c_{\text {pre }}}{d p}\right]
$$

Now, imposing $\sigma=\frac{-c_{p r e}(p) v^{\prime \prime}\left(c_{p r e}(p)\right)}{v^{\prime}\left(c_{p r e}(p)\right)}$ for all $p$, noting that $\frac{1}{c_{p r e}(p)} \frac{d c_{p r e}}{d p}=\frac{d \log \left(c_{p r e}\right)}{d p}$, and dividing by $\kappa$ yields:

$$
\frac{u^{\prime}\left(c_{u}\right)-v^{\prime}\left(c_{e}\right)}{v^{\prime}\left(c_{e}\right)}=\frac{\sigma}{\kappa} E\left[\frac{-d \log \left(c_{p r e}\right)}{d p}\right]
$$

\section{C.4 Ex-ante labor supply derivation}

This section illustrates how to use the spousal labor supply response, combined with known estimates of the spousal labor response to labor earnings, to estimate the ex-ante willingness to pay for UI.

To begin, one needs a model of extensive margin labor supply response. I assume spousal labor force participation generates income, $y$, but has an additively separable effort cost, $\eta(\theta)$. I assume a spouse labor supply decision, $l \in\{0,1\}$, is a binary decision and is contained in the set of other actions, $a$. Formally, let utility be given by

$$
v\left(c_{p r e}\right)+p u\left(c_{u}\right)+(1-p) v\left(c_{e}\right)+1\{l=1\} \eta(\theta)+\tilde{\Psi}_{i}(1-p, \tilde{a}, \theta)
$$

where $\eta(\theta)$ is the disutility of labor for type $\theta$, distributed $F_{\eta}$ in the population.

Let $k(y, l, p)$ denote the utility value to a type $p$ of choosing $l$ to obtain income $y$ when they face an unemployment probability of $p$. The labor supply decision is

$$
k(y, 1, p)-k(0,0, p) \geq \eta(\theta)
$$

so that types will choose to work if and only if it increases their utility. This defines a threshold rule whereby individuals choose to work if and only if $\eta(\theta) \leq \bar{\eta}(y, p)$ and the labor force participation rate is given by $\Phi(y, p)=$ $F(\bar{\eta}(y, p))$.

Now, note that

$$
\frac{d \Phi}{d p}=f(\bar{\eta}) \frac{\partial \bar{\eta}}{\partial p}=f(\bar{\eta})\left[\frac{\partial k(y, 1, p)}{\partial p}-\frac{\partial k(0,0, p)}{\partial p}\right]
$$

and making an approximation that the impact of the income $y$ does not discretely change the instantaneous marginal utilities (i.e. because it will be smoothed out over the lifetime or because the income is small), we have

$$
\frac{d \Phi}{d p} \approx f(\bar{\eta}) \frac{\partial^{2} k}{\partial p^{2}} y
$$

Finally, note that $\frac{\partial k}{\partial y}=v^{\prime}\left(c_{p r e}(p)\right)$ is the marginal utility of income. So,

$$
\frac{d \Phi}{d p} \approx f(\bar{\eta}) \frac{d}{d p}\left[v^{\prime}\left(c_{p r e}(p)\right)\right] y
$$


and integrating across all the types $p$ yields

$$
E_{p}\left[\frac{d \Phi}{d p}\right] \approx E_{p}\left[f(\bar{\eta}) \frac{d}{d p} v^{\prime}\left(c_{p r e}(p)\right) y\right]
$$

To compare this response to a wage elasticity, consider the response to a $\$ 1$ increase in wages

$$
\frac{d \Phi}{d y}=f(\bar{\eta}) \frac{\partial k}{\partial y}
$$

so,

$$
E_{p}\left[\frac{d \Phi}{d p}\right] \approx E_{p}\left[\frac{d \Phi}{d y} y \frac{\frac{d}{d p} v^{\prime}\left(c_{\text {pre }}(p)\right)}{v^{\prime}\left(c_{\text {pre }}(p)\right)}\right]
$$

Now, let $\epsilon^{s e m i}=\frac{d \Phi}{d \log (y)}$ denote the semi-elasticity of spousal labor force participation. This yields

$$
\frac{E_{p}\left[\frac{d \Phi}{d p}\right]}{\epsilon^{\text {semi }}} \approx E_{p}\left[\frac{\frac{d}{d p} v^{\prime}\left(c_{p r e}(p)\right)}{v^{\prime}\left(c_{\text {pre }}(p)\right)}\right]
$$

so that the ratio of the labor supply response to $p$ divided by the semi-elasticity of labor supply with respect to wages reveals the average elasticity of the marginal utility function. Assuming this elasticity is roughly constant and noting that a Taylor expansion suggests that for any function $f(x)$, we have $\frac{f(1)-f(0)}{f(0)} \approx \frac{d}{d x} \log (f)$,

$$
\frac{E_{p}\left[\frac{d \Phi}{d p}\right]}{\epsilon^{\text {semi }}} \approx \frac{v^{\prime}(1)-v^{\prime}(0)}{v^{\prime}(0)}
$$

Now, how does one estimate $\frac{d \Phi}{d p}$ ? Regressing labor force participation, $l$, on $Z$ will generate an attenuated coefficient because of measurement error in $Z$. If the measurement error is classical, one can inflate this by the ratio of the variance of $Z$ to the variance of $P$, or

$$
\frac{v^{\prime}(1)-v^{\prime}(0)}{v^{\prime}(0)} \approx \beta \frac{1}{\epsilon^{\operatorname{semi} i}} \frac{\operatorname{var}(Z)}{\operatorname{var}(P)}
$$




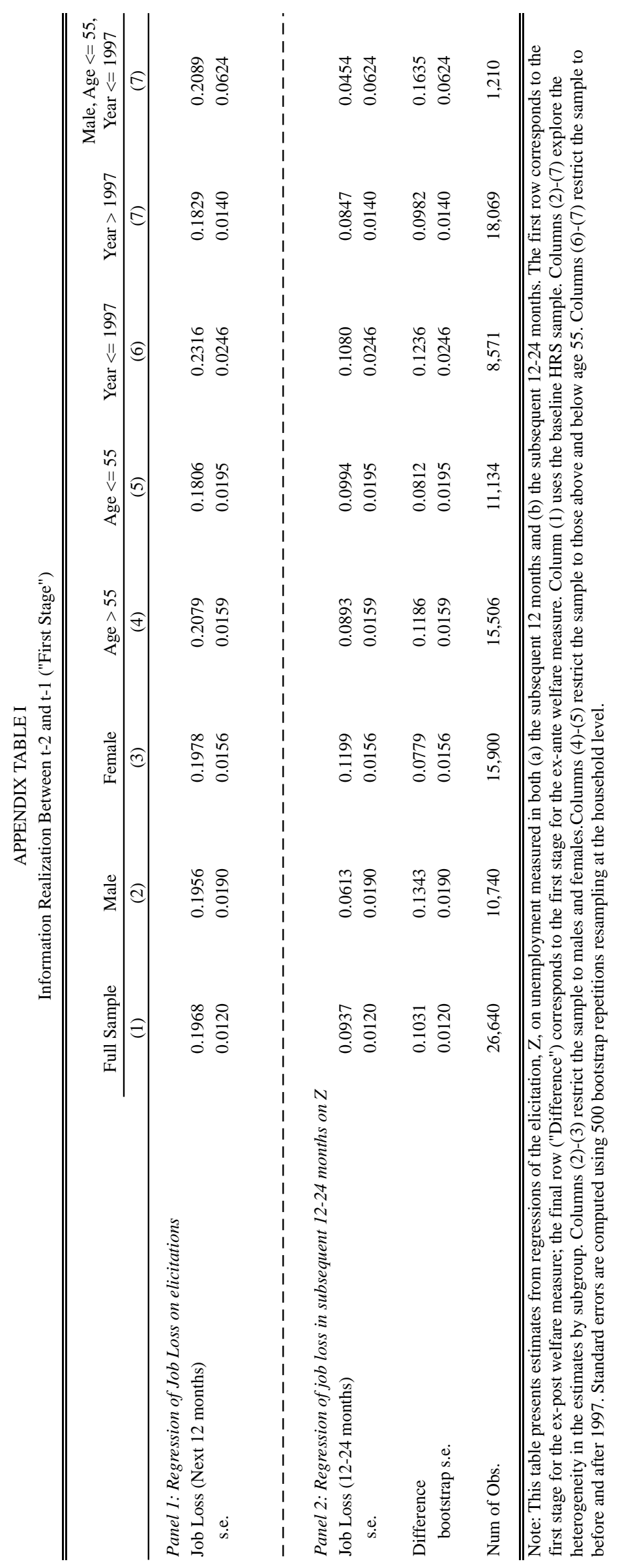


APPENDIX TABLE II

Maximum Causal Effect of Unemployment on Food Expenditure

\begin{tabular}{c}
\hline \\
\cline { 2 - 2 }
\end{tabular}

Estimate for $\max \left\{\log \left(\mathrm{c}_{\mathrm{u}}(\mathrm{p})\right)-\log \left(\mathrm{c}_{\mathrm{e}}(\mathrm{p})\right)\right\}, \Delta^{\min }$

$-0.137$

s.e.

Lower bound for drop when unemployed, $\Delta_{\mathrm{u}}^{\mathrm{min}}$

$-0.138$

s.e.

Upper bound for increase when unemployed, $\Delta_{\mathrm{e}} \max$

$-0.001$

s.e.

(0.002)

Fraction unemployed with positive consumption change $\quad 0.415$

$\begin{array}{ll}\text { Fraction employed with negative consumption change } & 0.499\end{array}$

Num of Obs.

65,808

Num of HHs

9,562

\begin{abstract}
Note: This table presents the calculation for the maximum causal effect of unemployment on food expe resulting estimate, $\Delta^{\min }$. The second rows present the estimates for the lower bound on the consumption third rows present the estimates for the upper bound for the increase in consumption when employed, $L$ fraction of people who are unemployed, $\mathrm{U}_{\mathrm{it}}=1$, who experience a positive consumption change, $\Delta_{\mathrm{it}}^{*}>0$, $\mathrm{U}_{\mathrm{it}}=0$, who experience a negative consumption change, $\Delta_{\mathrm{it}}^{*}>0$. All standard errors are constructed using (10nก ranatitions)
\end{abstract}




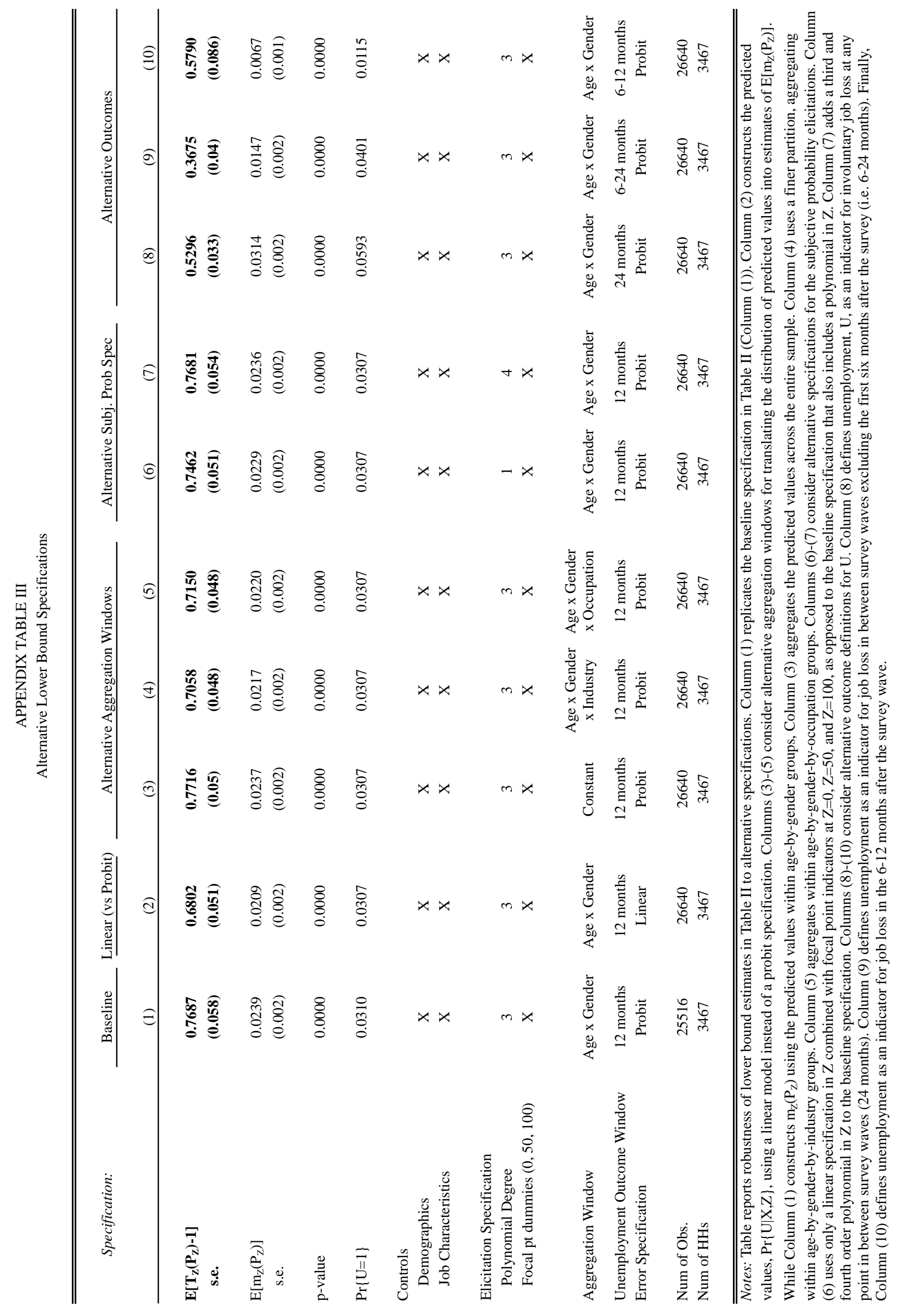




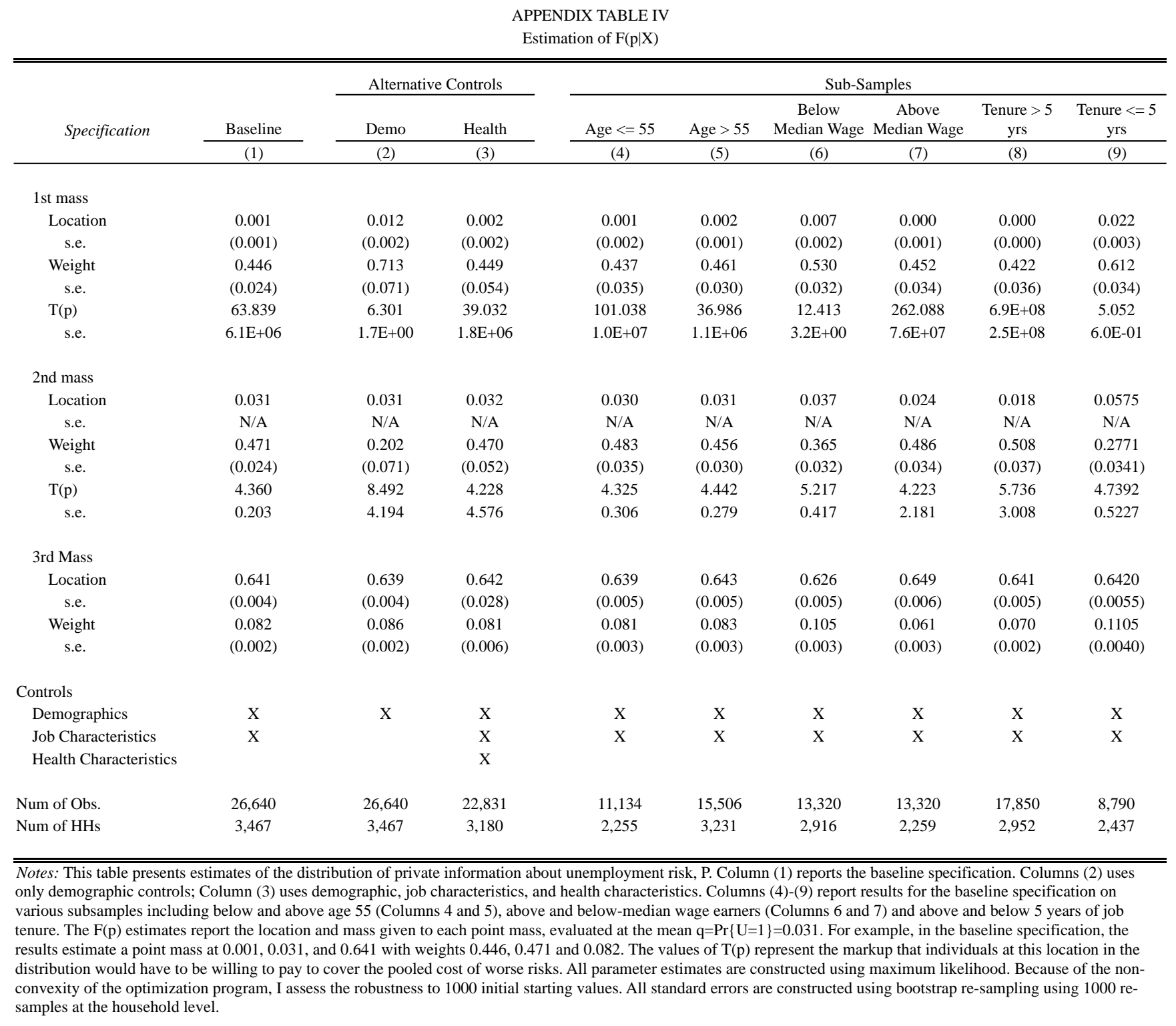




\section{ONLINE APPENDIX FIGURE I: "First Stage" Impact of Unemployment on Beliefs}

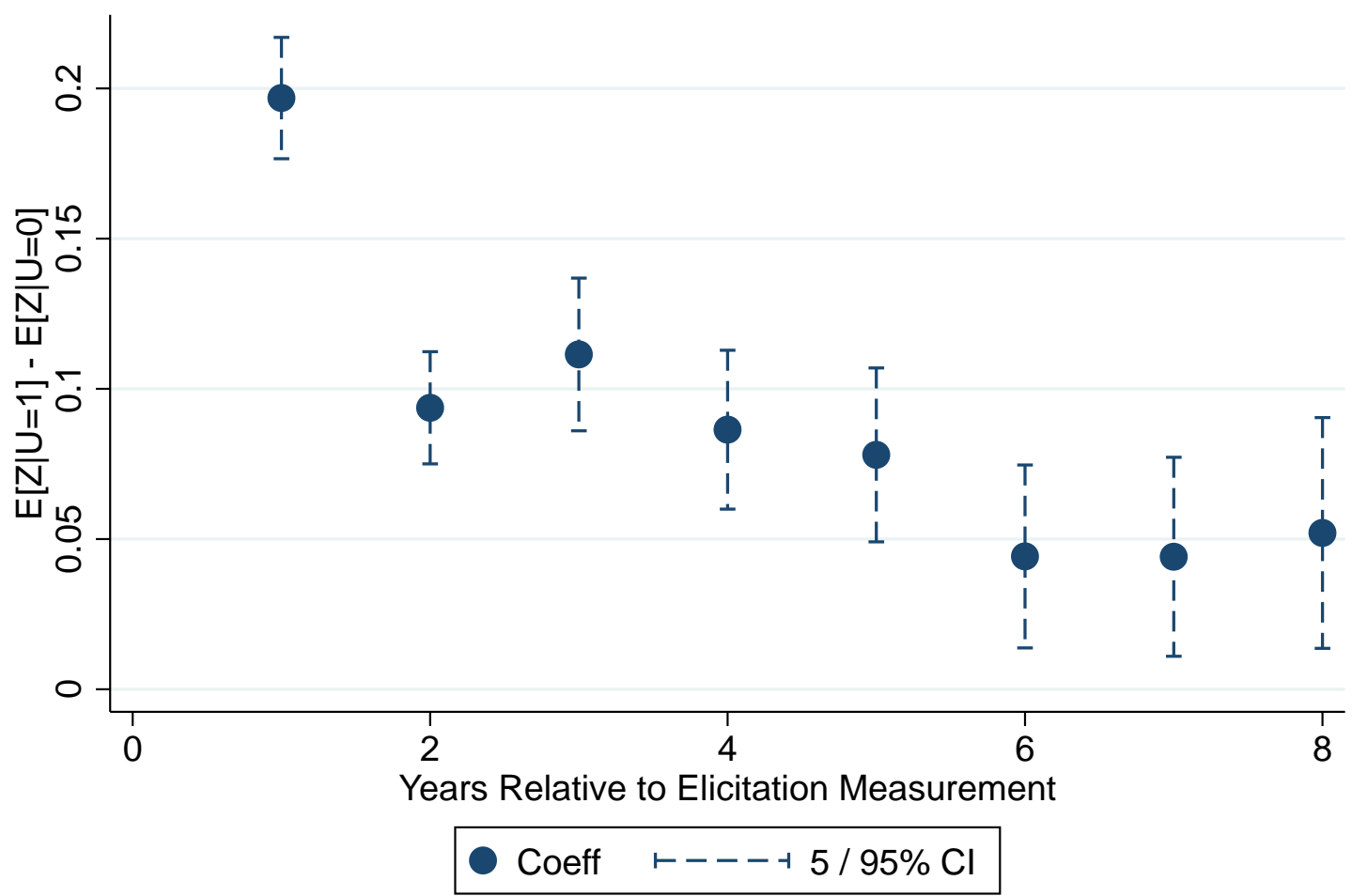

Notes: This figure presents the estimated coefficients of a regression of the elicitations (elicited in year $t$ ) on unemployment indicators in year $t+j$ for $j=1, . ., 8$. To construct the unemployment indicators for each year $t+j, \mathrm{I}$ construct an indicator for involuntary job loss in any survey wave (occurring every 2 years). I then use the data on when the job loss occurred to assign the job loss to either the first or second year in between the survey waves. Because of the survey design, this definition potentially misses some instances of involuntary separation that occur in back-to-back years in between survey waves. To the extent to which such transitions occur, the even-numbered years in the Figure are measured with greater measurement error. The figure presents estimated 5/95\% confidence intervals using standard errors clustered at the household level. 


\section{ONLINE APPENDIX FIGURE II: Impact of Unemployment on Total Consumption Expenditure}

(2-year intervals)

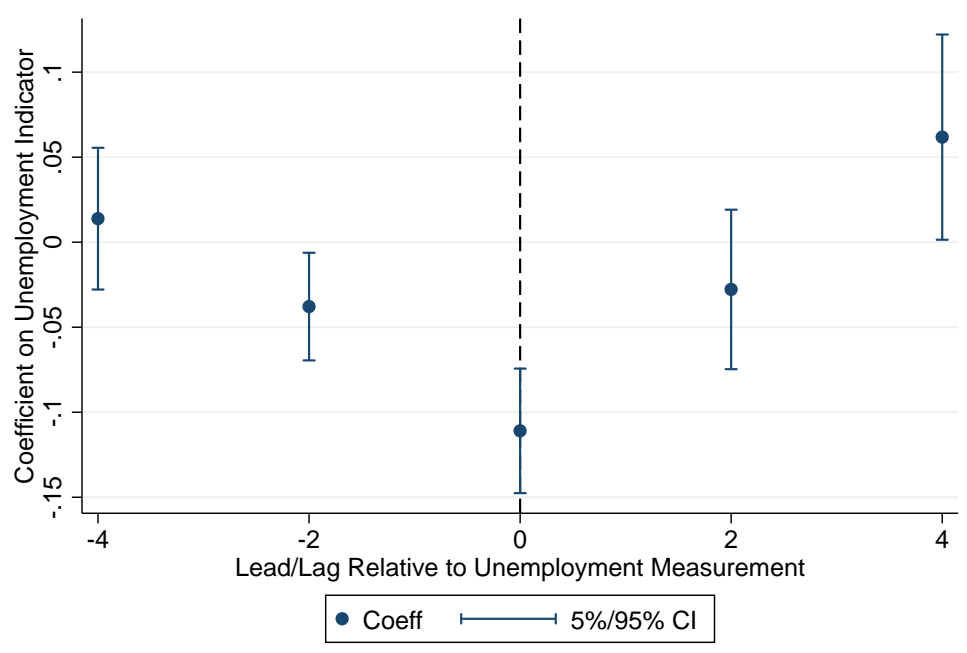

Notes: This figure presents the estimated coefficients of a regression of leads and lags of log household consumption expenditure on an indicator for unemployment. The figure replicates the sample and specification in Figure IV (Panel B) by replacing the dependent variable with log total consumption expenditure on a sample beginning in 1999, surveyed every two years. I restrict the sample to household heads who are employed in $t-2$ or $t-4$. Following the baseline specification, the sample is restricted to observations with less than a threefold change in consumption expenditures. Note that after 1999, the PSID asks a broader set of consumption questions but is conducted only every two years, which prevents analyzing total 1-year interval responses to unemployment. 


\section{ONLINE APPENDIX FIGURE III: Impact of Job Loss on Consumption}

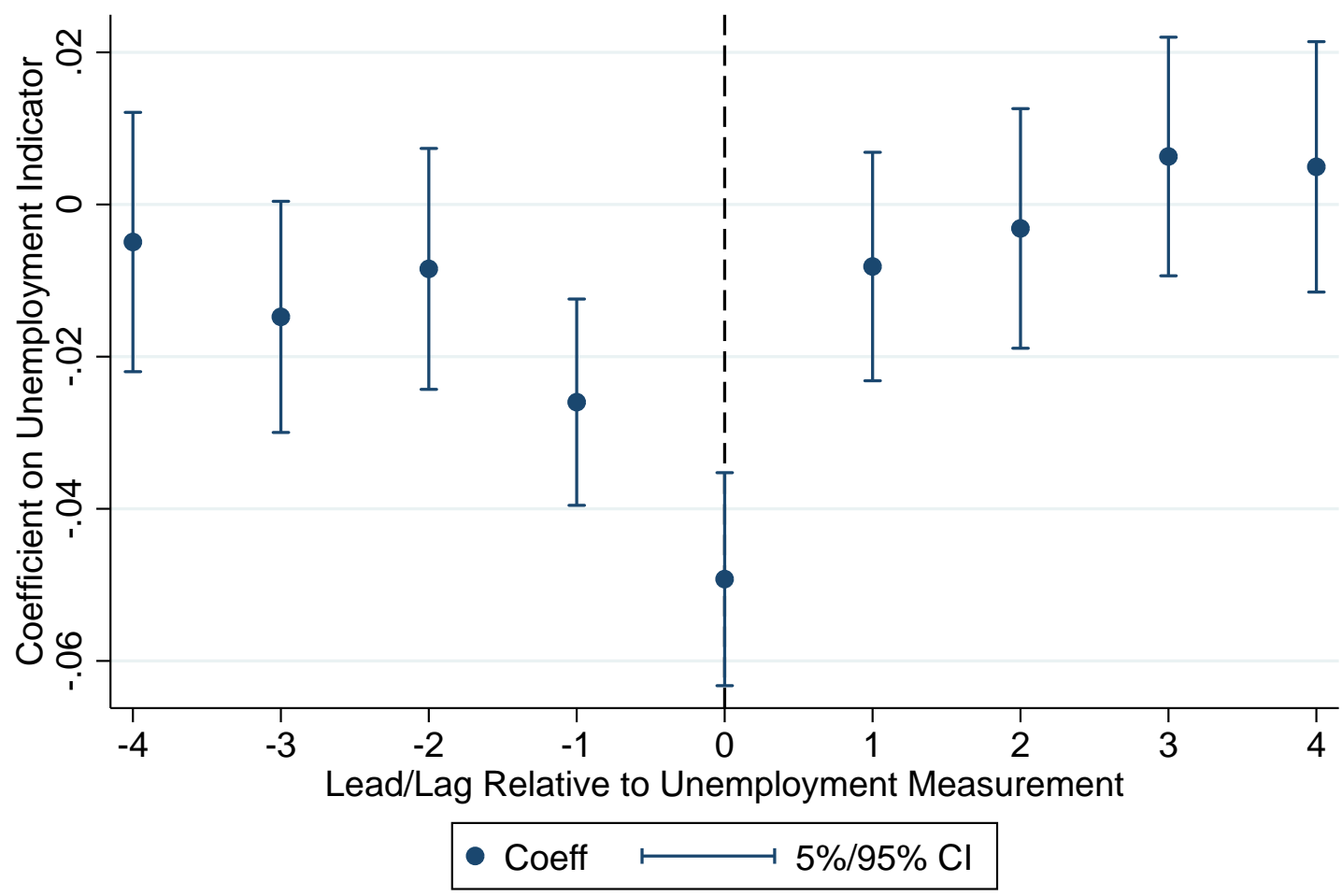

Notes: This figure re-constructs the analysis in Figure IV using job loss instead of unemployment. I define job loss as an indicator for being laid off or fired from the job held in the previous wave of the survey. The figure present coefficients from separate regressions of leads and lags of the log change in food expenditure on an indicator of job loss, along with controls for year indicators and a cubic in age. Sample is restricted to household heads who are employed in years $t-1$ and $t-2$. 


\section{ONLINE APPENDIX FIGURE IV: Household Income Pattern Around Unemployment}

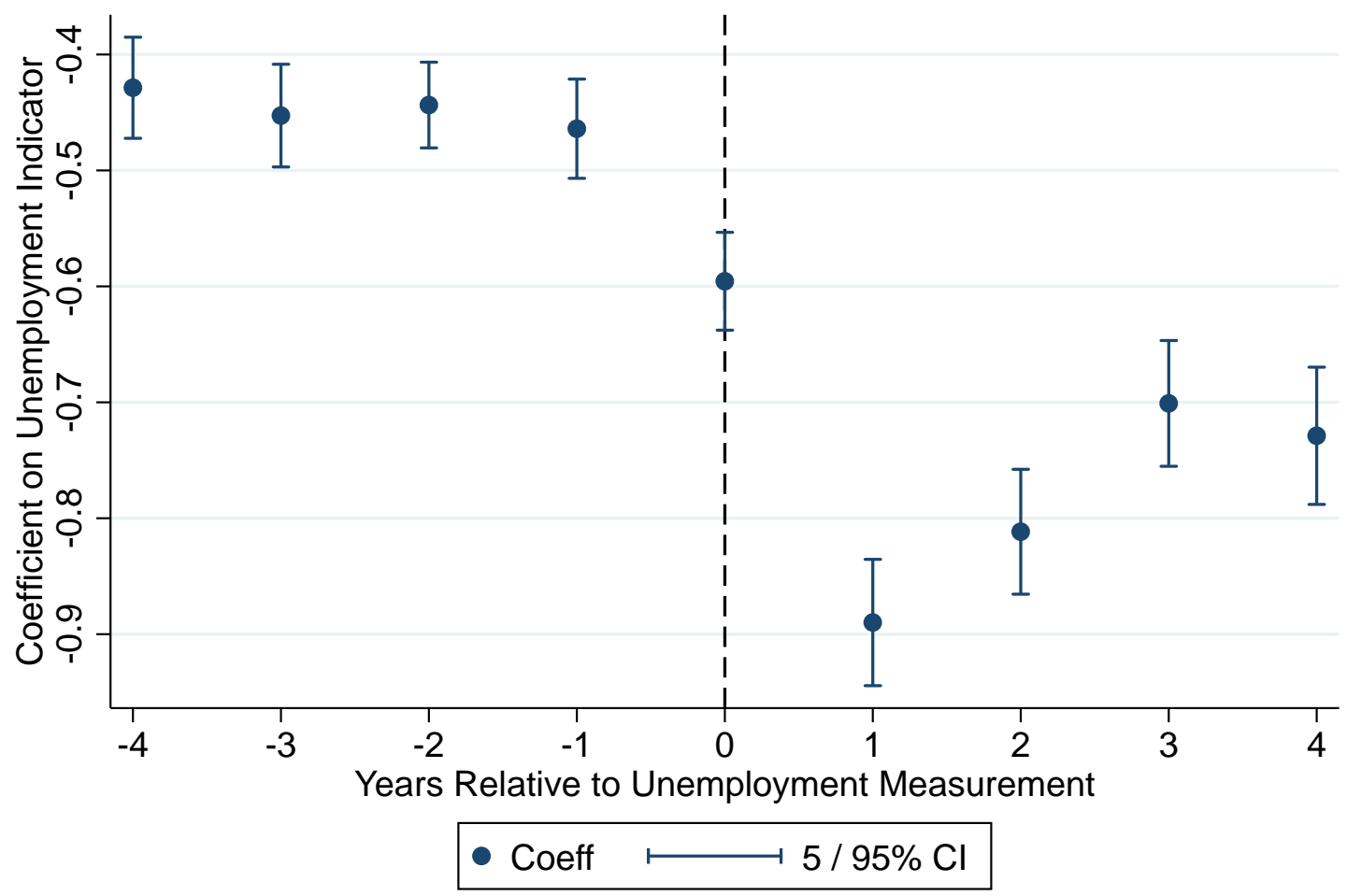

Notes: This figure presents the estimated coefficients of a regression of leads and lags of log household income on an indicator for unemployment. The figure replicates the sample and specification in Figure IV by replacing the dependent variable with $\log$ household income as opposed to the change in log food expenditure. I restrict the sample to household heads who are not unemployed in $t-1$ or $t-2$. 


\section{ONLINE APPENDIX FIGURE V: Illustration of No Trade Condition Using Demand and Average Cost Curves}

\section{A. MRS versus Average Cost}

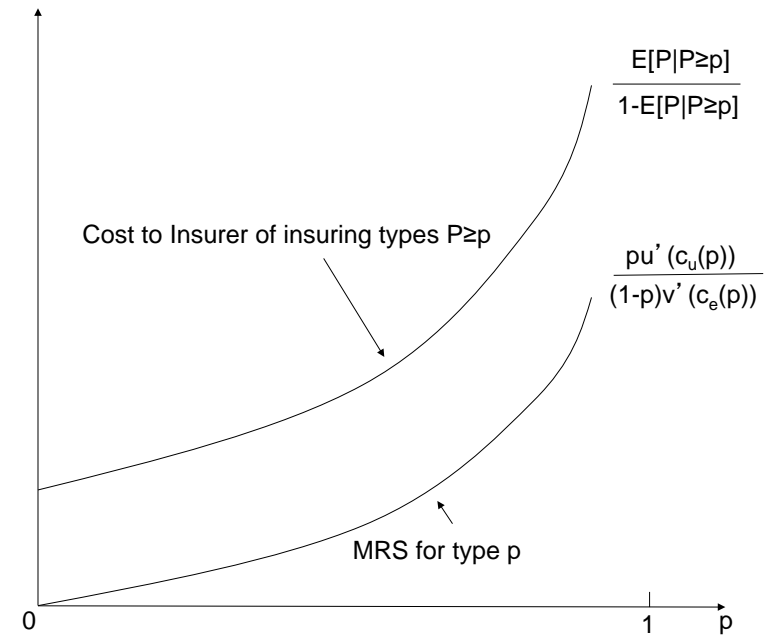

B. Pooled Price Ratio versus $1+$ Willingness to pay (Markup)

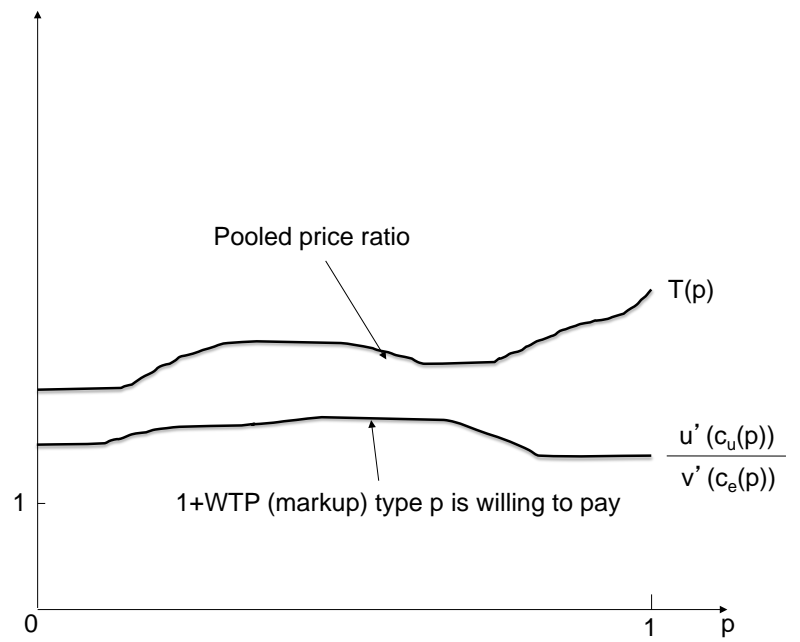

Notes: This figure illustrates the no trade condition using the marginal and average cost curves as in Einav, Finkelstein and Cullen (2010). Panel A presents an illustrative example for the demand for a contract that pays $\$ 1$ in the event of becoming unemployed. The willingness to pay out of income if employed is given by the marginal rate of substitution, $\frac{p}{1-p} \frac{u^{\prime}\left(c_{u}(p)\right)}{v^{\prime}\left(c_{e}(p)\right)}$. Under a standard single crossing condition, all types $P \geq p$ would also purchase the insurance policy (see text for discussion of multi-dimensional heterogeneity). Therefore, the cost to the insurer of the contract is given by the average likelihood that the payment is made, $E[P \mid P \geq p]$ relative to the likelihood the payment is received, $1-E[P \mid P \geq p], \frac{E[P \mid P \geq p]}{1-E[P \mid P \geq p]}$. Panel $\mathrm{B}$ normalizes by $\frac{1-p}{p}$ to illustrate the empirical approach that compares the pooled price ratio, $T(p)=\frac{1-p}{p} \frac{E[P \mid P \geq p]}{1-E[P \mid P \geq p]}$, to one plus the markup individuals are willing to pay for insurance, $\frac{u^{\prime}\left(c_{u}(p)\right)}{v^{\prime}\left(c_{e}(p)\right)}$. The empirical results suggest the willingness to pay lies below the pooled price ratio, as depicted in Panels A and B. 
ONLINE APPENDIX FIGURE VI: Distribution of Reported Log Food Expenditure Growth, $\Delta_{i t}^{*}$, for Employed and Unemployed

A. Unemployed $\left(U_{i t}=1\right)$

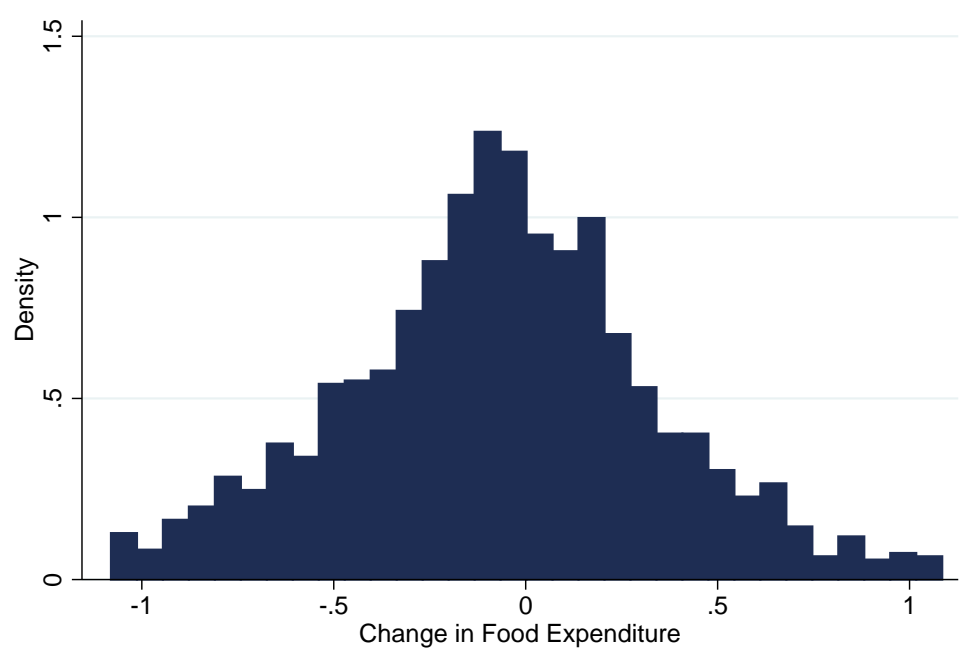

B. Employed $\left(U_{i t}=0\right)$

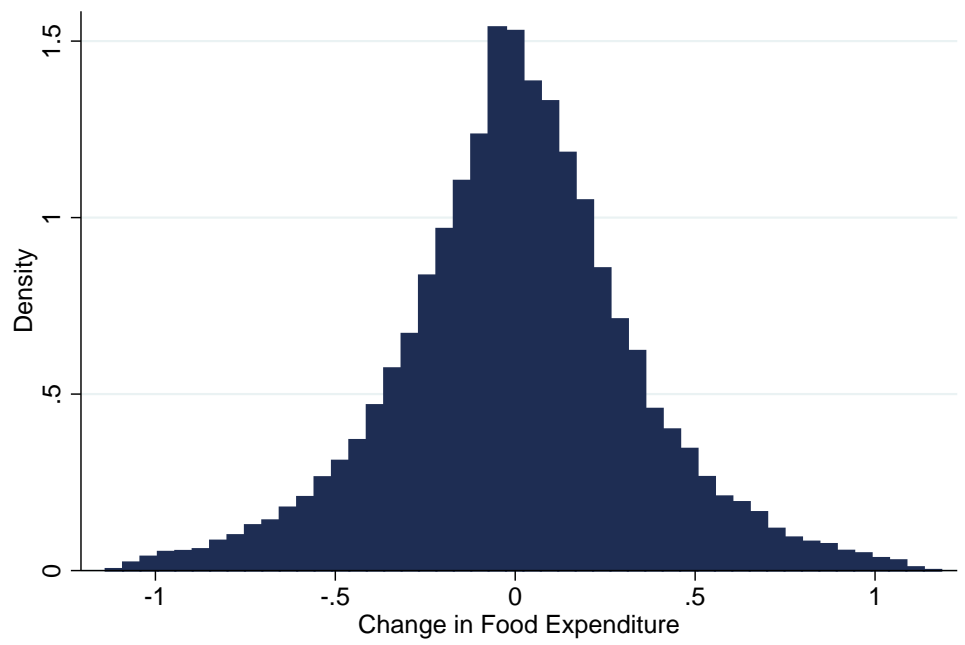

Notes: This figure plots histograms of $\Delta_{i t}^{*}$ for those who are employed, $U_{i t}=0$, and unemployed, $U_{i t}=1$. $\Delta_{i t}^{*}$ is defined as the residual from a regression of $\log \left(c_{i t}\right)-\log \left(c_{i t-1}\right)$ on an age cubic and year dummies, $X$. I restrict the sample to household heads who are employed in $t-1$ and $t-2$. Following the baseline specification, the sample is restricted to observations with less than a threefold change in consumption expenditures. 